\title{
Forging C-S Bonds through Nickel-Catalyzed Aryl anhydrides with Thiophenols : Decarbonylation or Decarbonylation accompanied by Decarboxylation
}

Jing-Ya Zhou, Shou-Wei Tao, Rui-Qing Liu, Yong-Ming Zhu*

${ }^{\dagger}$ College of Pharmaceutical Sciences, Soochow University, Suzhou 215123, China 


\section{Contents}

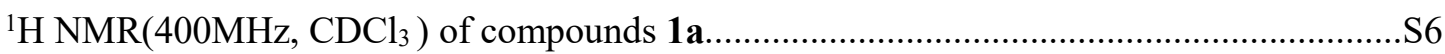

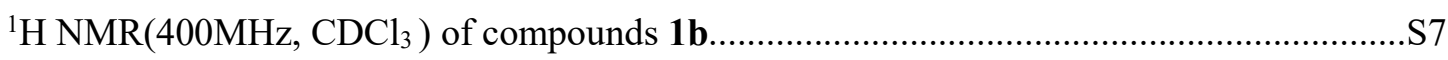

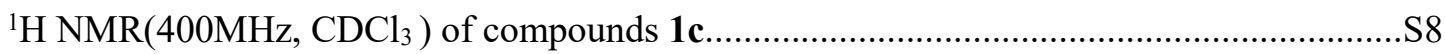

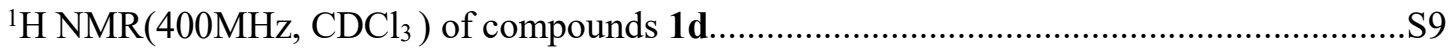

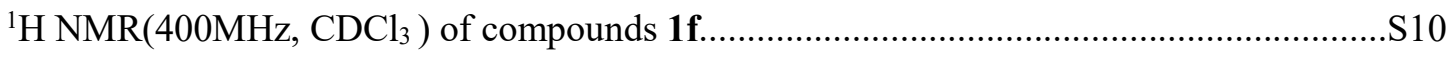

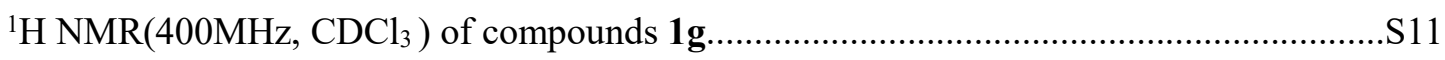

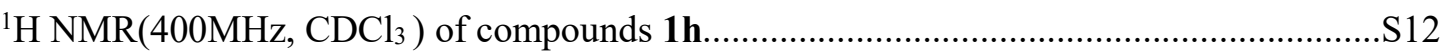

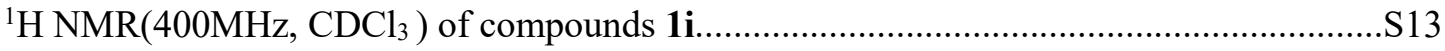

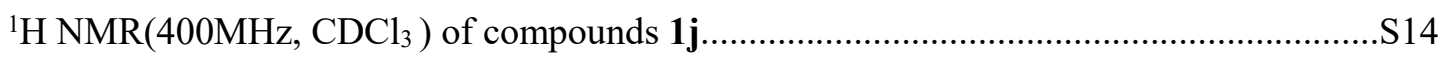

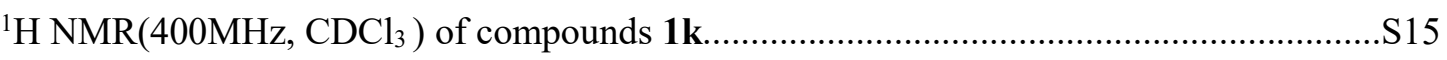

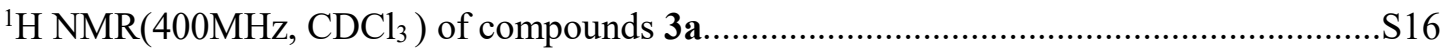

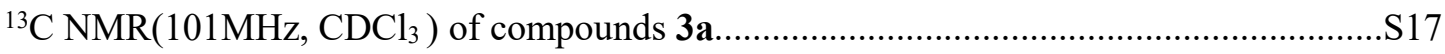

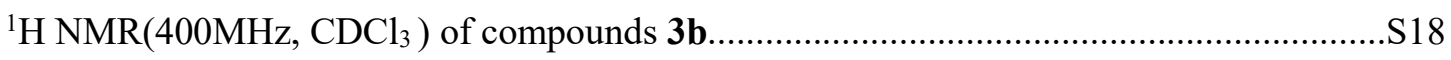

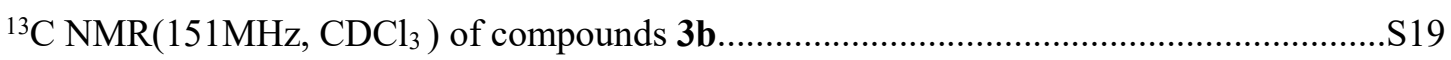

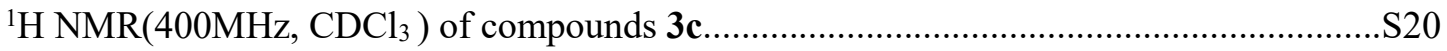

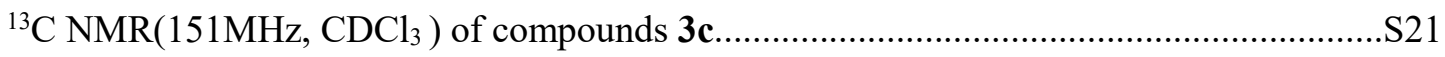

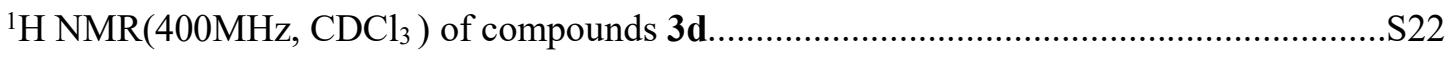

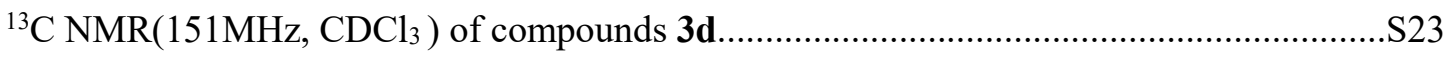

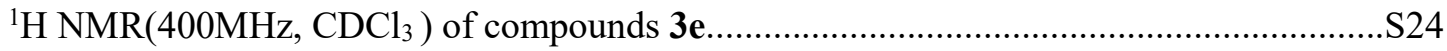

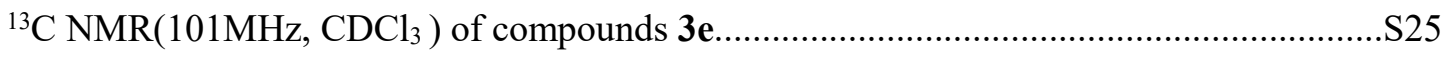


${ }^{1} \mathrm{H} \mathrm{NMR}\left(400 \mathrm{MHz}, \mathrm{CDCl}_{3}\right)$ of compounds $\mathbf{3 e}$ '.

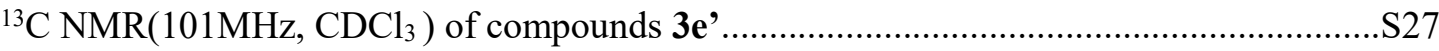

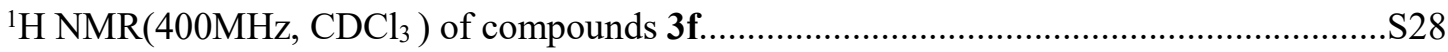

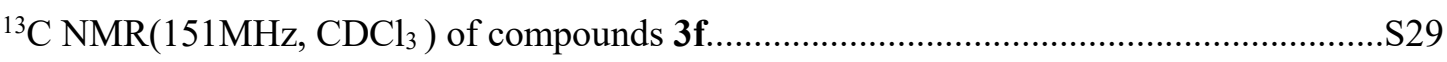

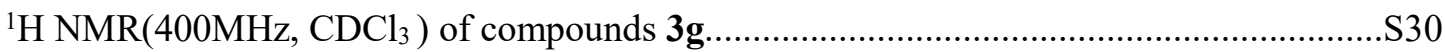

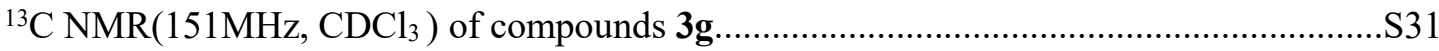

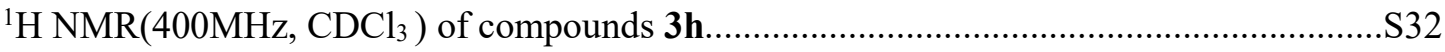

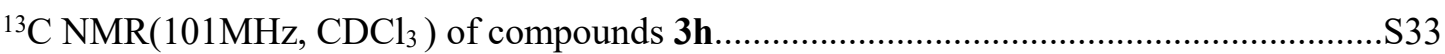

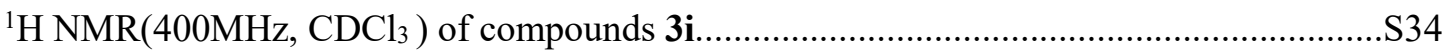

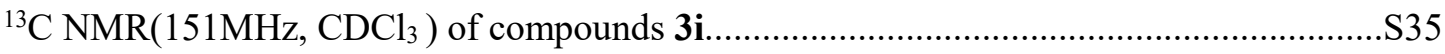

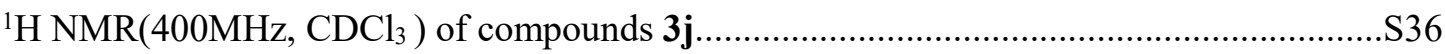

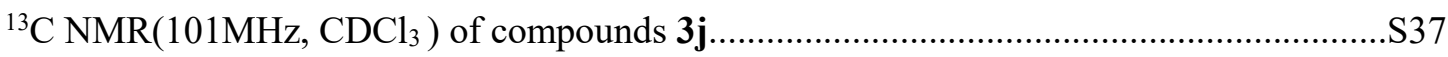

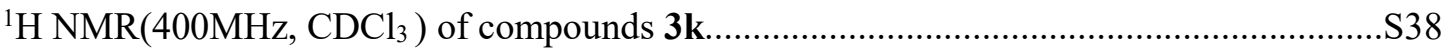

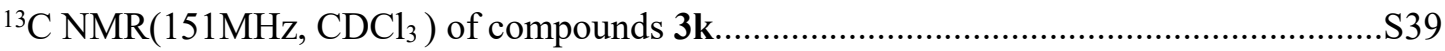

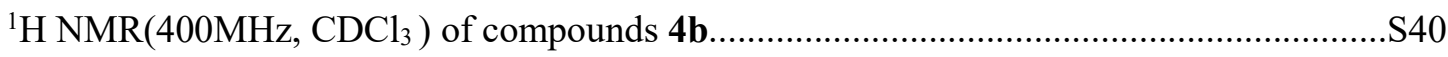

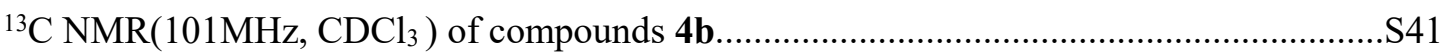

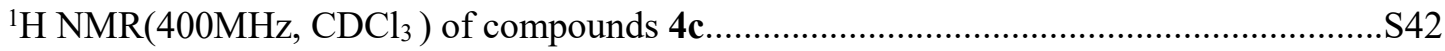

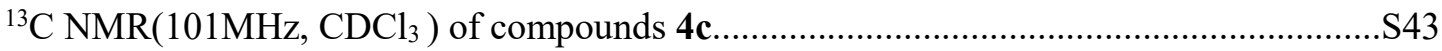

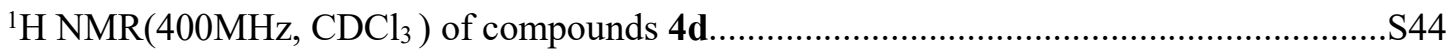

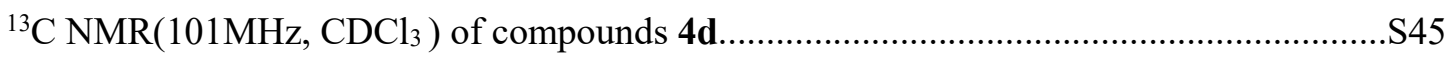

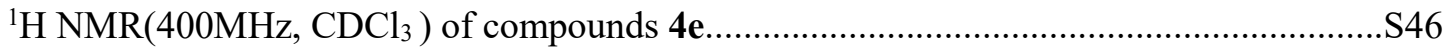

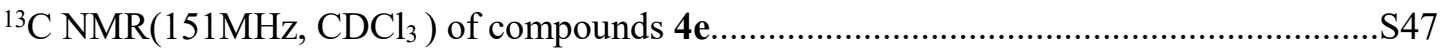


${ }^{1} \mathrm{H}$ NMR(400MHz, $\left.\mathrm{CDCl}_{3}\right)$ of compounds $\mathbf{4 f}$.

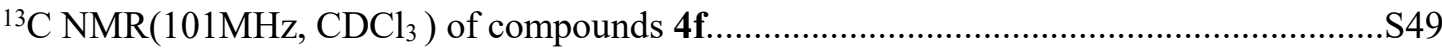

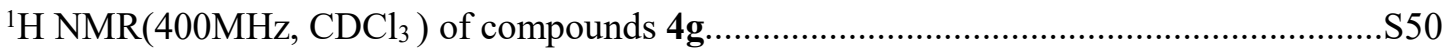

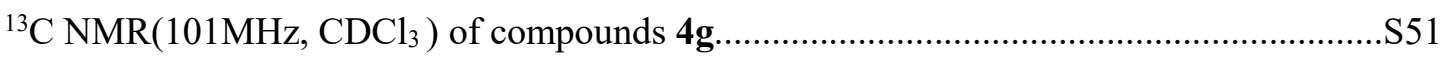

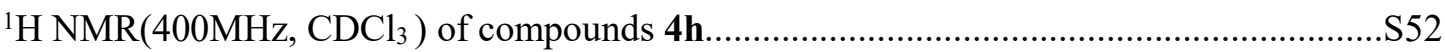

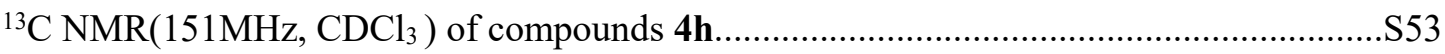

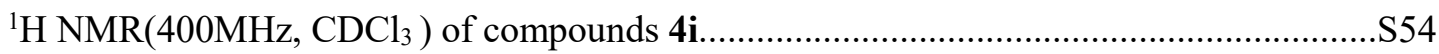

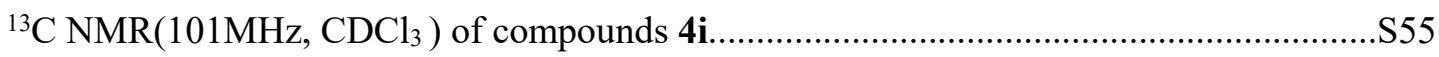

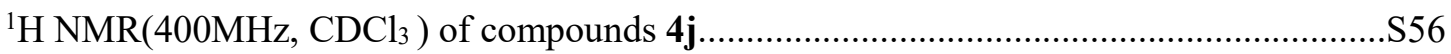

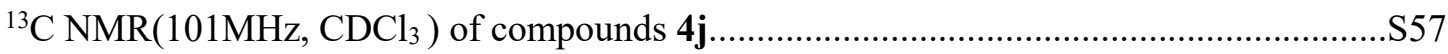

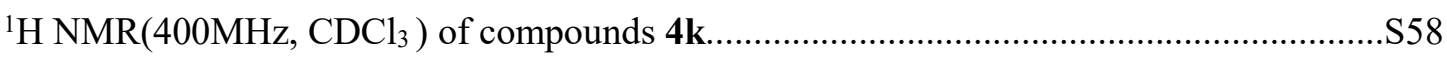

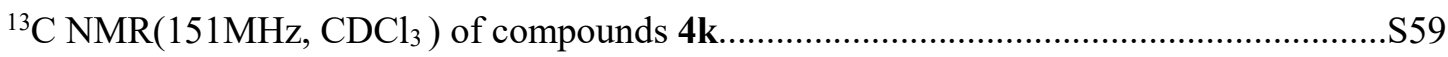

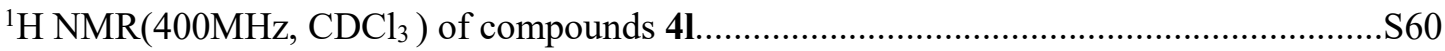

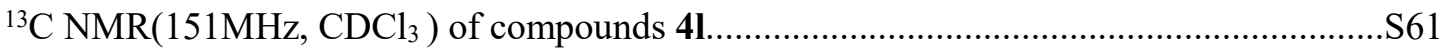

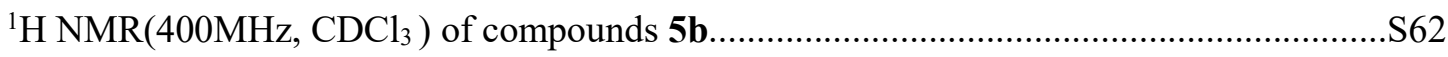

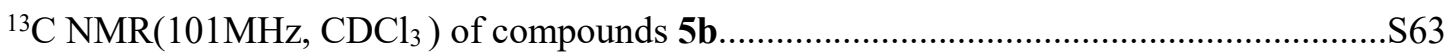

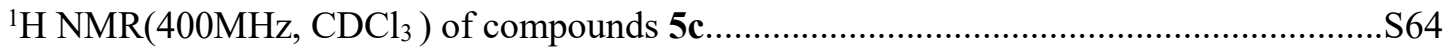

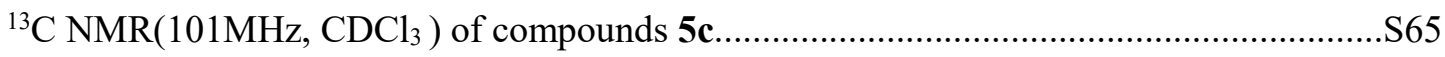

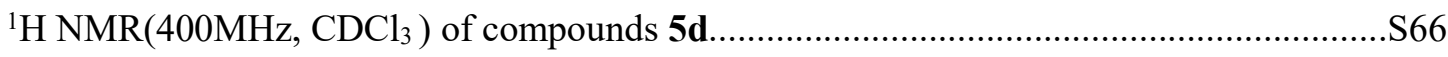

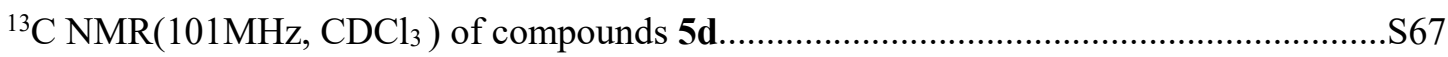

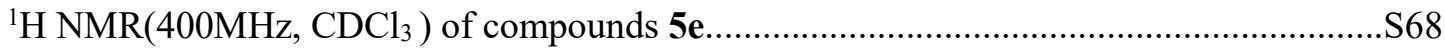

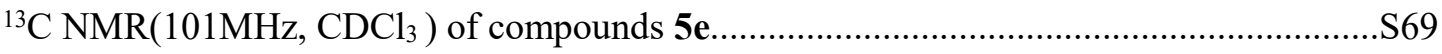


${ }^{1} \mathrm{H}$ NMR(400MHz, $\left.\mathrm{CDCl}_{3}\right)$ of compounds $\mathbf{5 i}$. $\mathrm{S} 70$

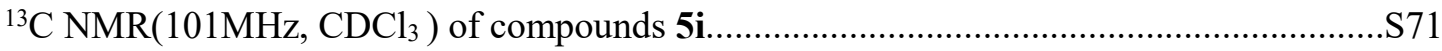

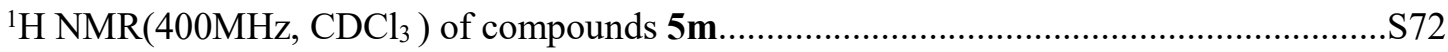

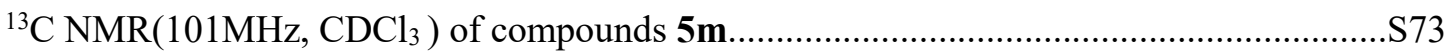

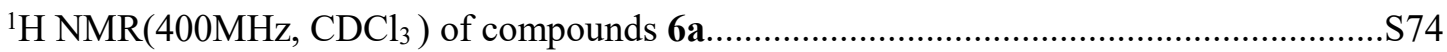

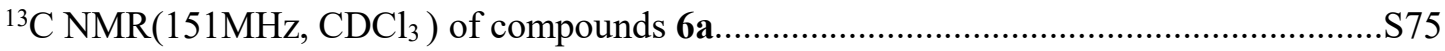

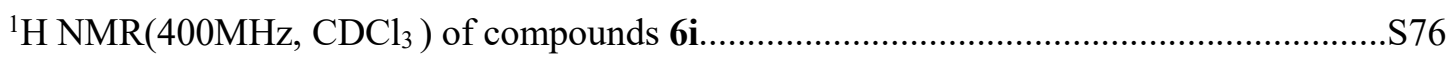

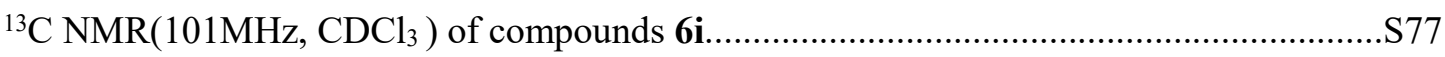

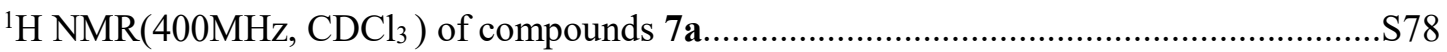

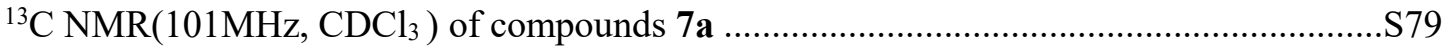

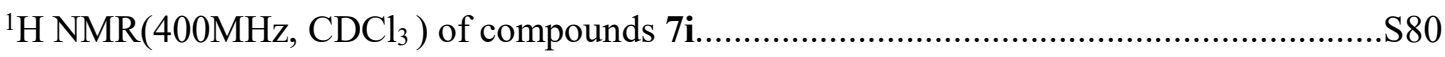

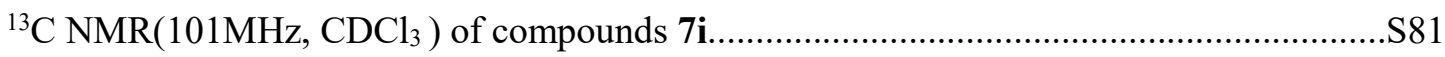




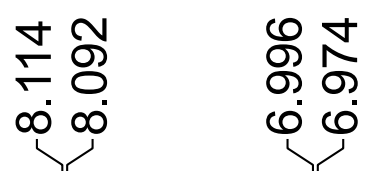
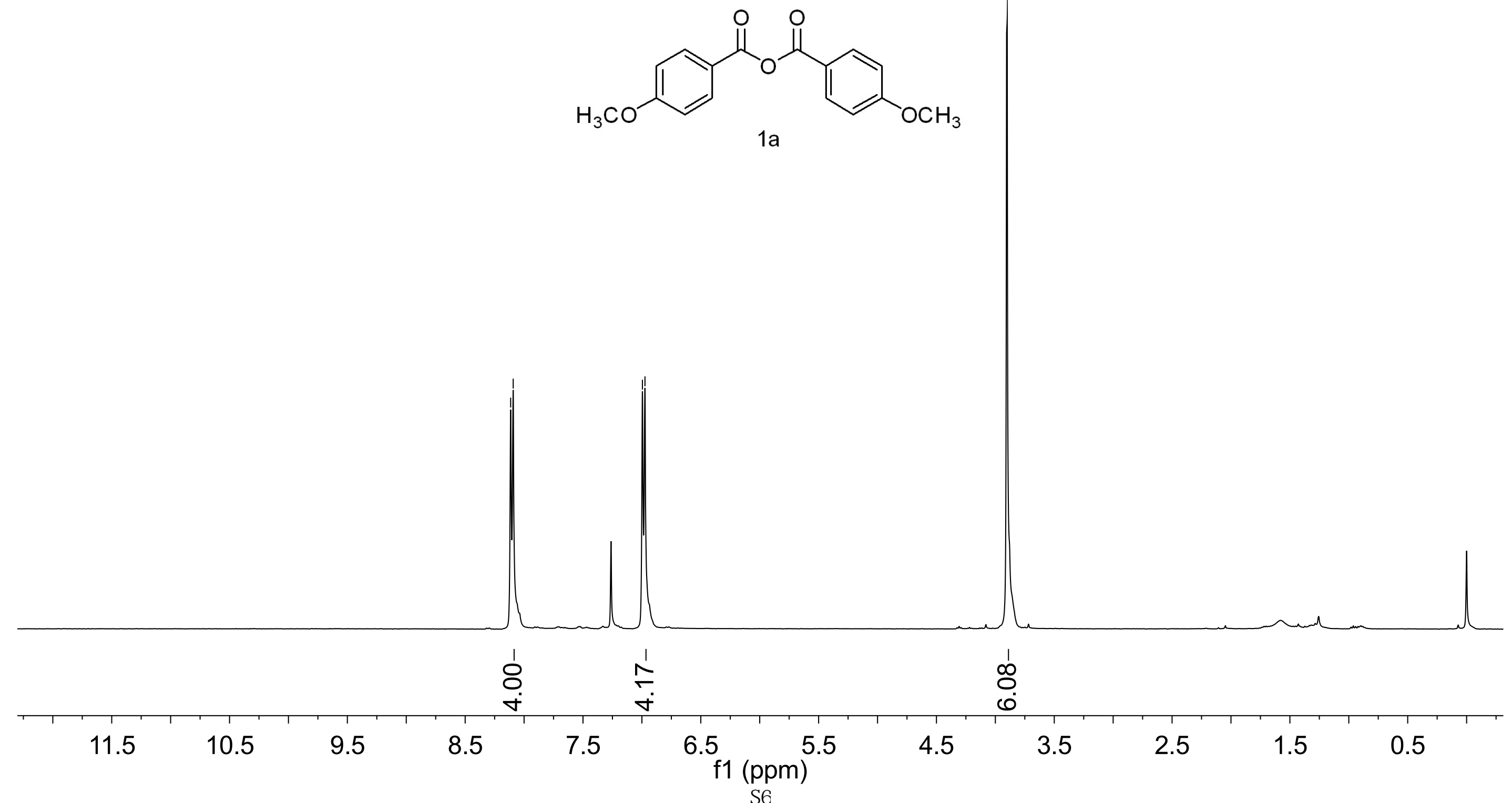

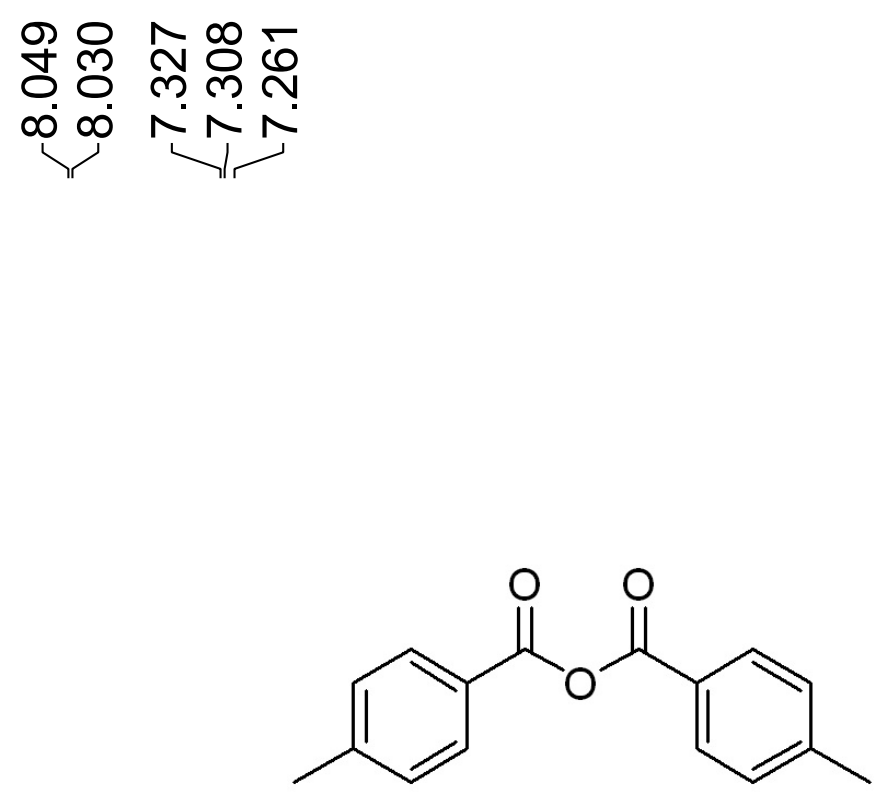

$1 b$

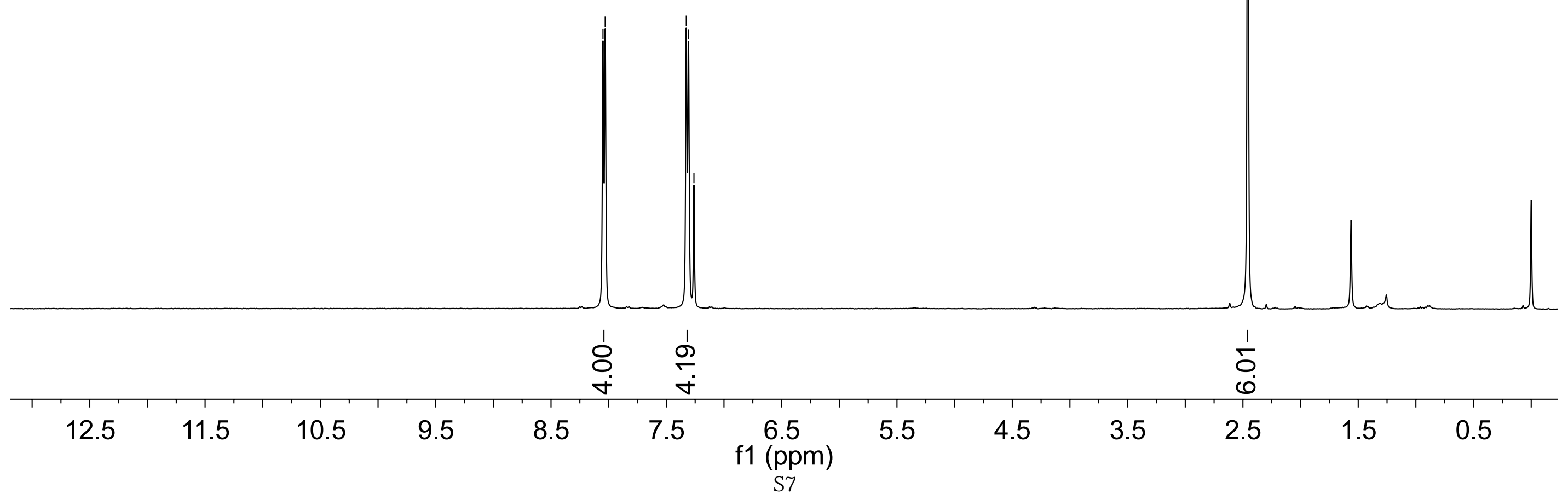




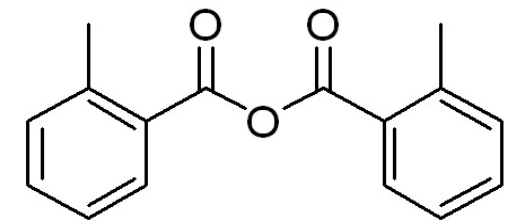

1c

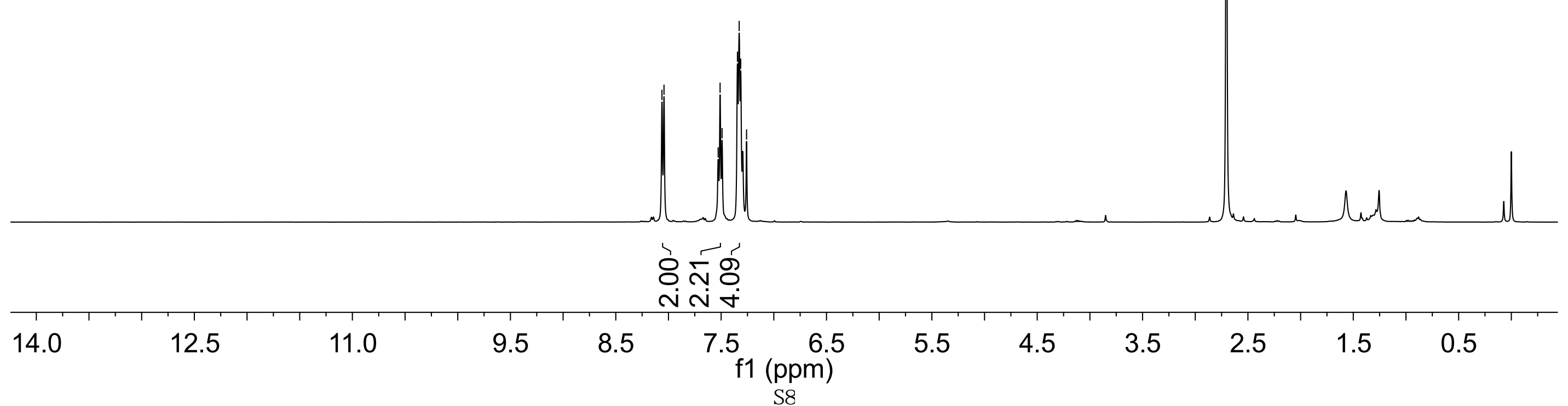




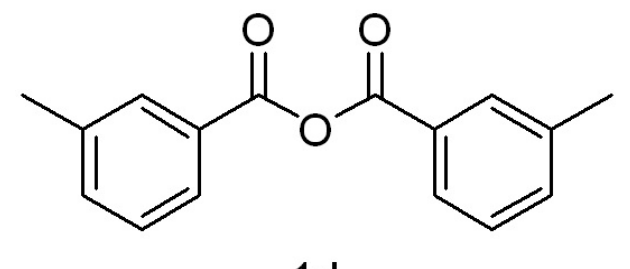

1d

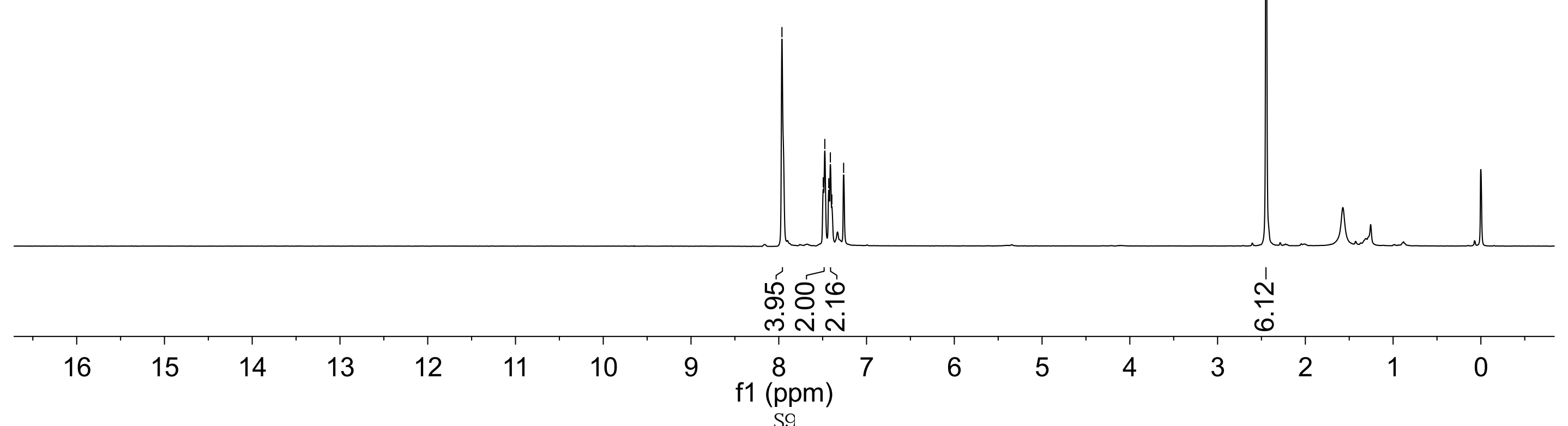




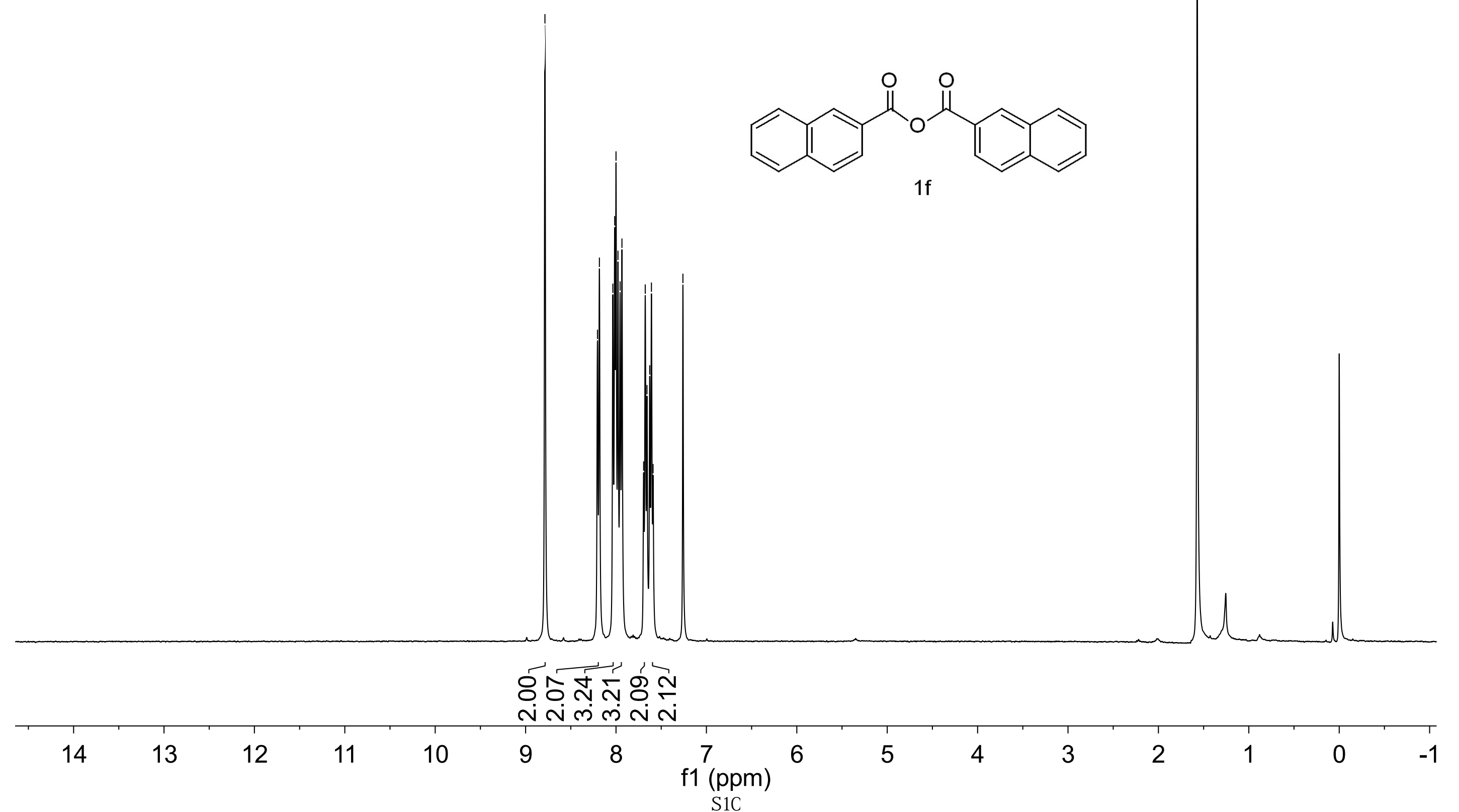




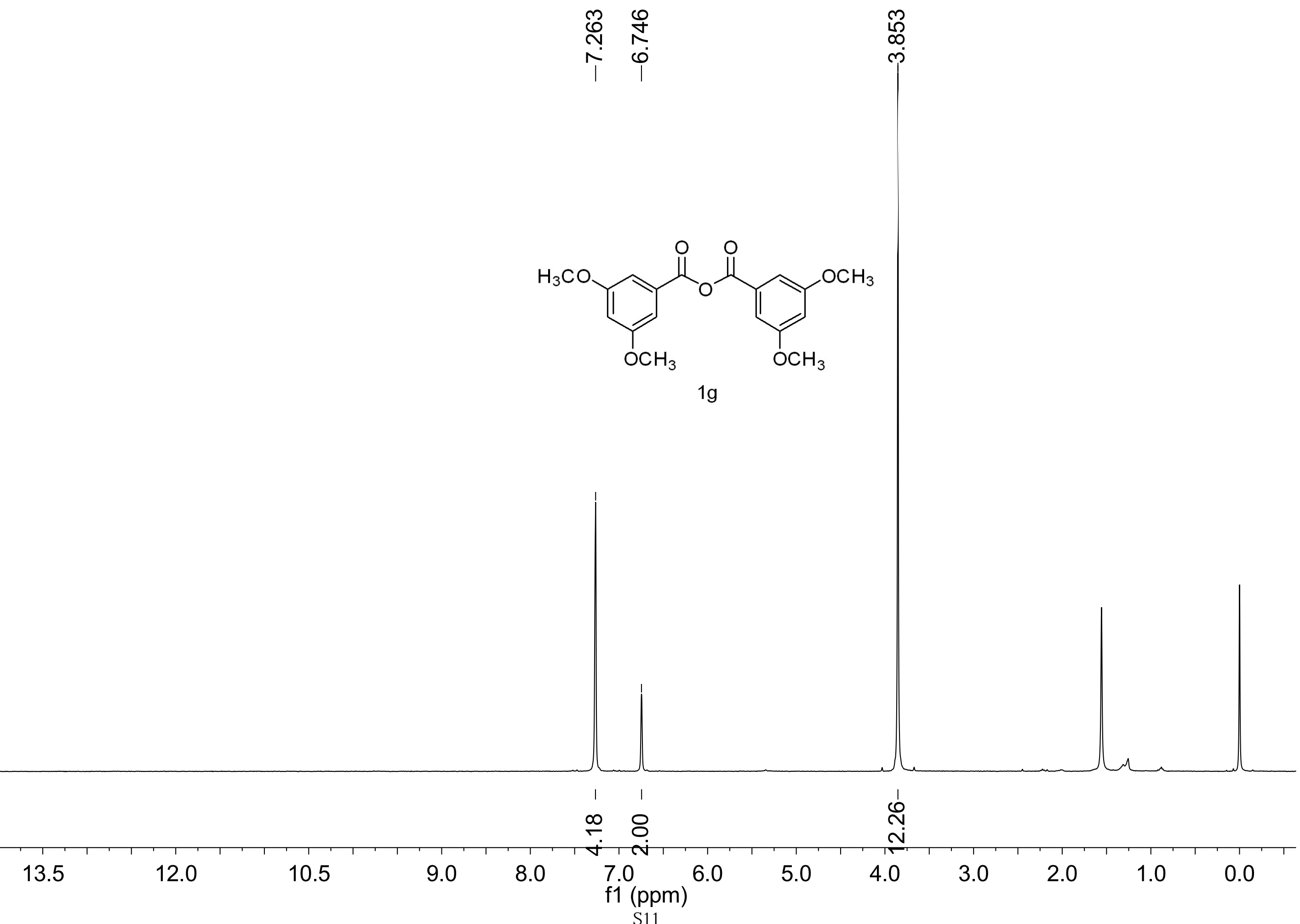




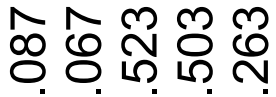

促

少式
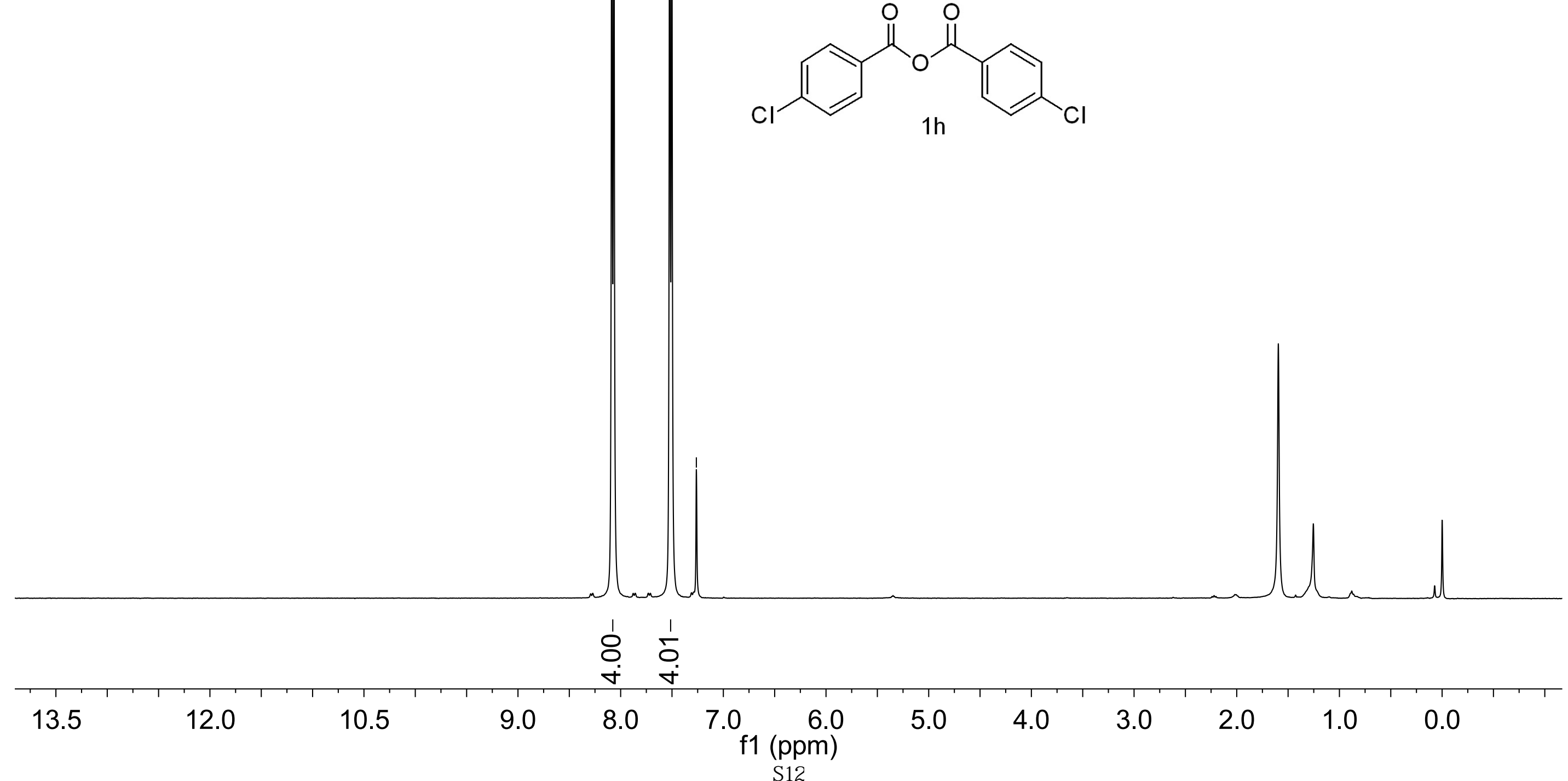


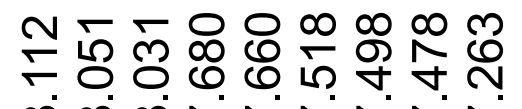

$\infty \infty \infty N N N$

L

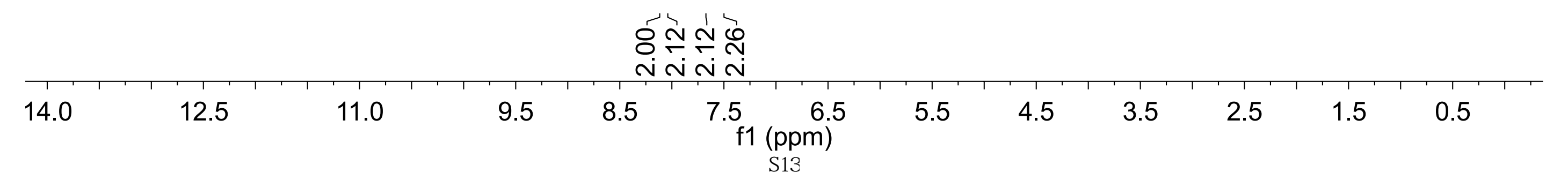




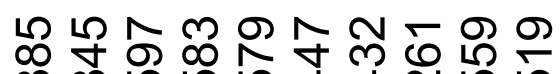

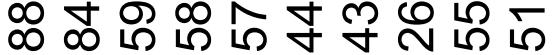

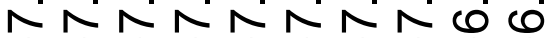

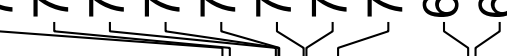

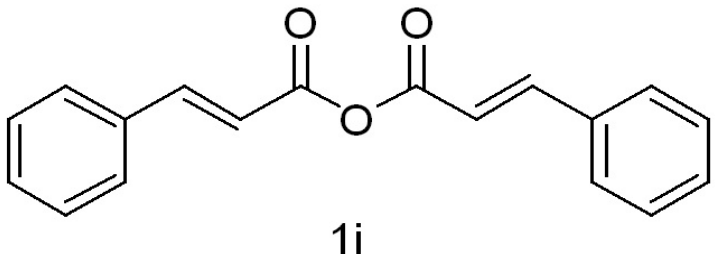

$1 \mathrm{j}$

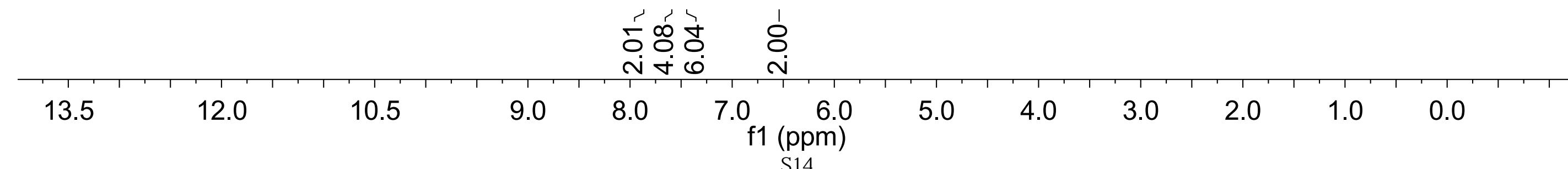



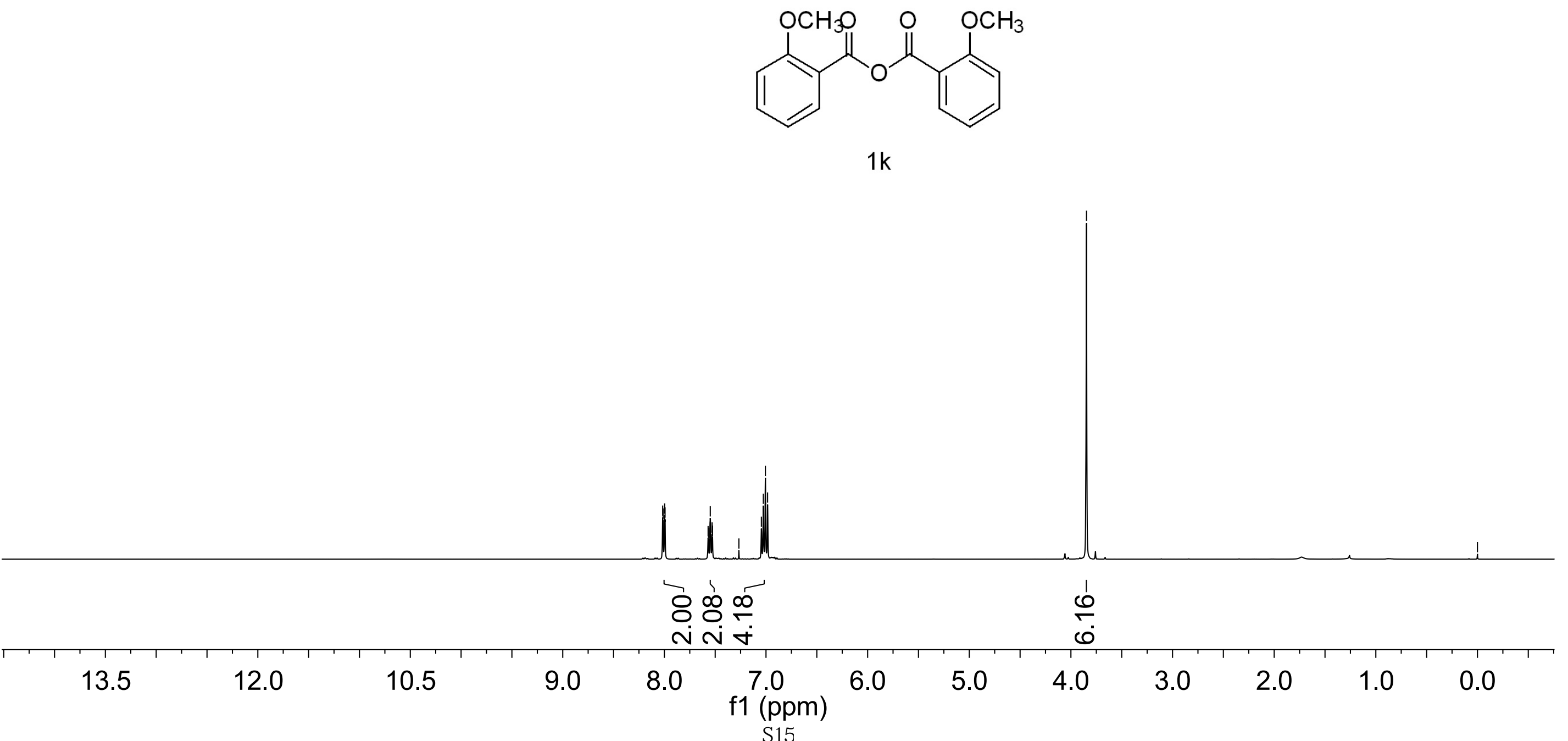


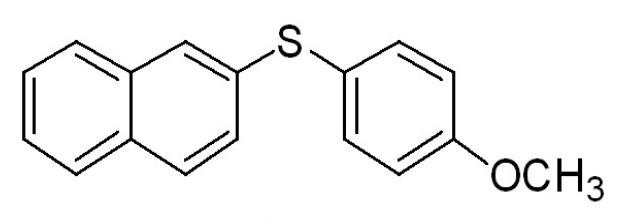

$3 a$
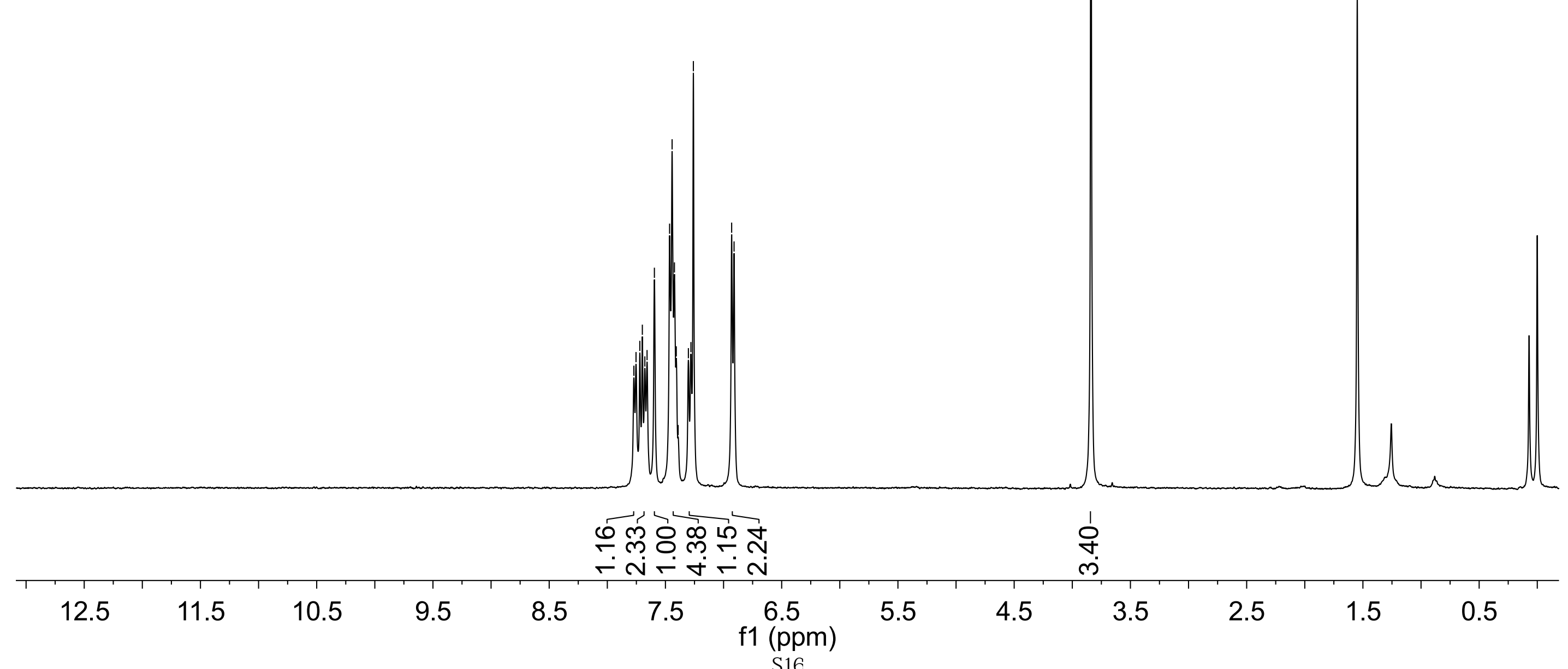

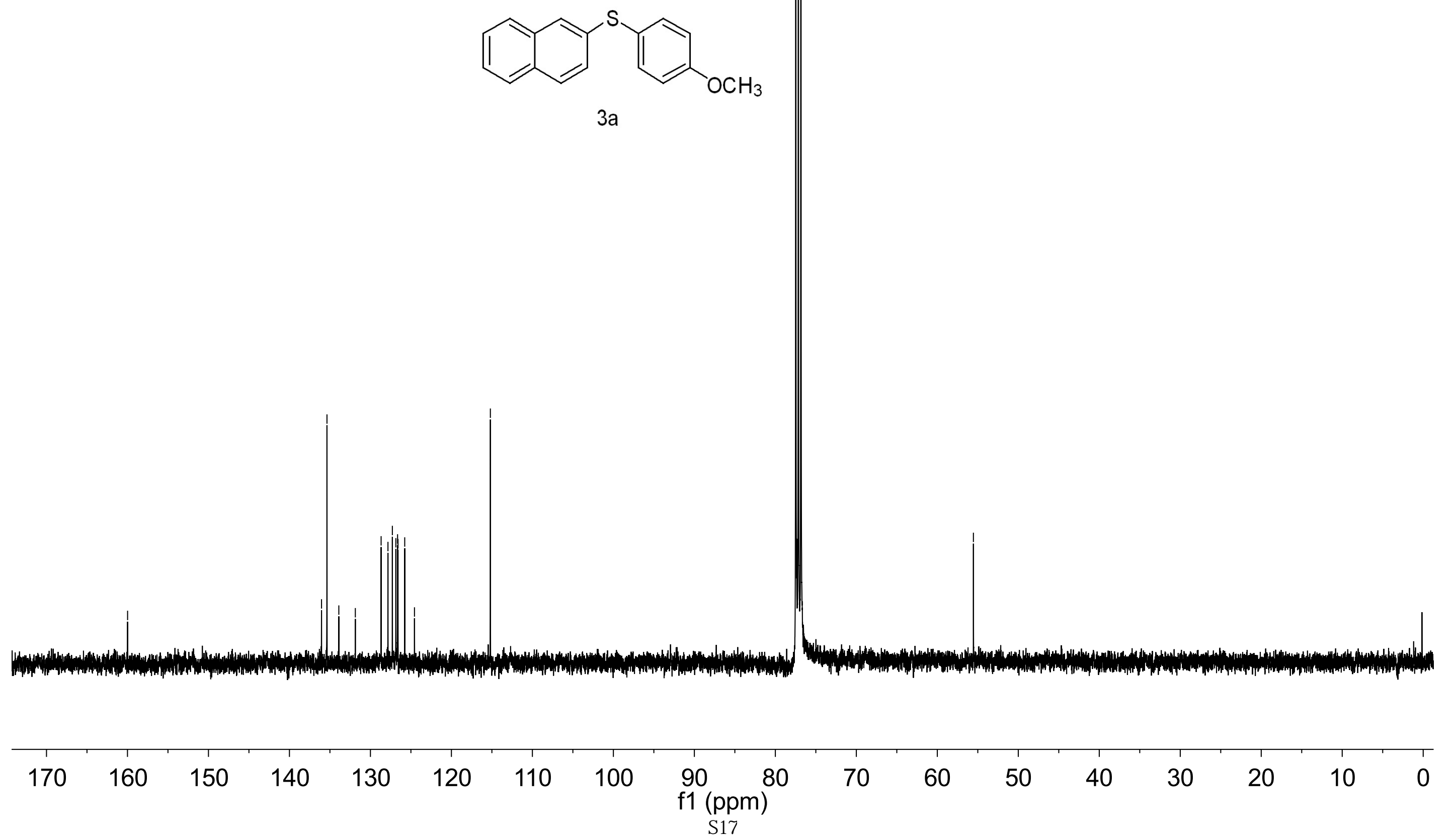

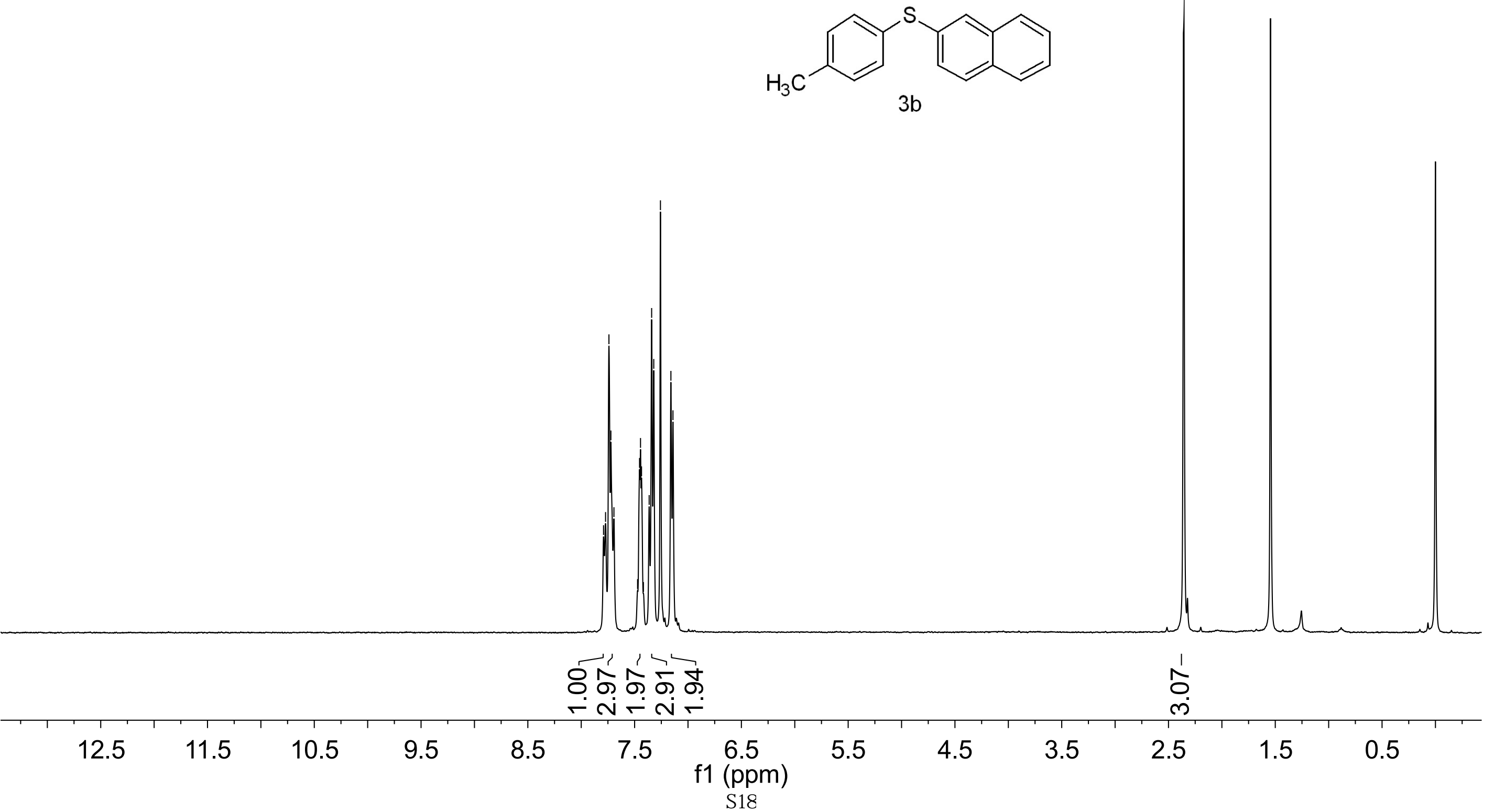

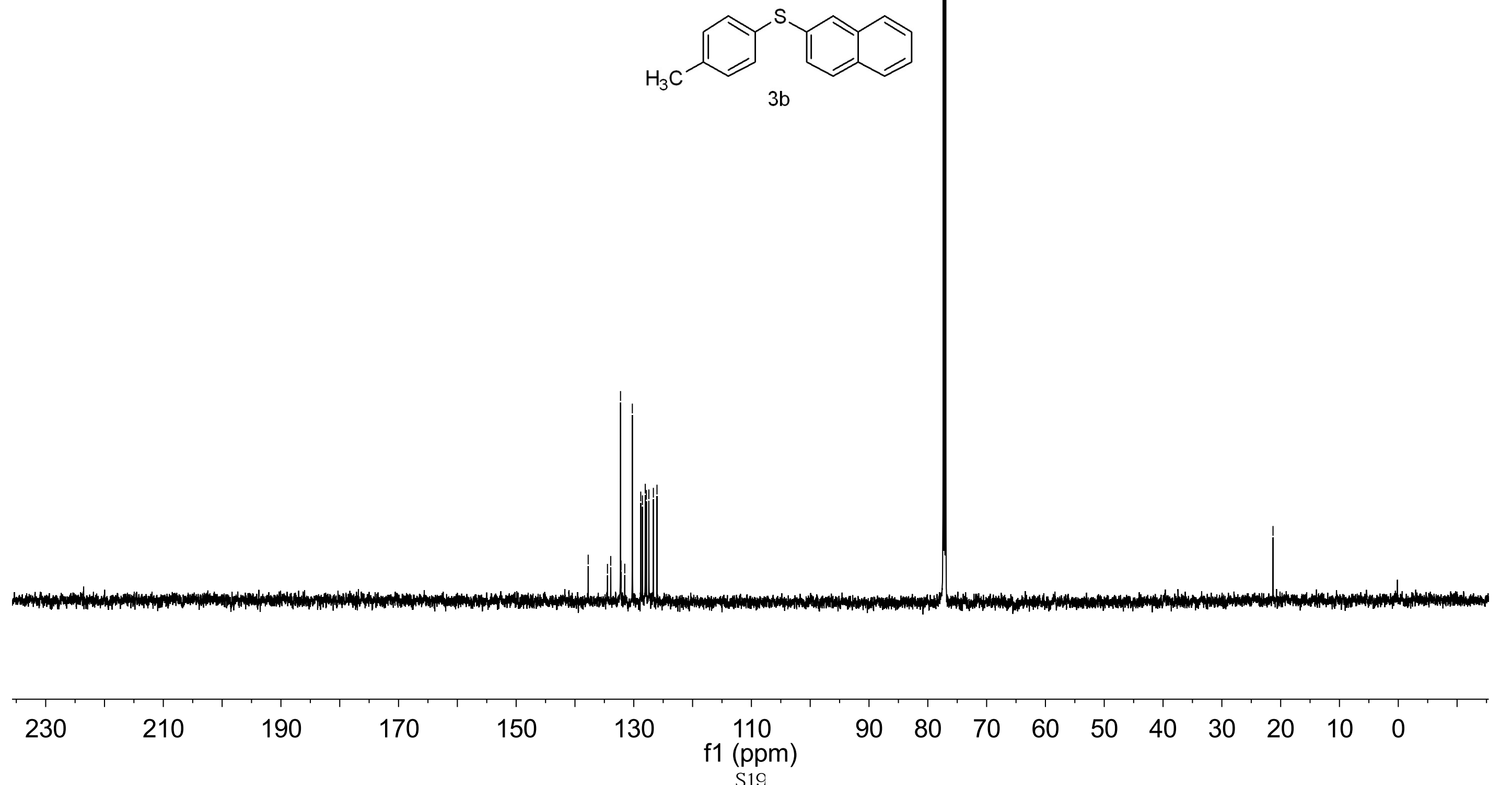


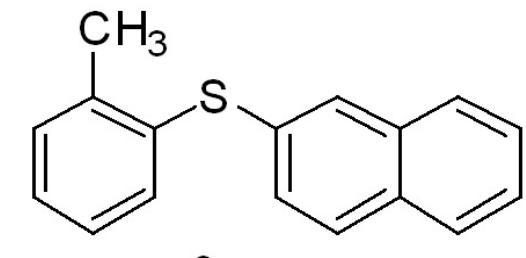

$3 c$

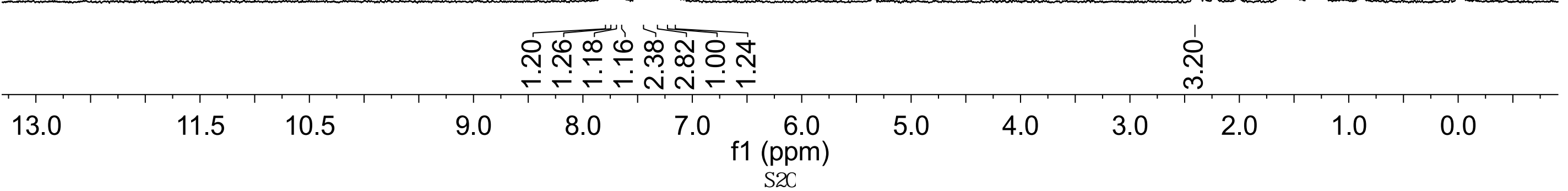


<smiles>Cc1ccccc1Sc1ccc2ccccc2c1</smiles> 

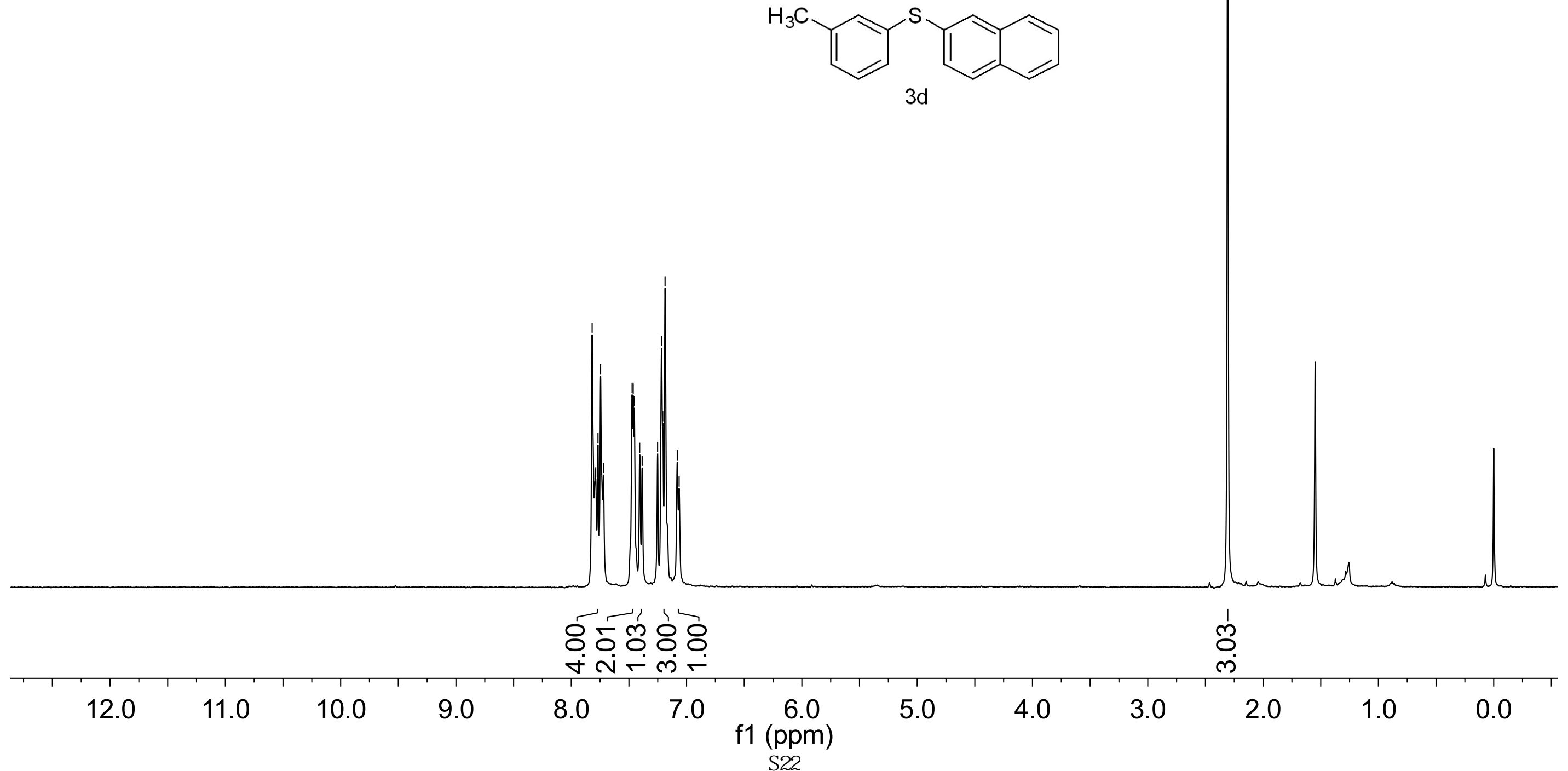


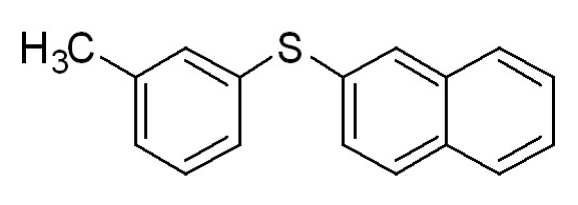

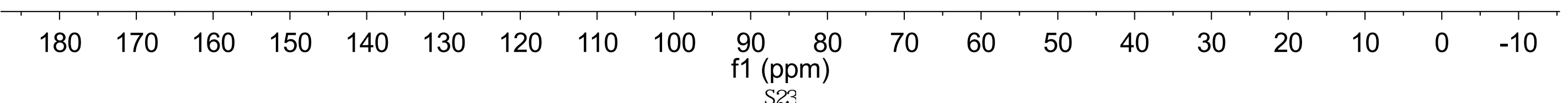



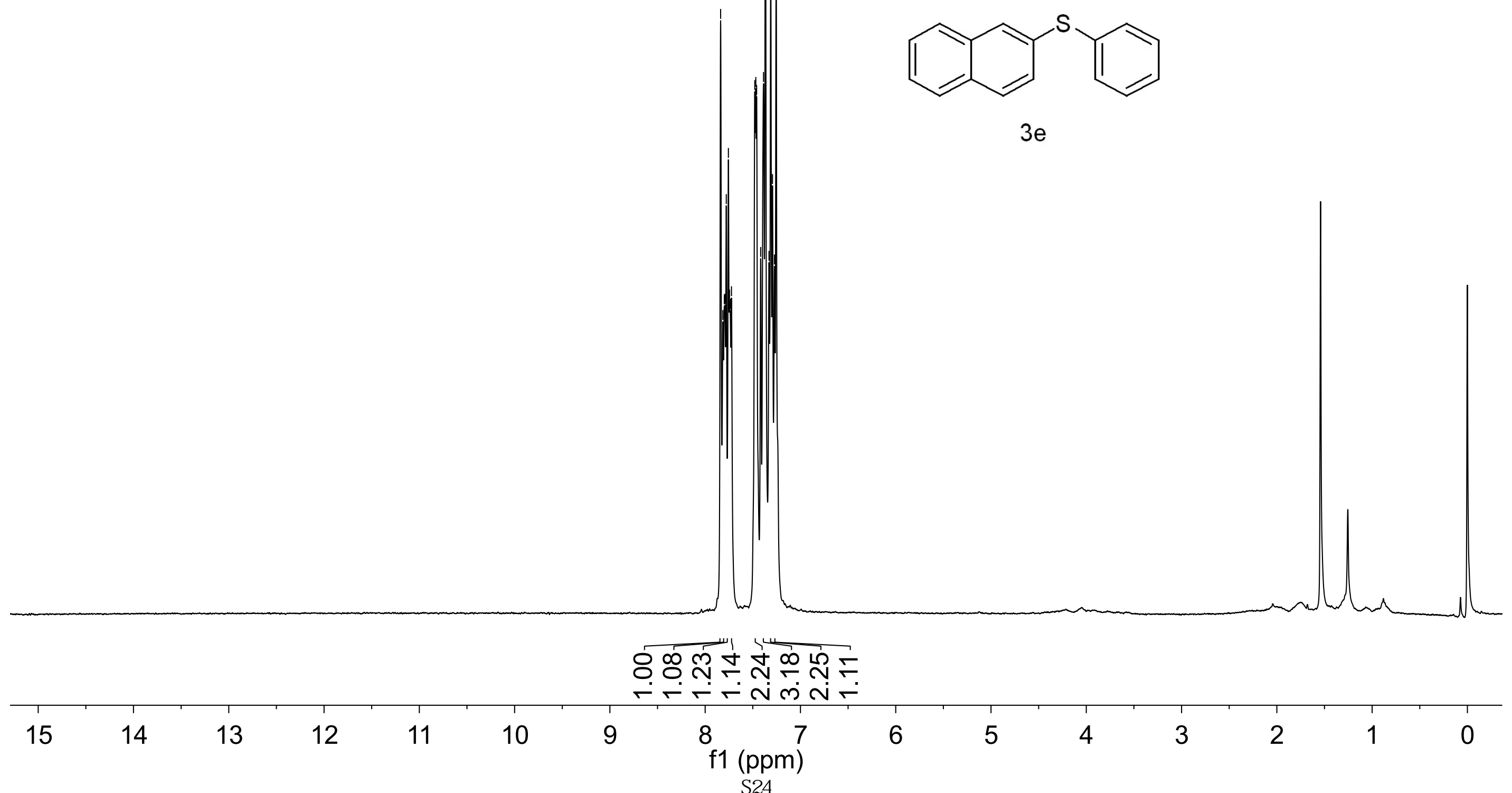


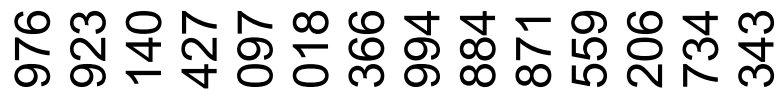

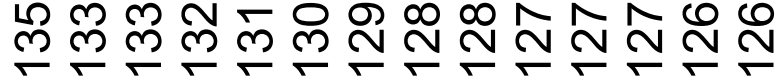

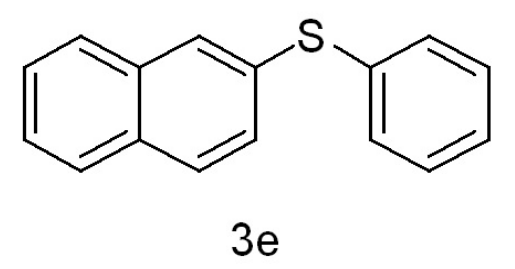

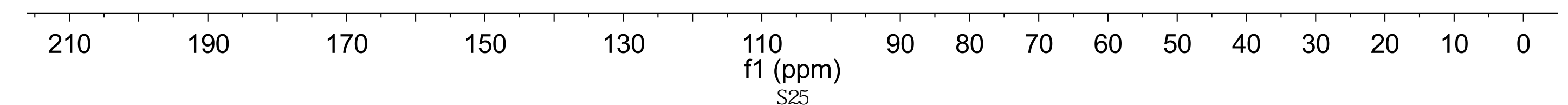




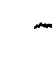

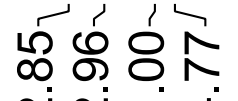
ก $\sim \dot{\sim}$ 

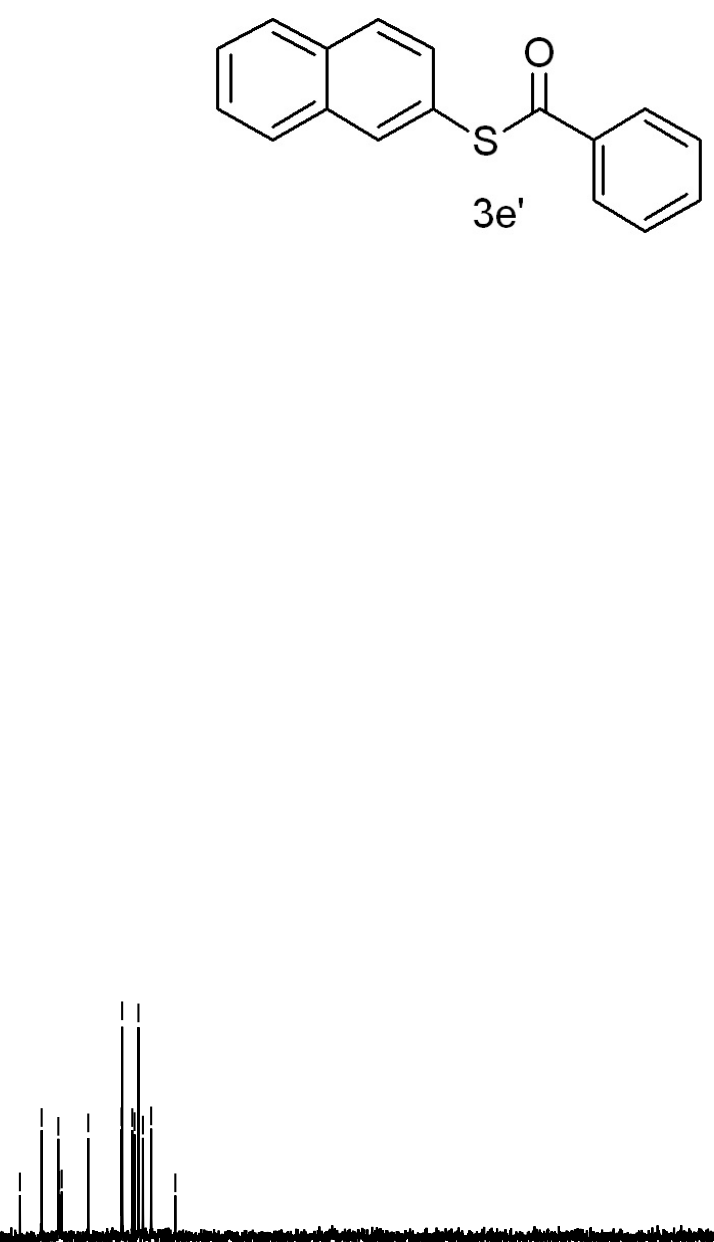

\begin{tabular}{|c|c|c|c|c|c|c|c|c|c|c|c|c|c|c|}
\hline 210 & 190 & 170 & 150 & 130 & $\begin{array}{l}110 \\
\mathrm{f1}(\mathrm{ppm}) \\
\text { s27 }\end{array}$ & 90 & 80 & 70 & 60 & 50 & 40 & 30 & 20 & 10 \\
\hline
\end{tabular}




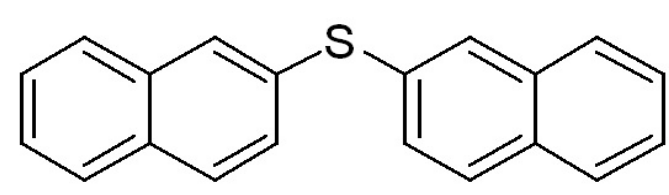

$3 f$

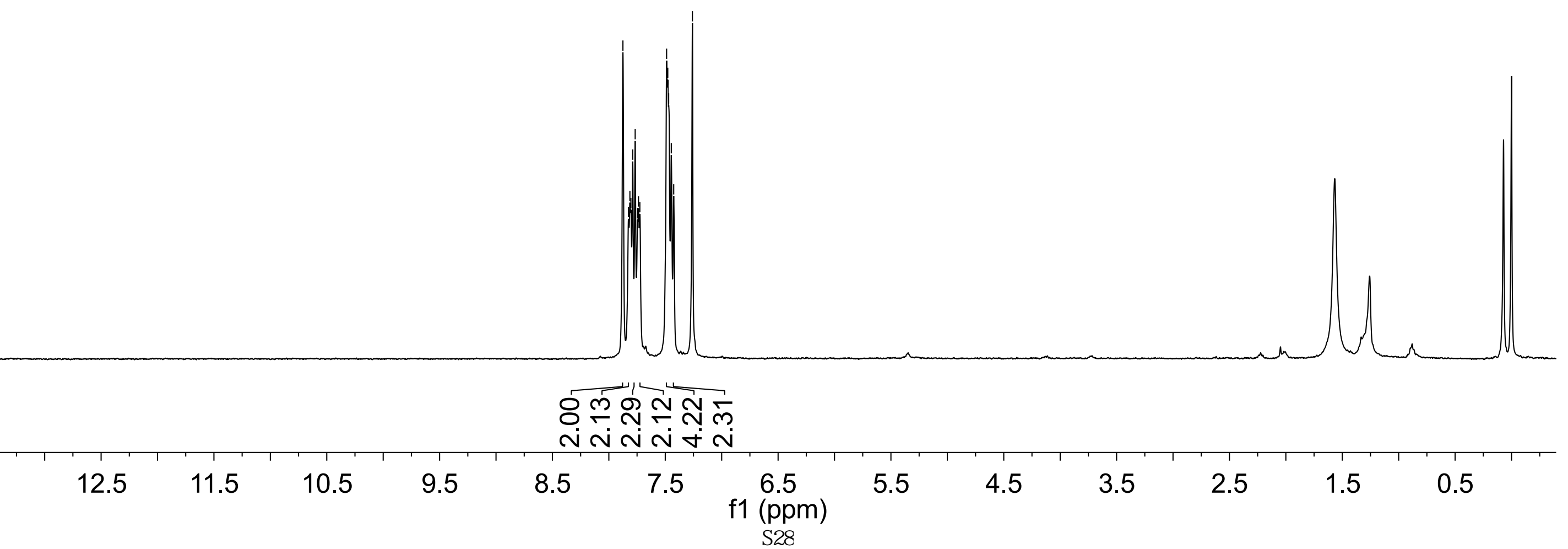




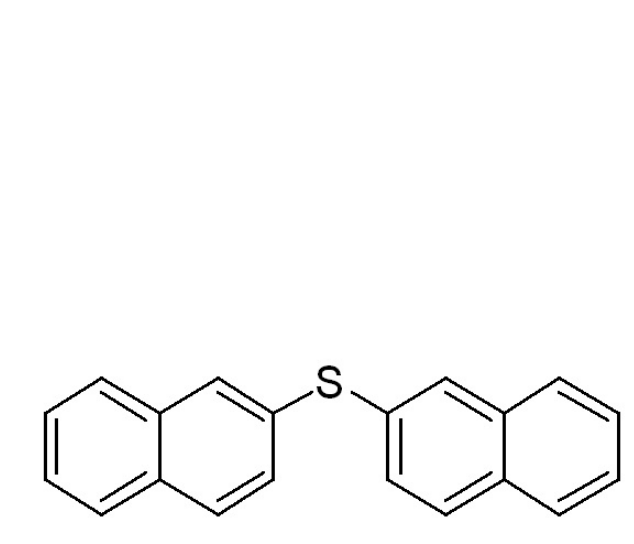

$\begin{array}{llllllllllllllllllllllll}200 & 190 & 180 & 170 & 160 & 150 & 140 & 130 & 120 & 110 & \begin{array}{c}100 \\ \mathrm{f} 1(\mathrm{ppm})\end{array} & 90 & 80 & 70 & 60 & 50 & 40 & 30 & 20 & 10 & 0\end{array}$




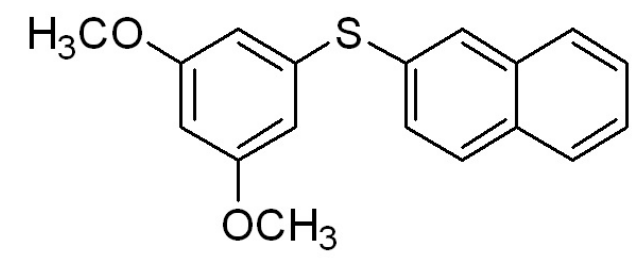

$3 g$

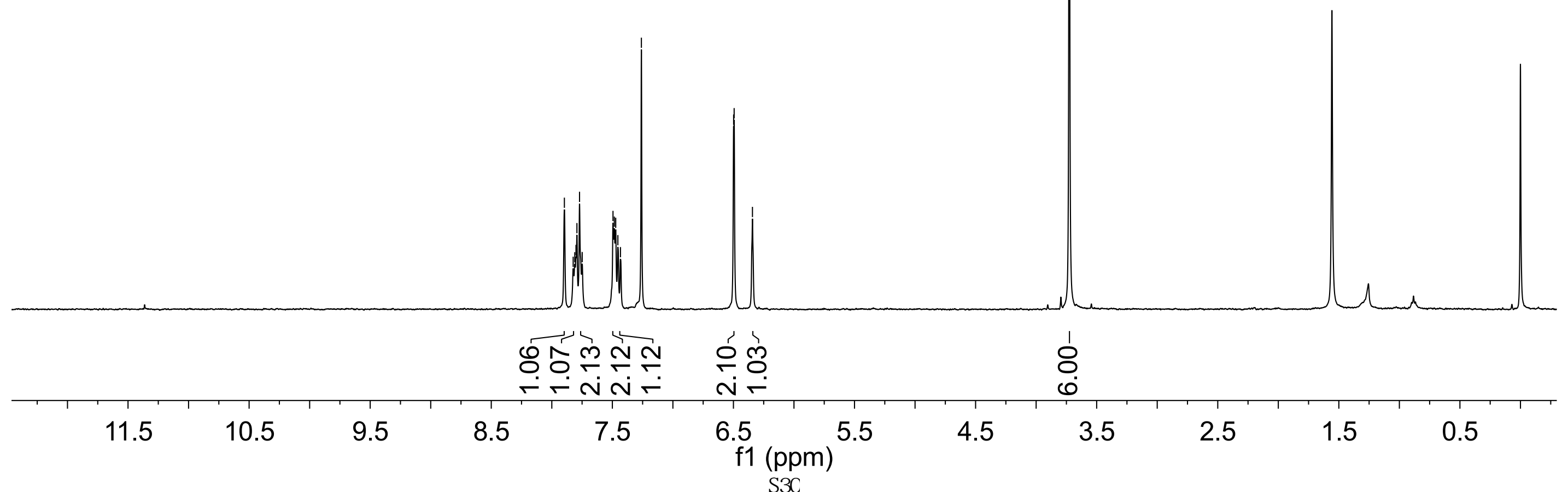


ฟ

○

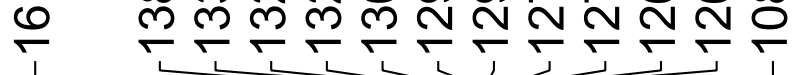

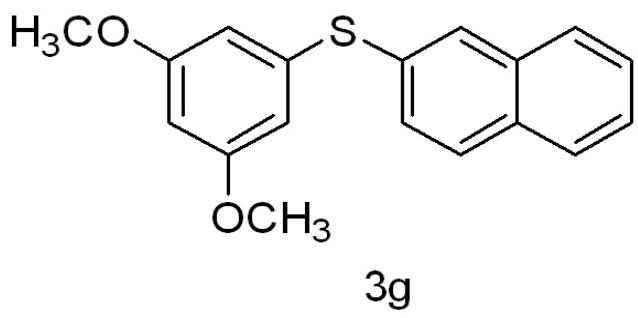

$\begin{array}{llll}30 & 20 & 10 & 0\end{array}$




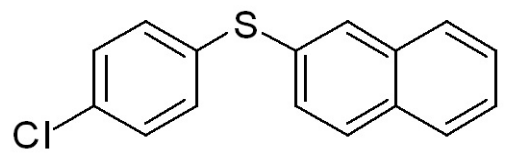

$3 \mathrm{~h}$

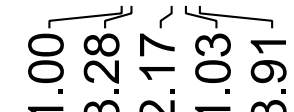

$\begin{array}{llllllllllllllllllllllllllll}16 & 15 & 14 & 13 & 12 & 11 & 10 & 9 & 8 & 7 & 6 & 5 & 4 & 3 & 2 & 1 & 0 & -1 & -2 & -3 & -4\end{array}$




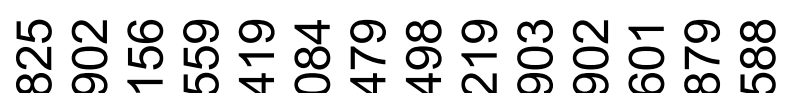

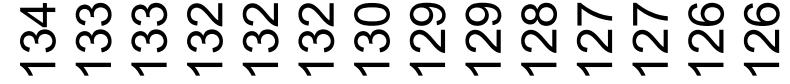
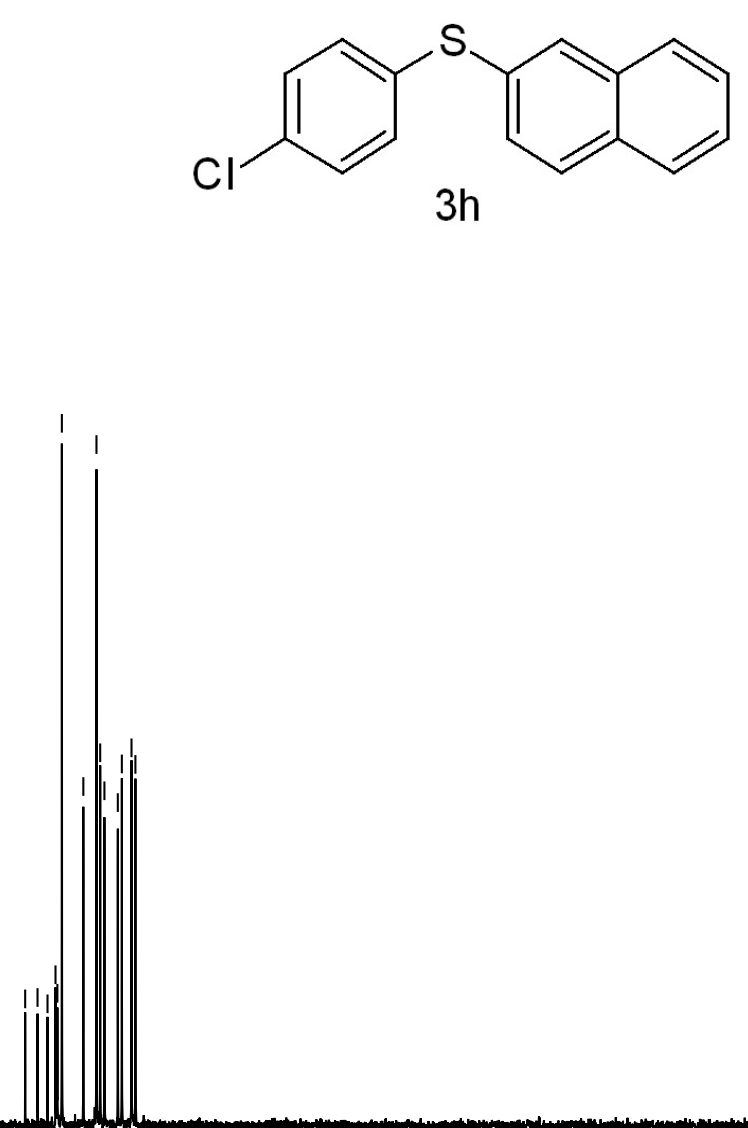

$\begin{array}{llllllllllllllllllll}200 & 190 & 180 & 170 & 160 & 150 & 140 & 130 & 120 & \begin{array}{c}110 \\ \mathrm{f} 1(\mathrm{ppm})\end{array} & 90 & 80 & 70 & 60 & 50 & 40 & 30 & 20 & 10 & 0\end{array}$




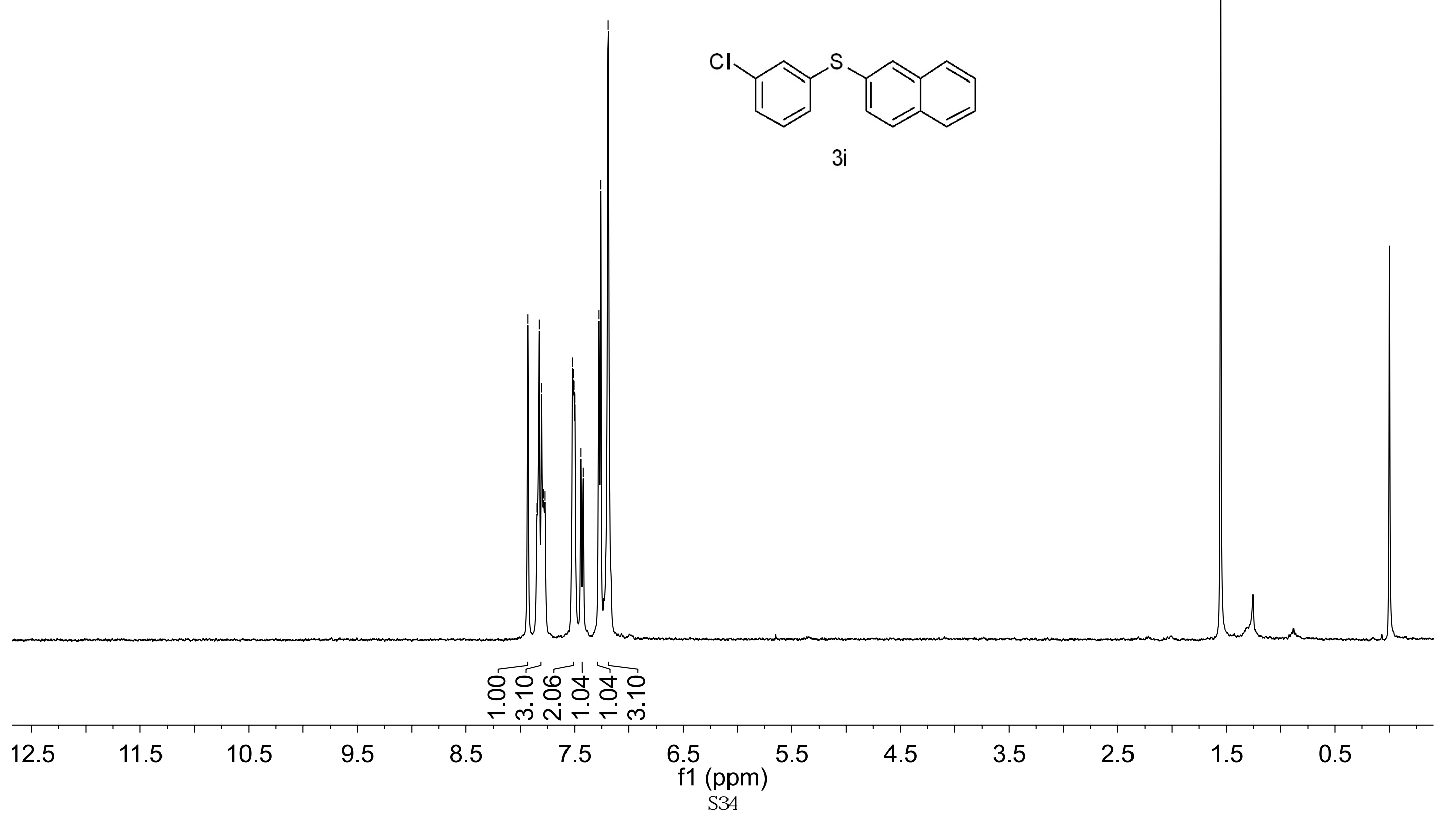




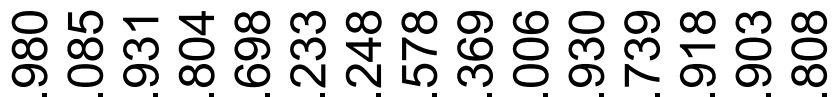

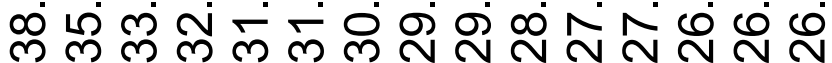

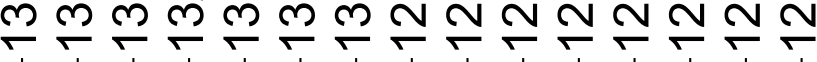

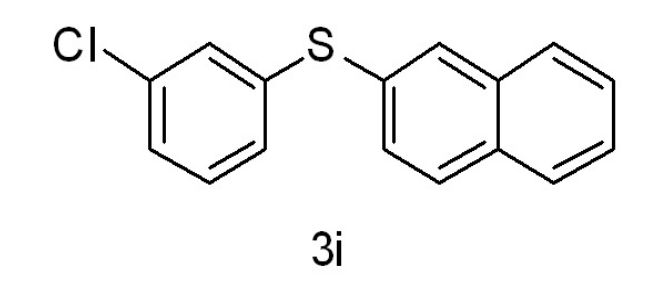

$\begin{array}{llllllllllllllllllllllll}00 & 190 & 180 & 170 & 160 & 150 & 140 & 130 & 120 & 110 & \begin{array}{c}100 \\ \mathrm{f} 1(\mathrm{ppm})\end{array} & 90 & 80 & 70 & 60 & 50 & 40 & 30 & 20 & 10 & 0\end{array}$


중유

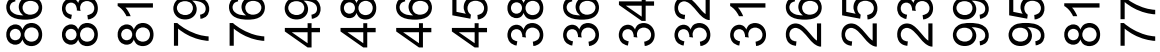

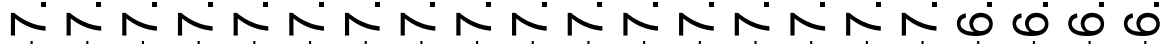

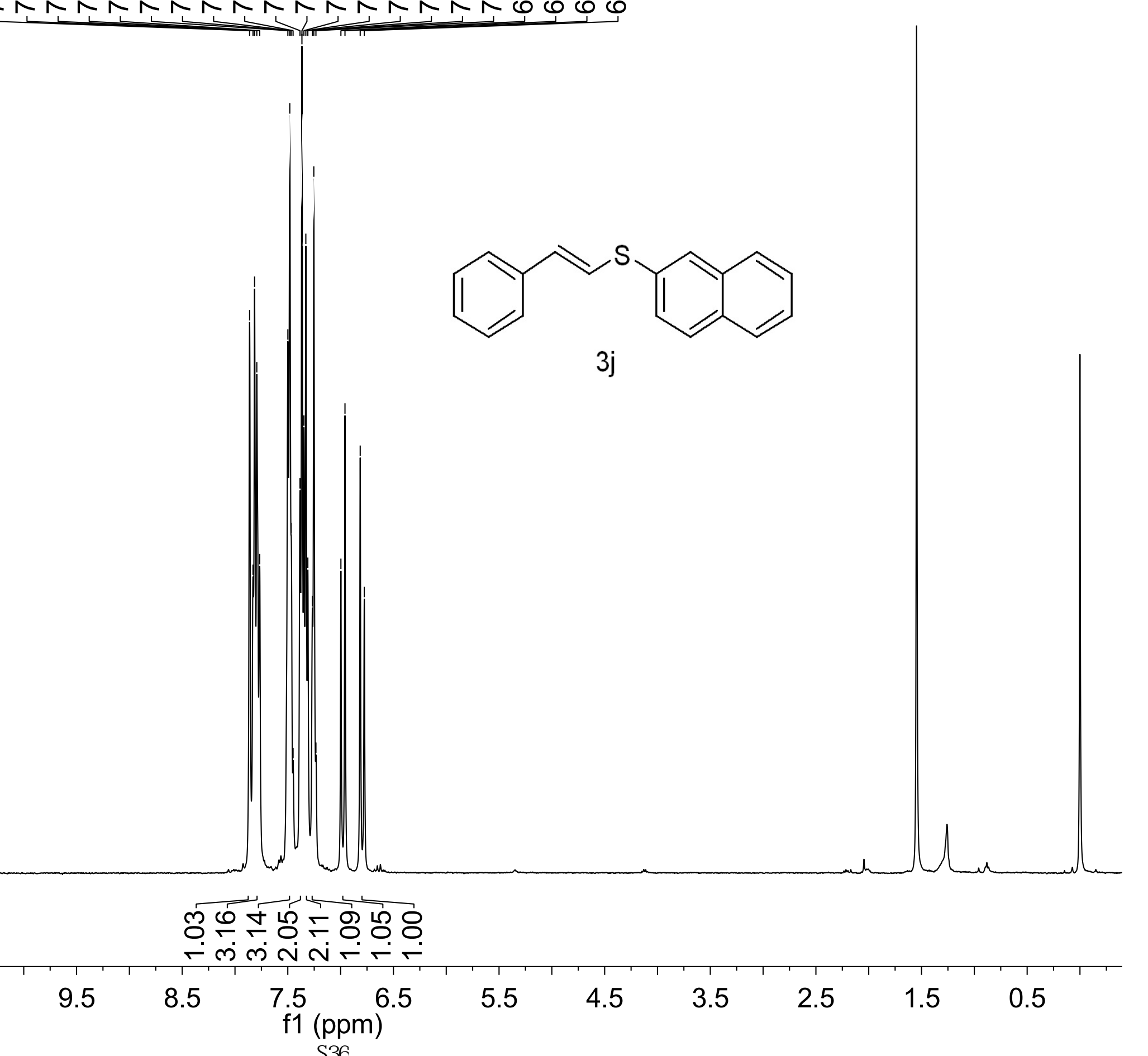




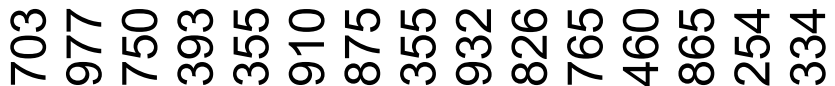


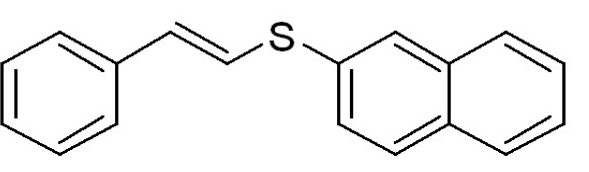

3j

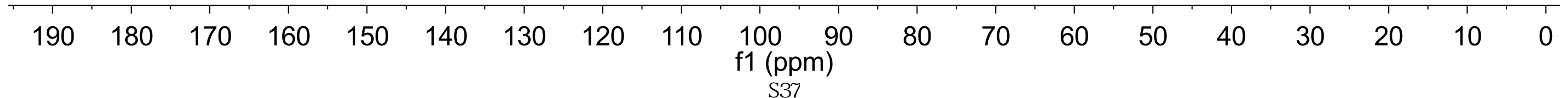




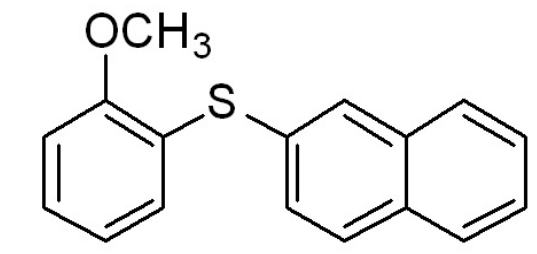

$3 \mathrm{k}$

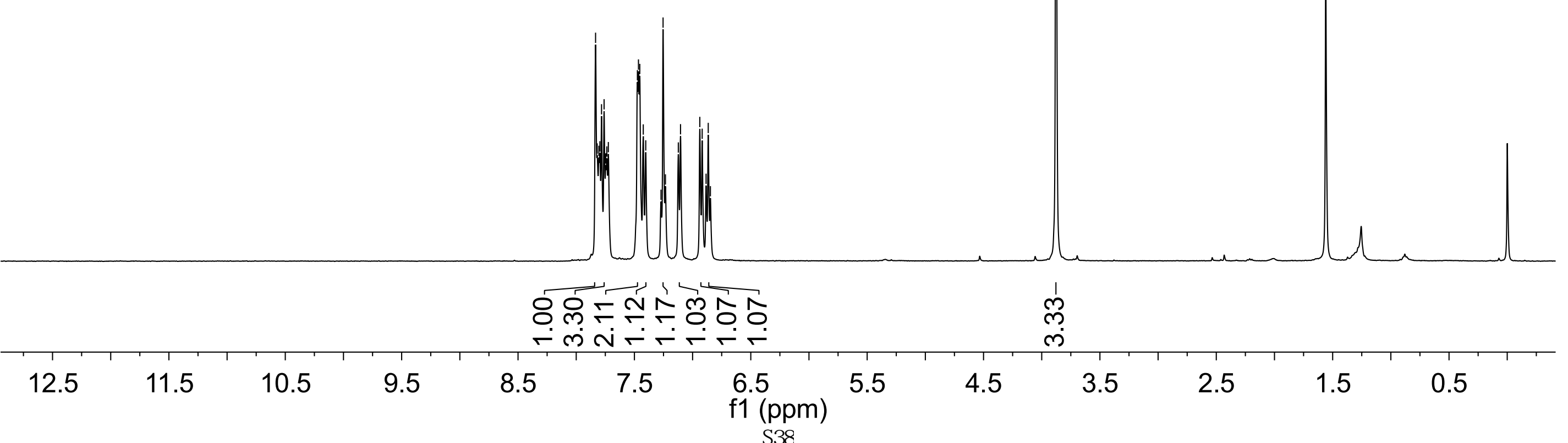




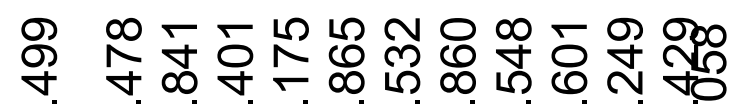

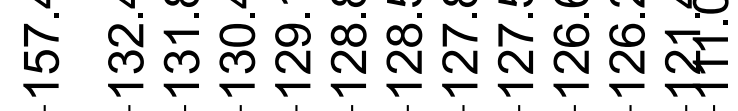

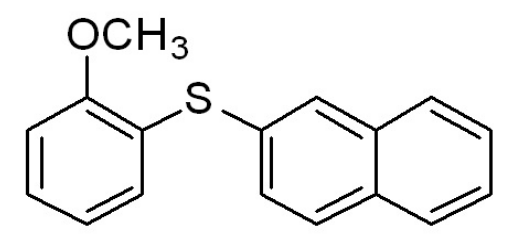

3k

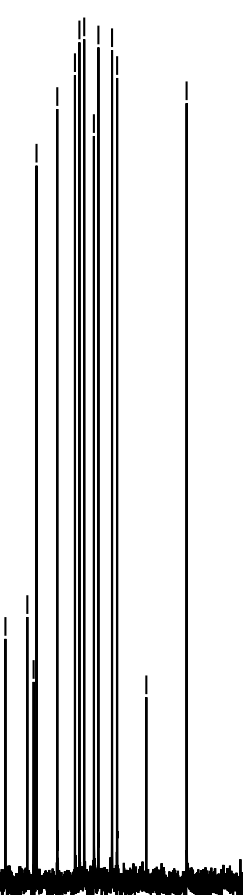

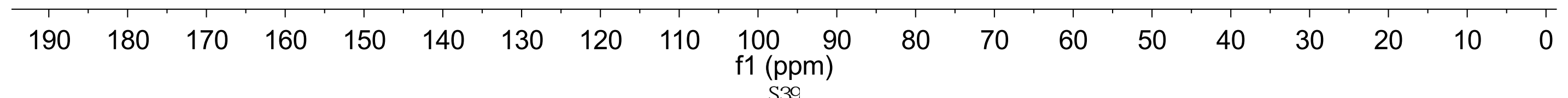




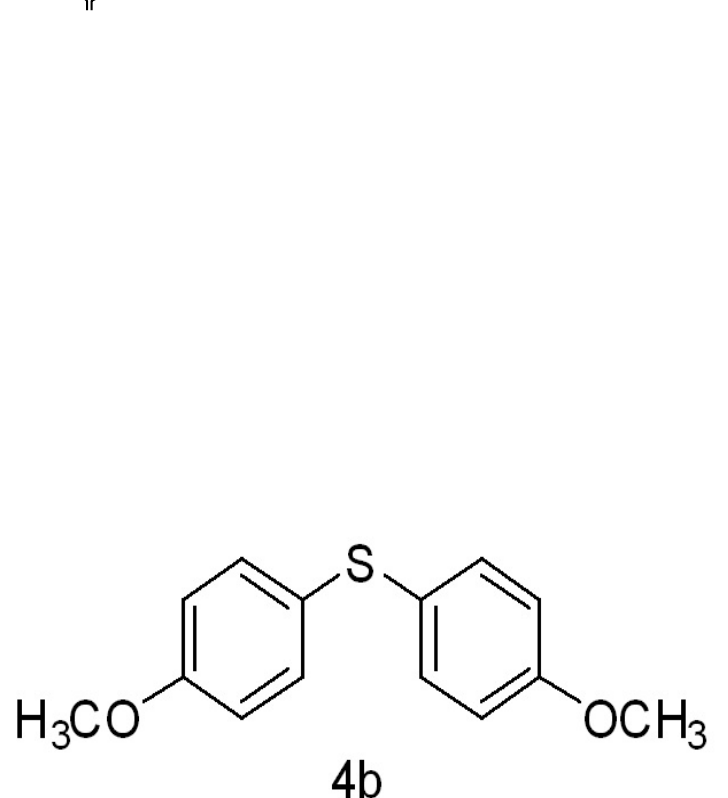

$4 b$

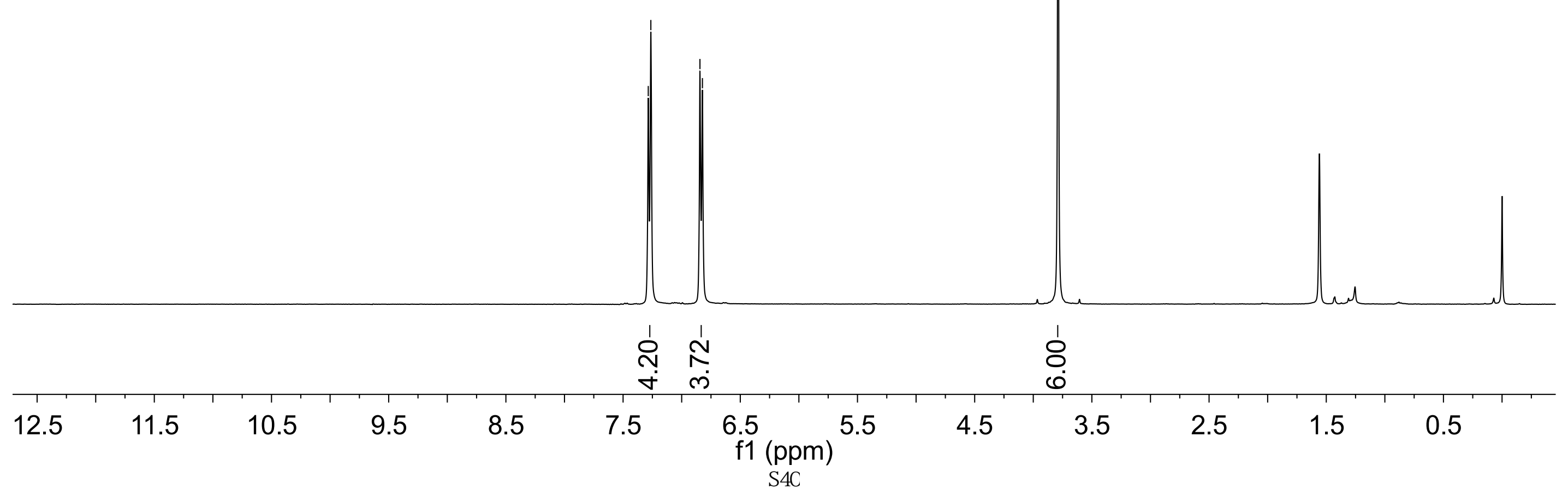




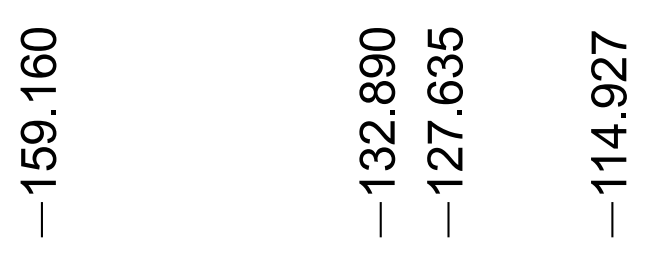

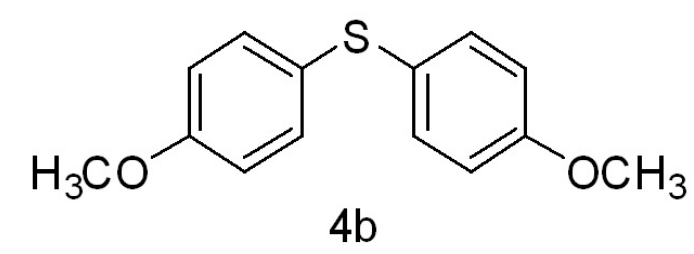

\begin{tabular}{|c|c|c|c|c|c|c|c|c|c|c|c|c|c|c|c|}
\hline 210 & 190 & 170 & 150 & 130 & $\begin{array}{l}110 \\
\mathrm{f} 1 \text { (ppm) } \\
\text { s41 }\end{array}$ & 90 & 80 & 70 & 6 & 50 & 40 & 30 & 20 & 10 & 0 \\
\hline
\end{tabular}



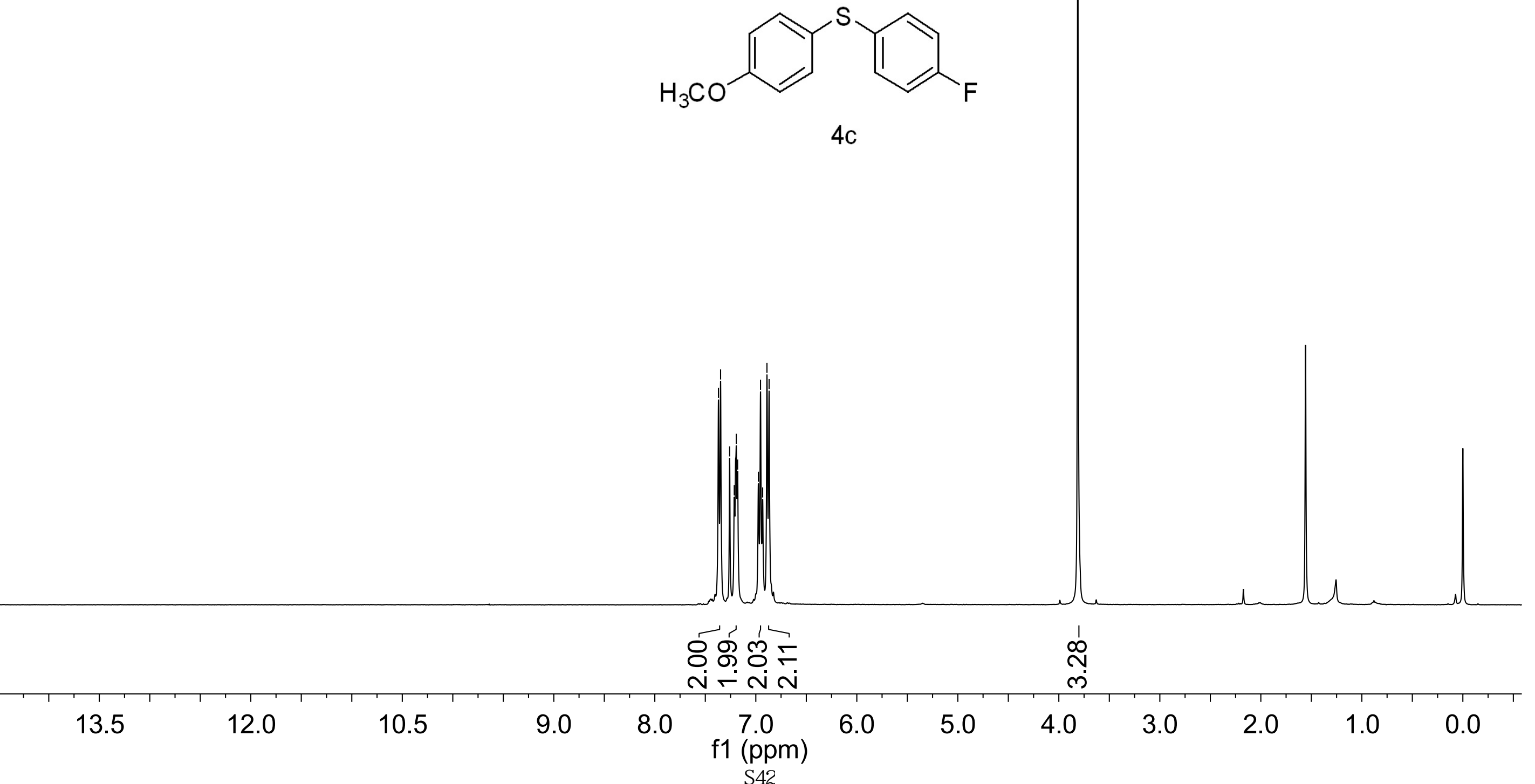

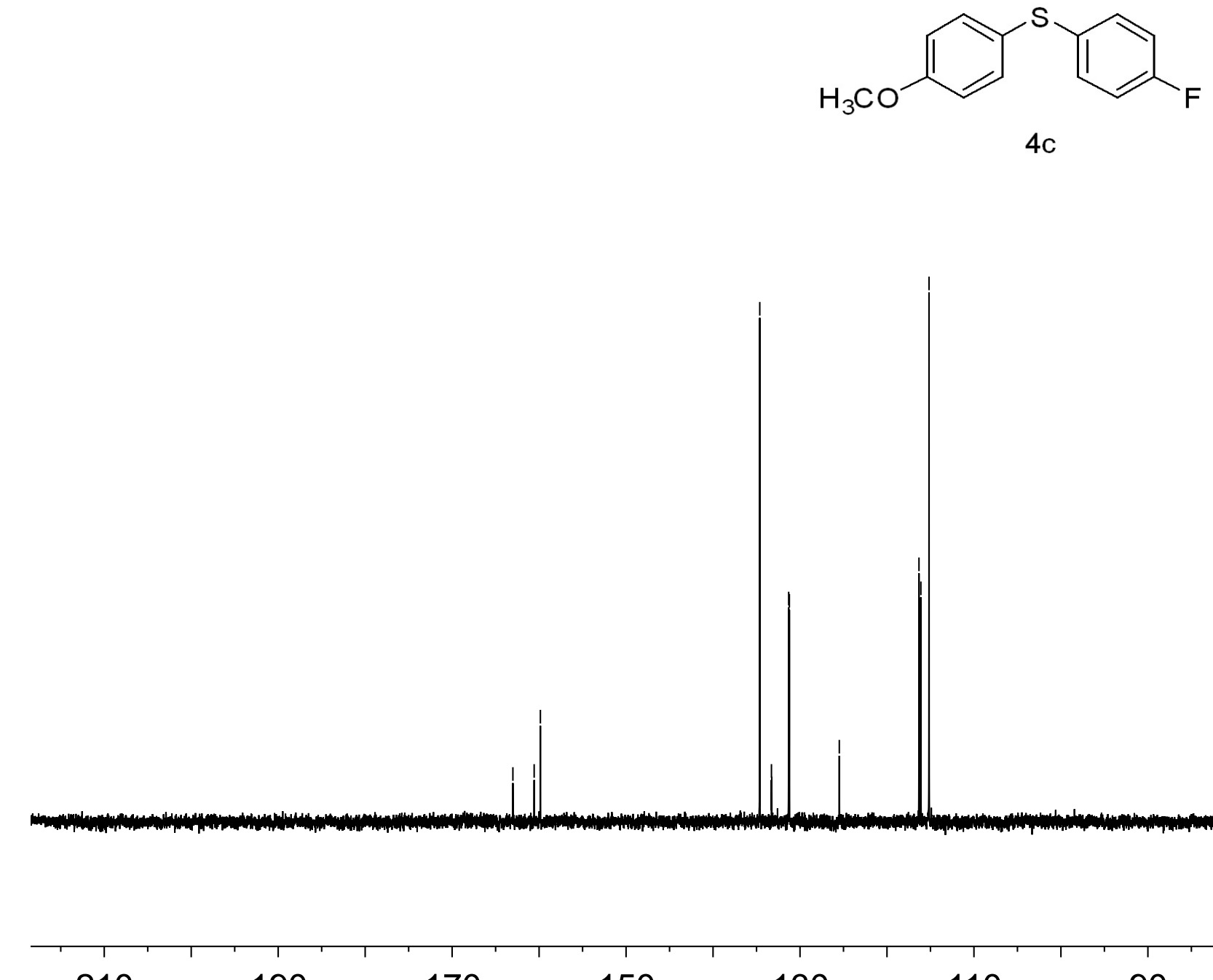


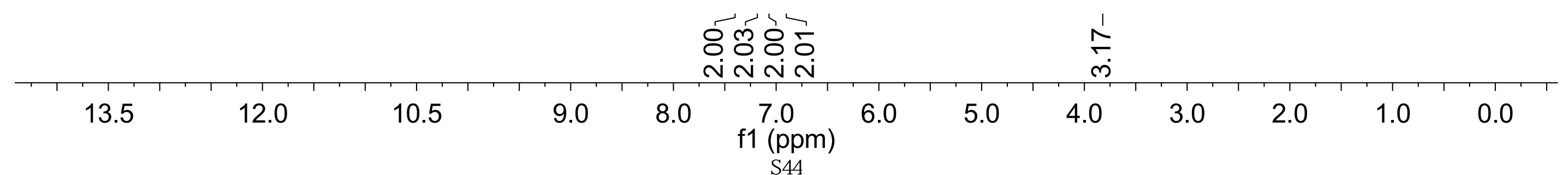




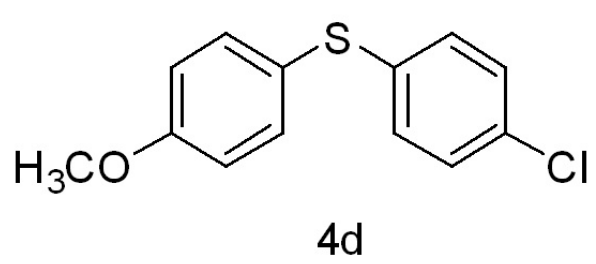

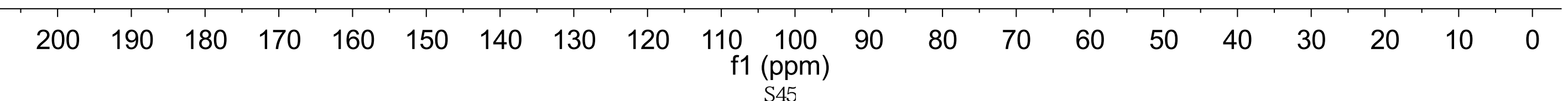



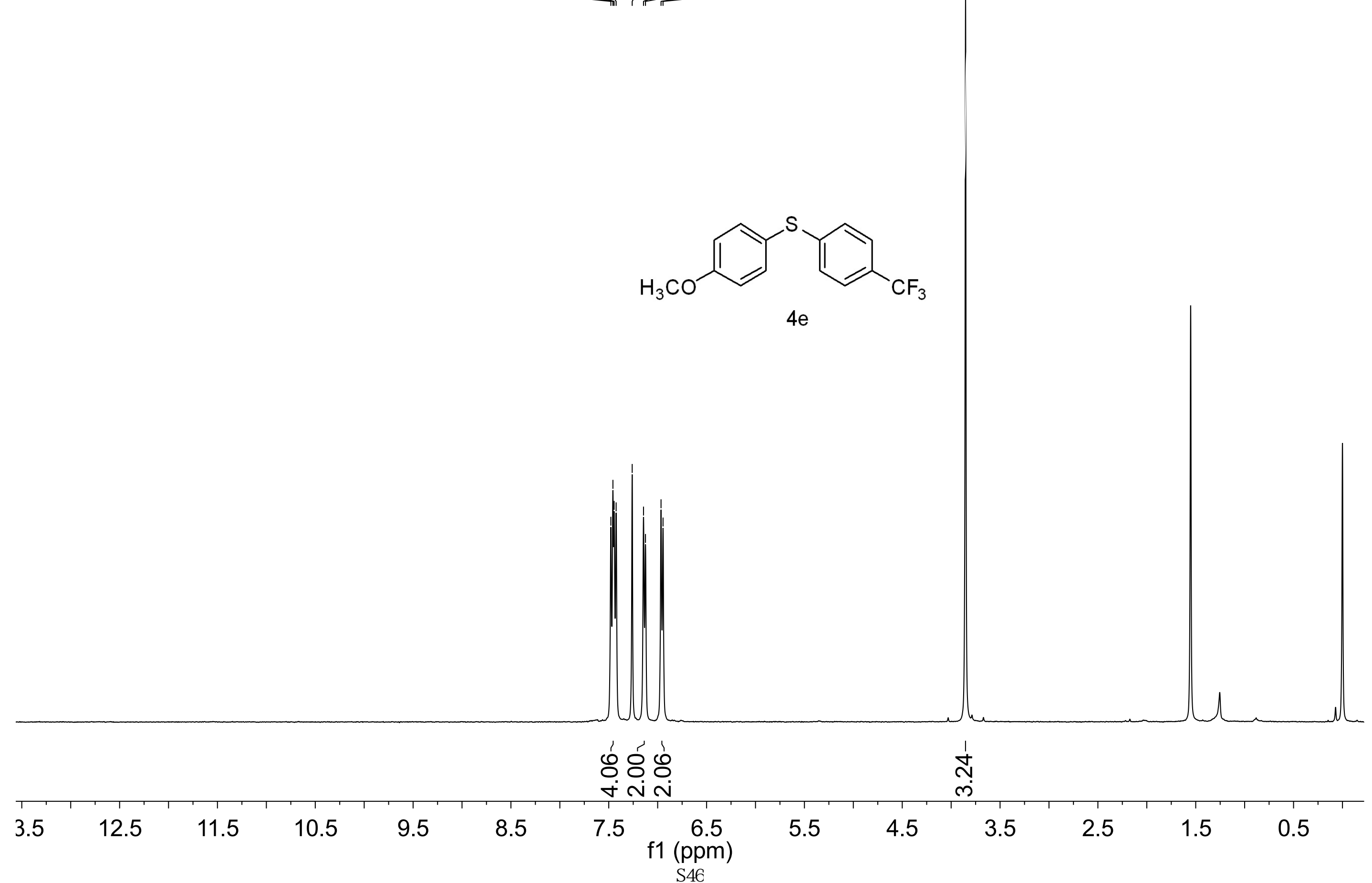


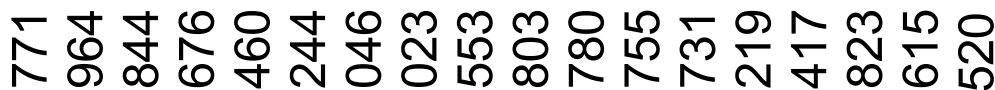

ठ்่

는

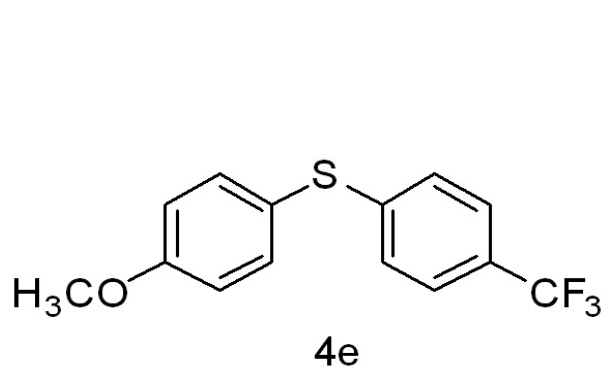

$4 \mathrm{e}$

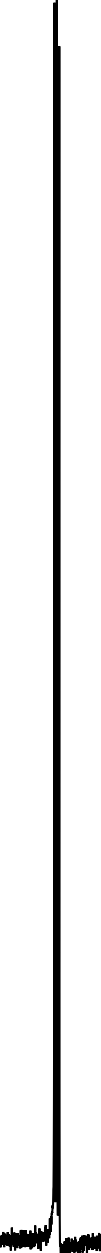

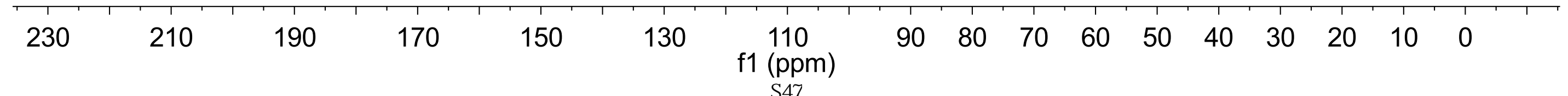



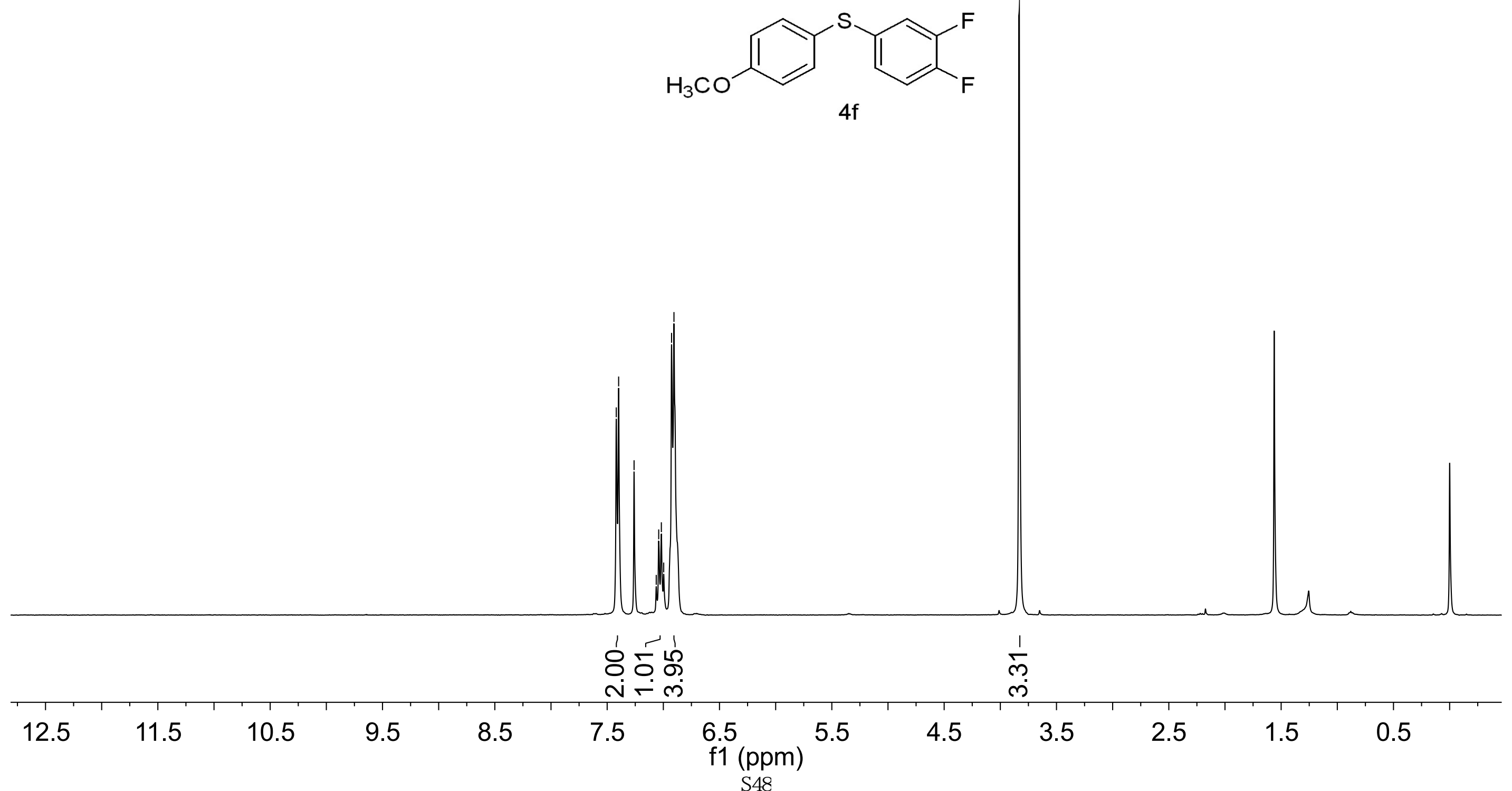


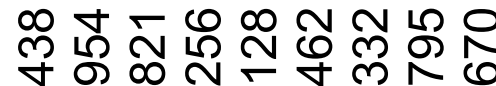

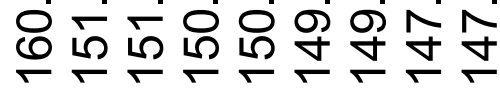

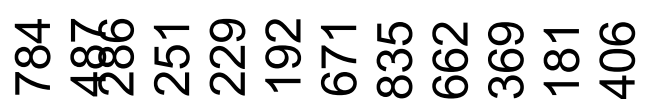

m
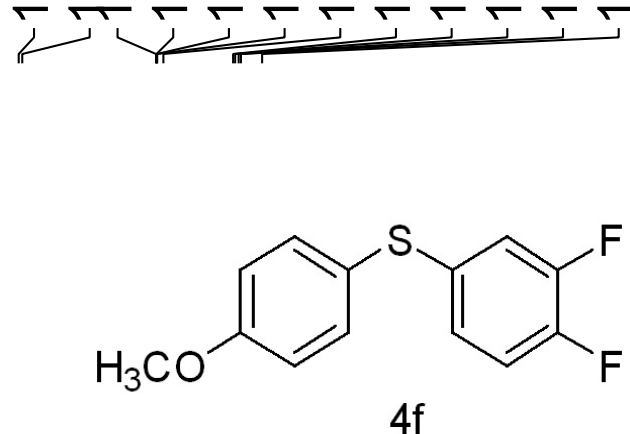

$4 f$

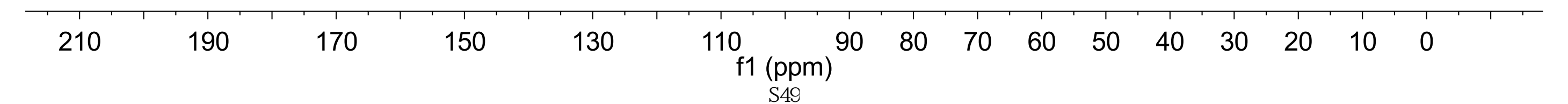



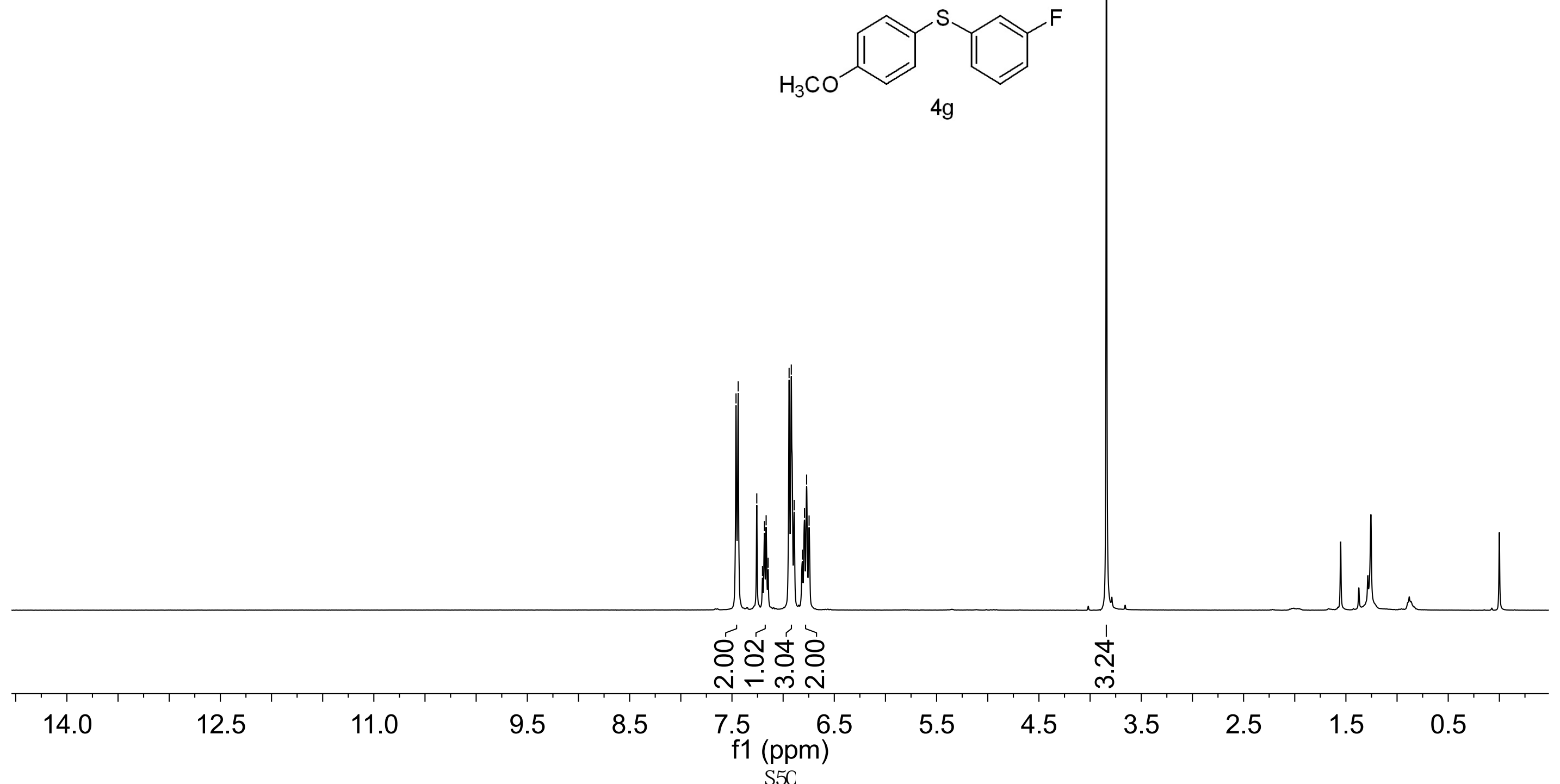

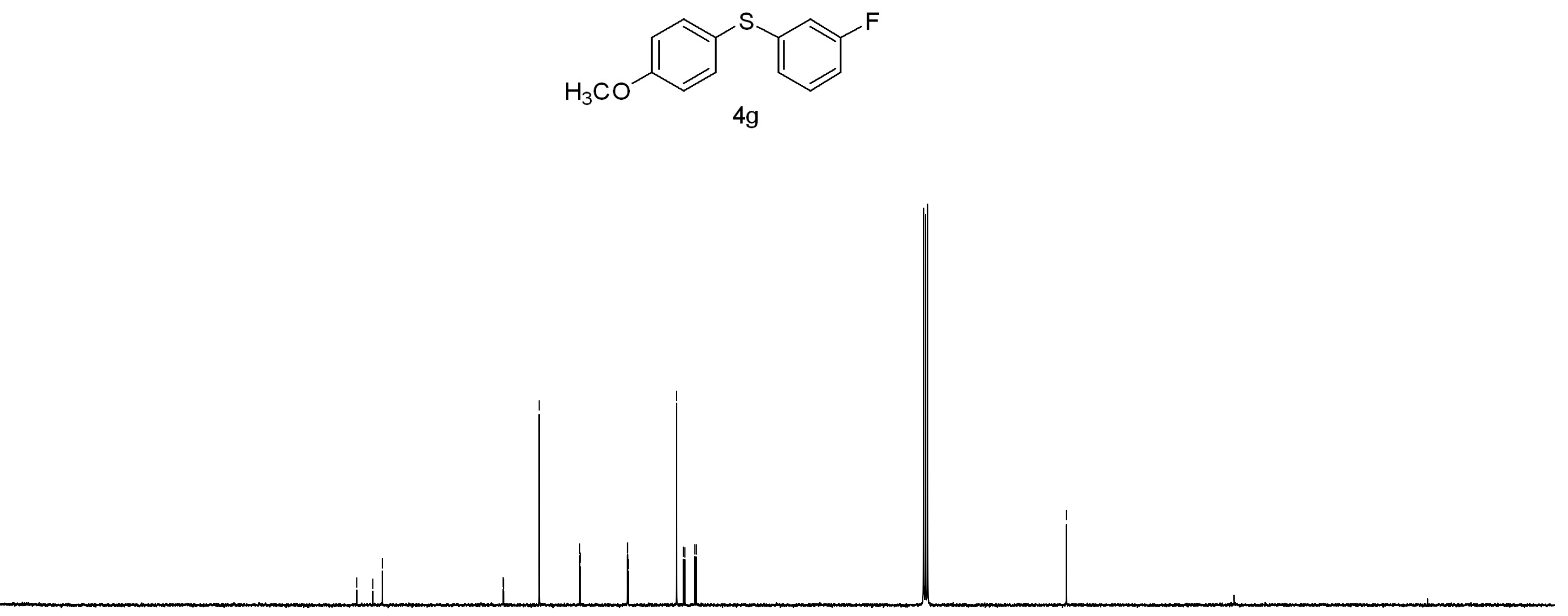

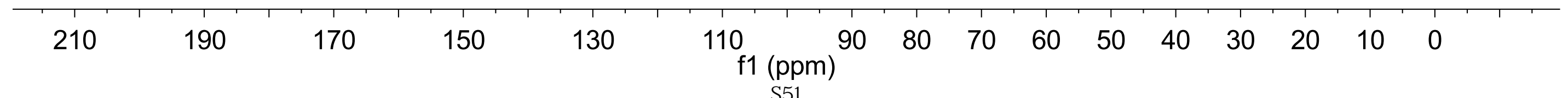




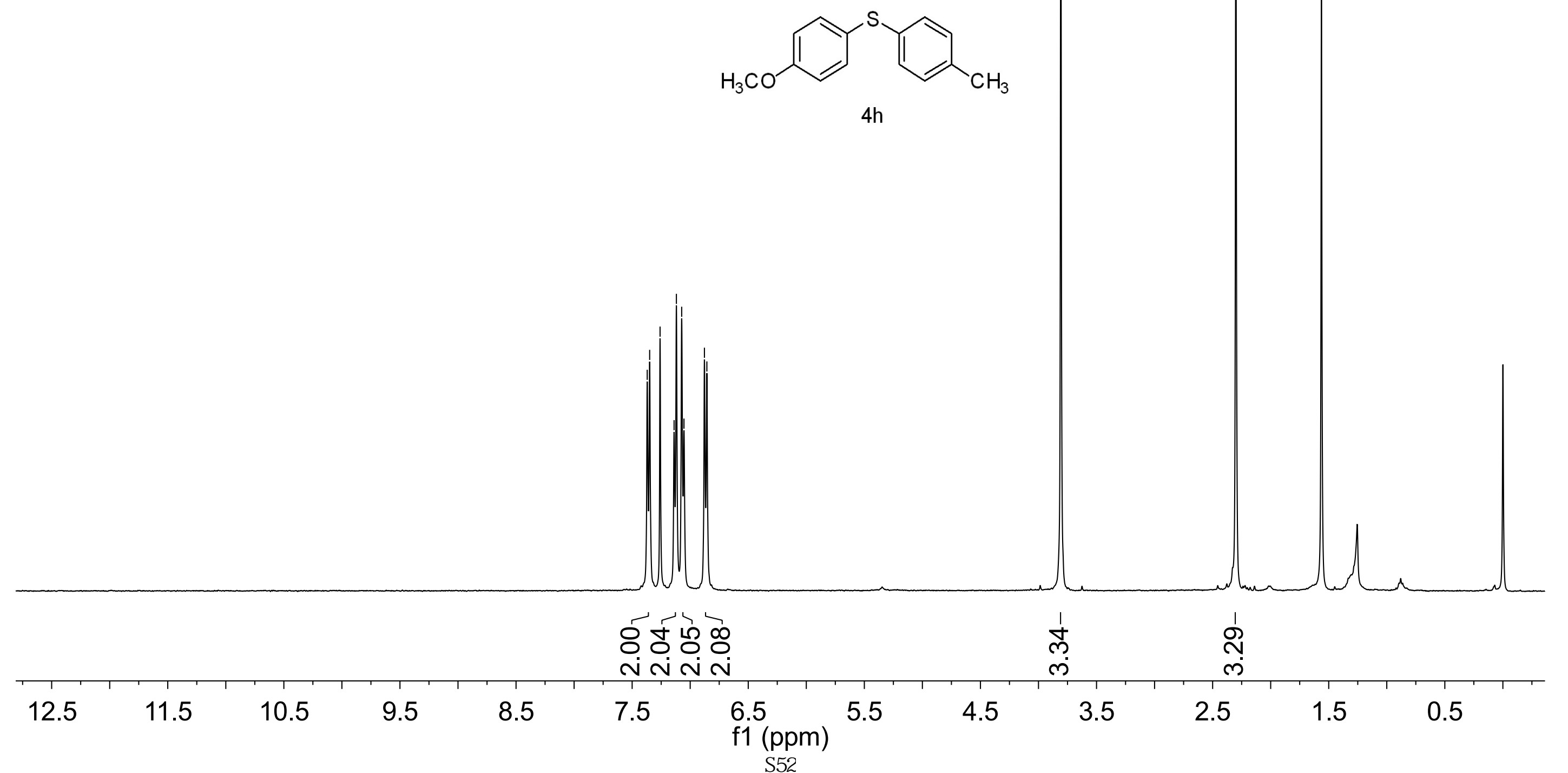




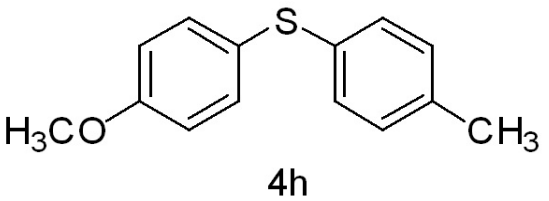

(2)
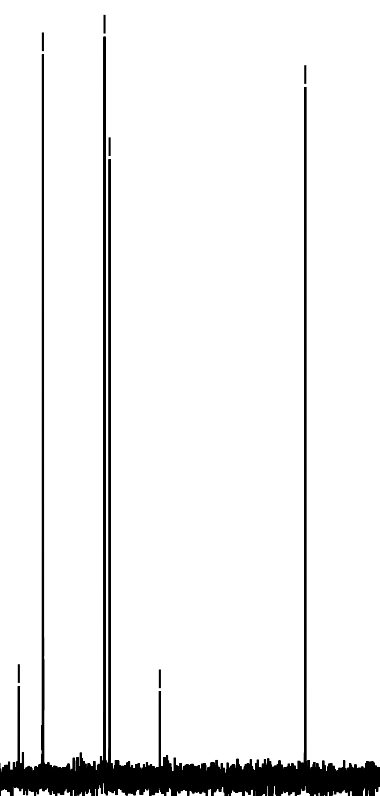

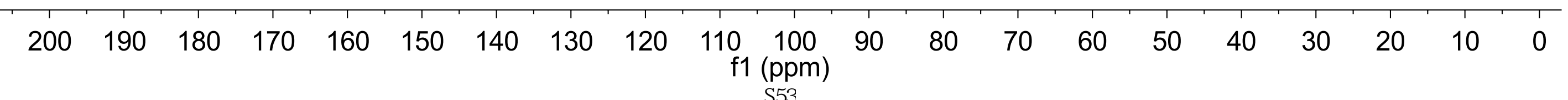



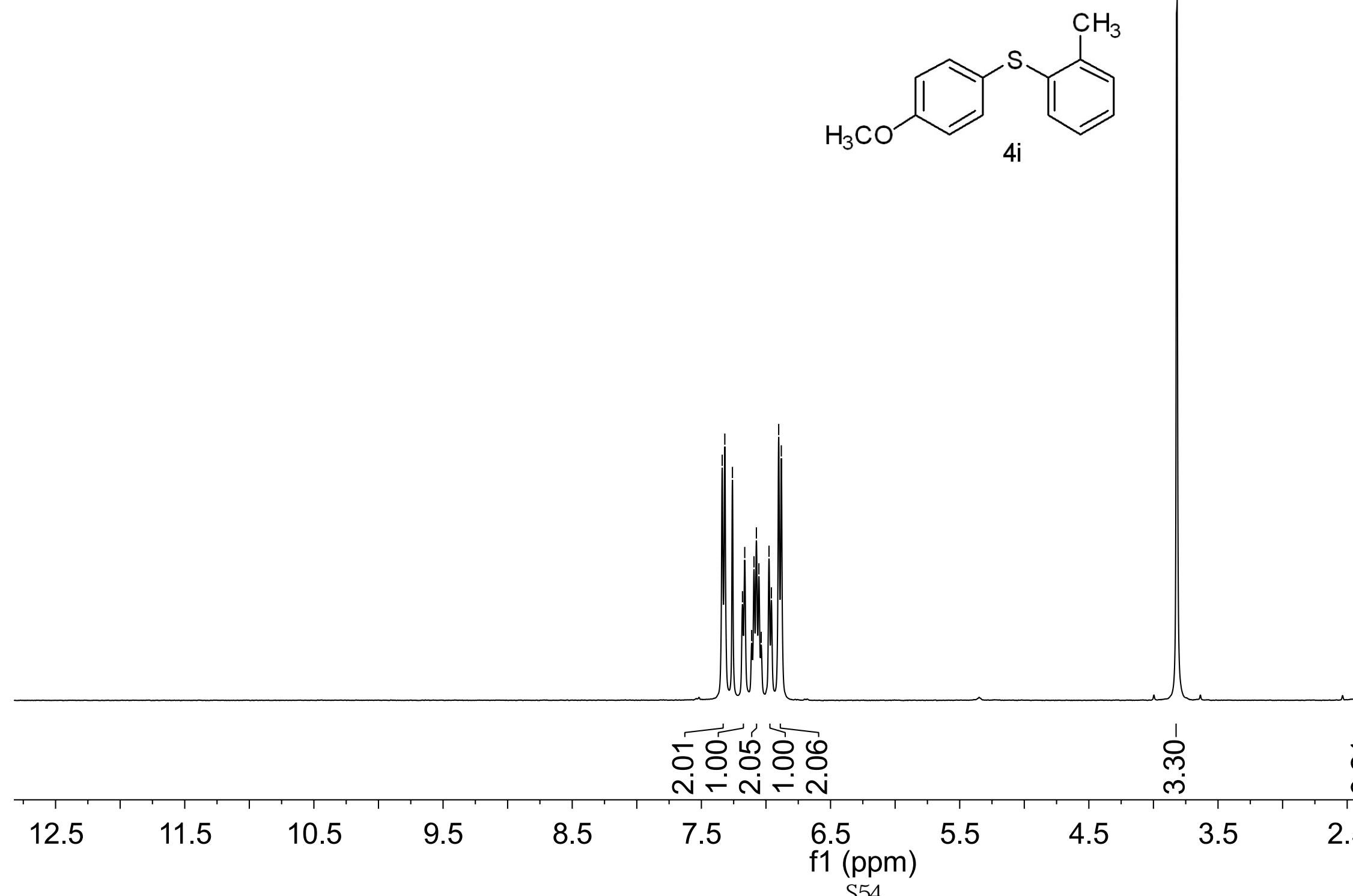

$\frac{1}{\sqrt{2}}$

ming

2.5 

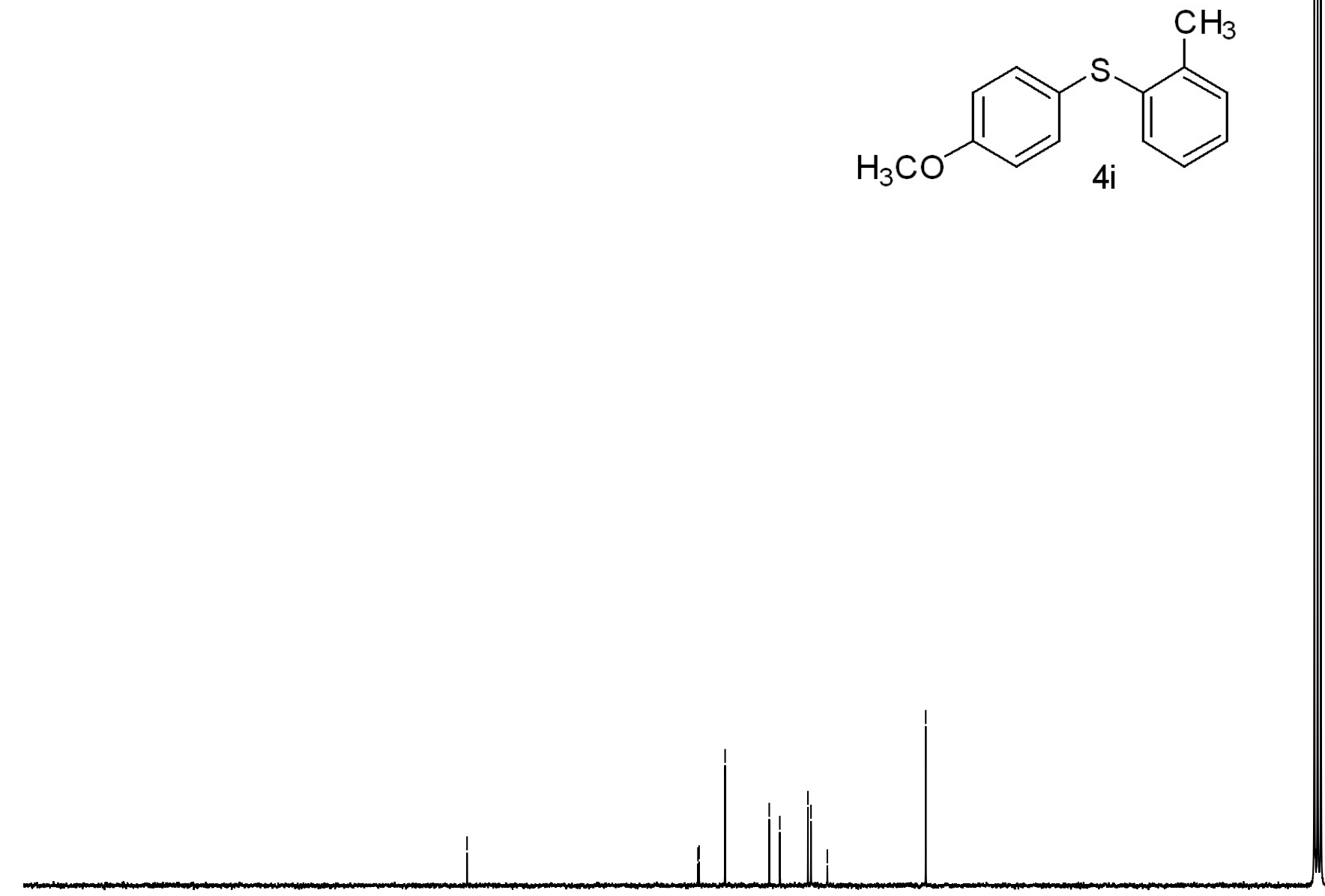

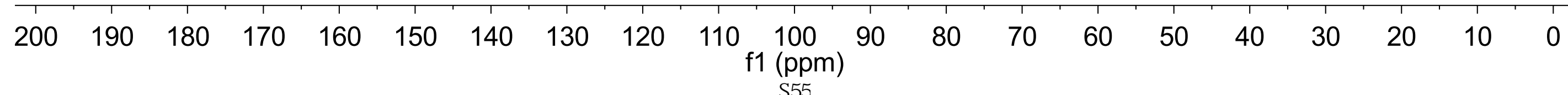




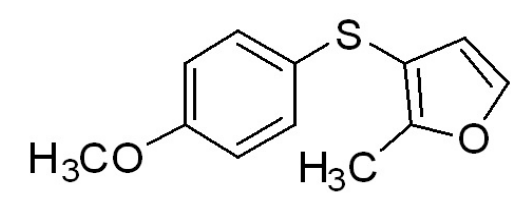

$4 \mathrm{j}$

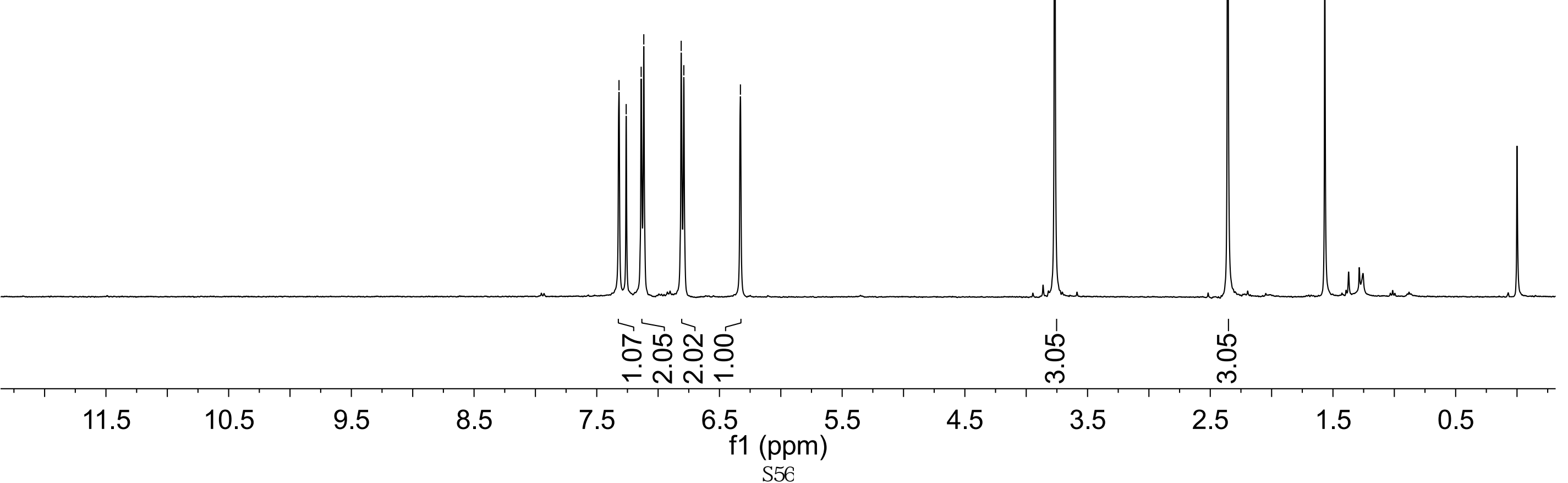




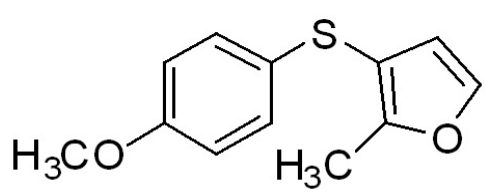

$4 \mathrm{j}$

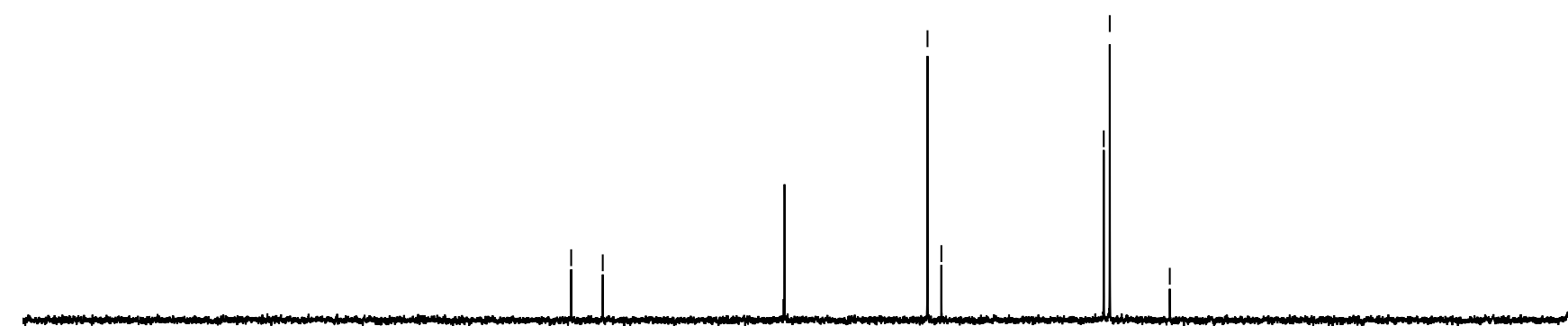

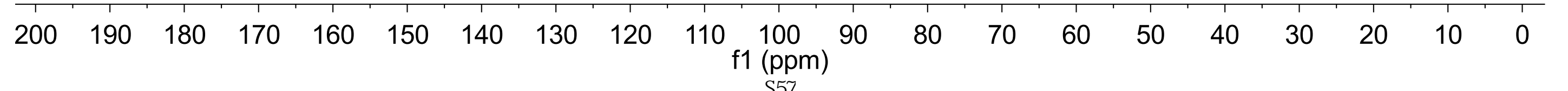




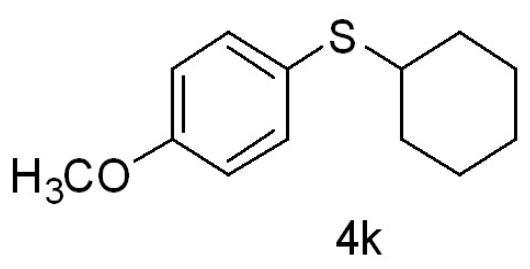

\begin{tabular}{|c|c|c|c|c|c|c|c|c|c|c|c|c|c|c|c|c|c|c|c|c|c|}
\hline & & & & & & & & & & & & & & & & $\stackrel{1}{8}$ & 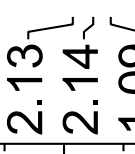 & ڤ్రి & & & \\
\hline 21 & 20 & 19 & 18 & 17 & 16 & 15 & 14 & 13 & 12 & 11 & $\begin{array}{c}10 \\
\mathrm{f} 1(\mathrm{ppm}\end{array}$ & 7 & 6 & 5 & 4 & 3 & 2 & 1 & 0 & -1 & -2 \\
\hline
\end{tabular}


<smiles>COc1ccc(SC2CCCCC2)cc1</smiles>

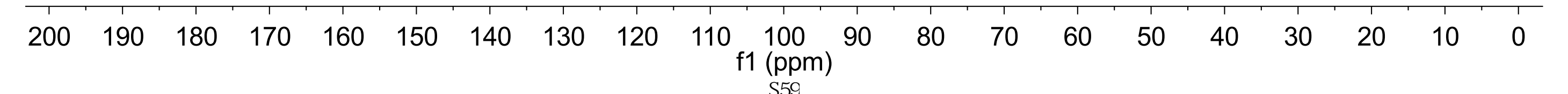




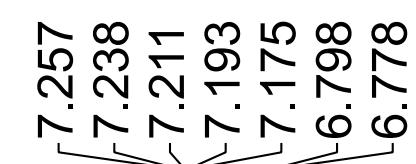

\section{索品}



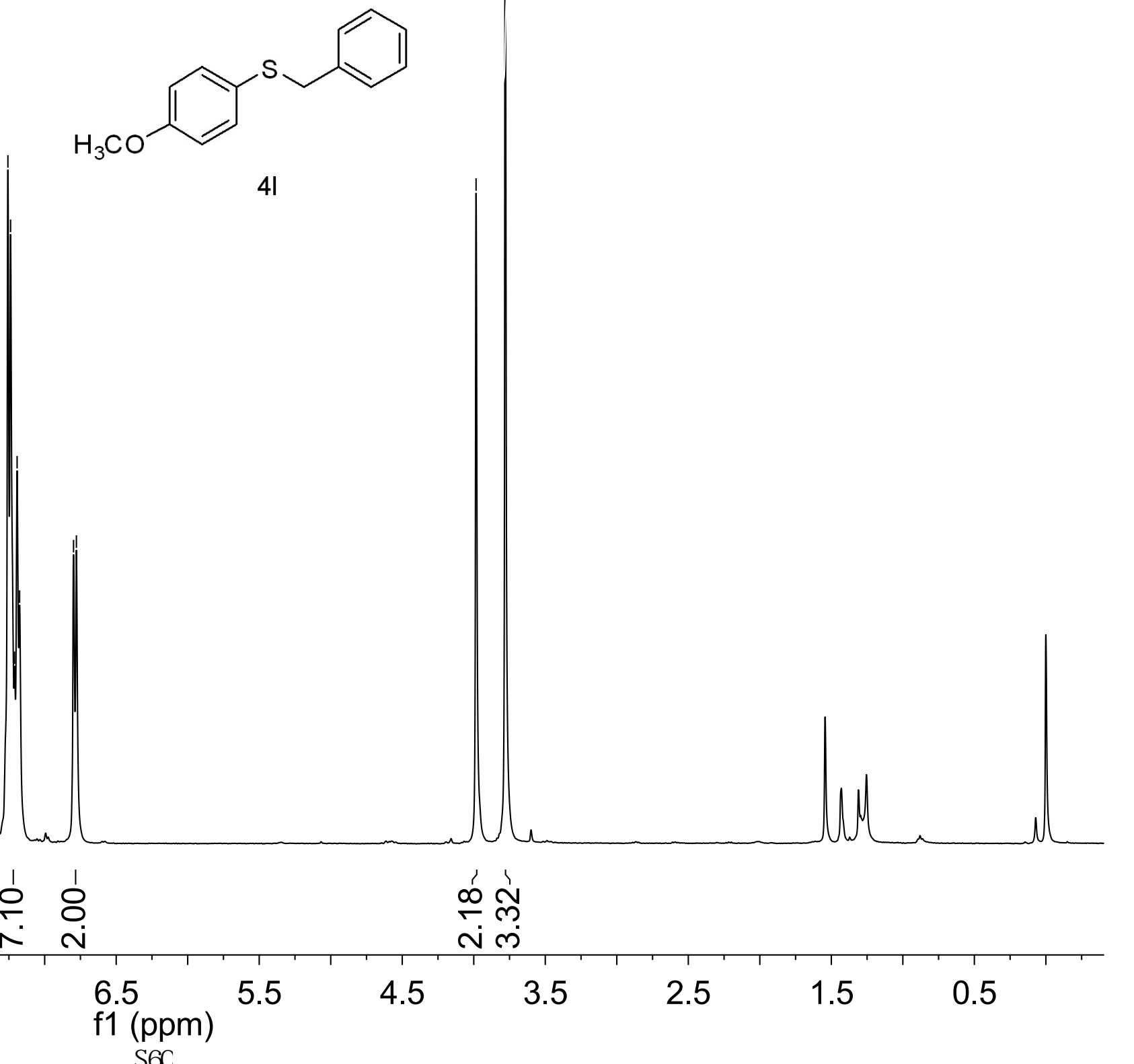




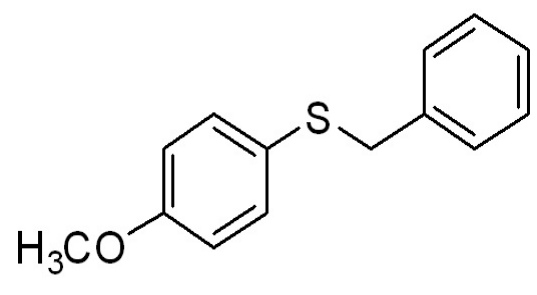

\begin{tabular}{|c|c|c|c|c|c|c|c|c|c|c|c|c|c|c|c|}
\hline 210 & 190 & 170 & 150 & 130 & $\begin{array}{c}110 \\
\mathrm{f} 1(\mathrm{ppm}) \\
\text { s61 }\end{array}$ & 90 & 80 & 70 & 60 & 50 & 40 & 30 & 20 & 10 & 0 \\
\hline
\end{tabular}




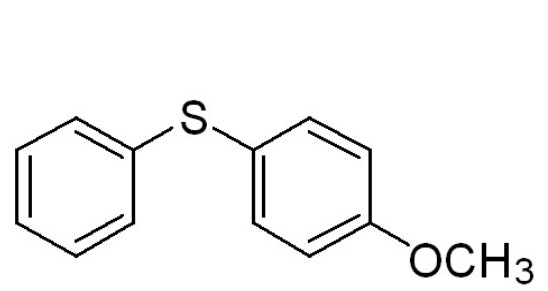

$5 b$

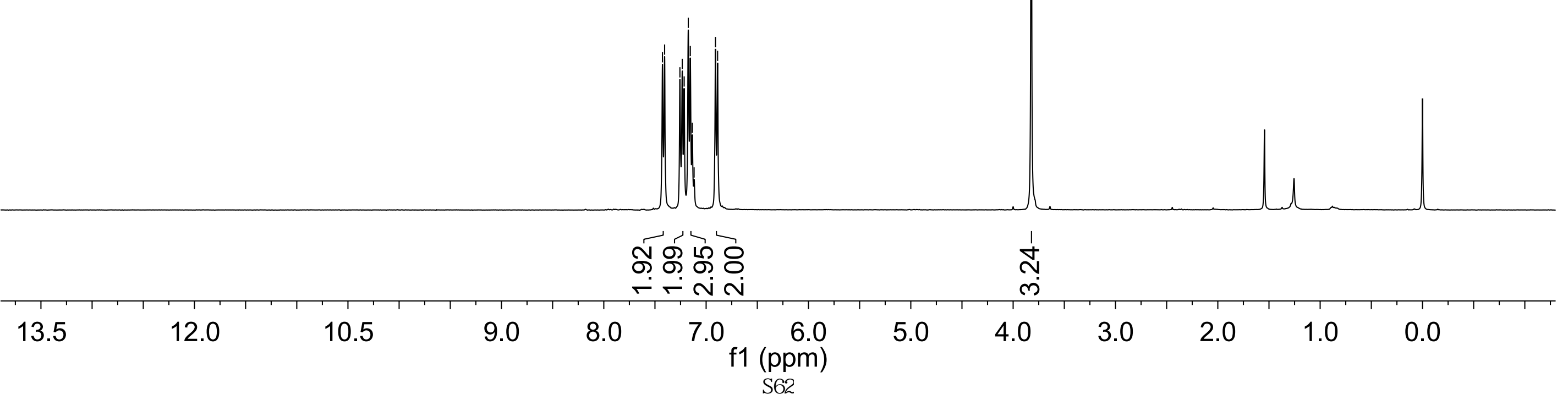




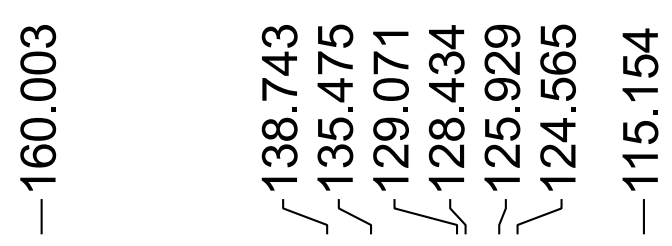

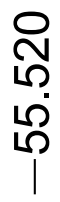

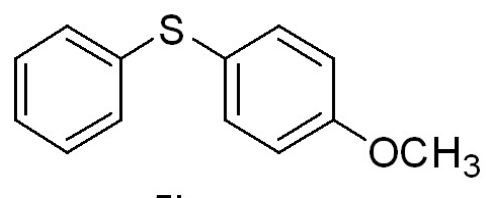

$5 b$

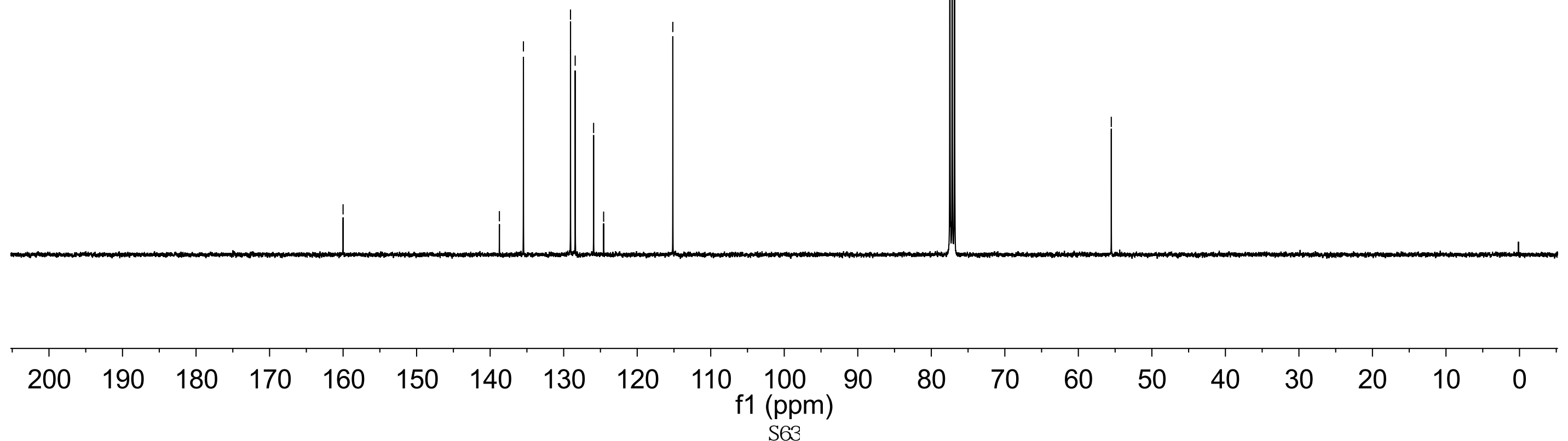



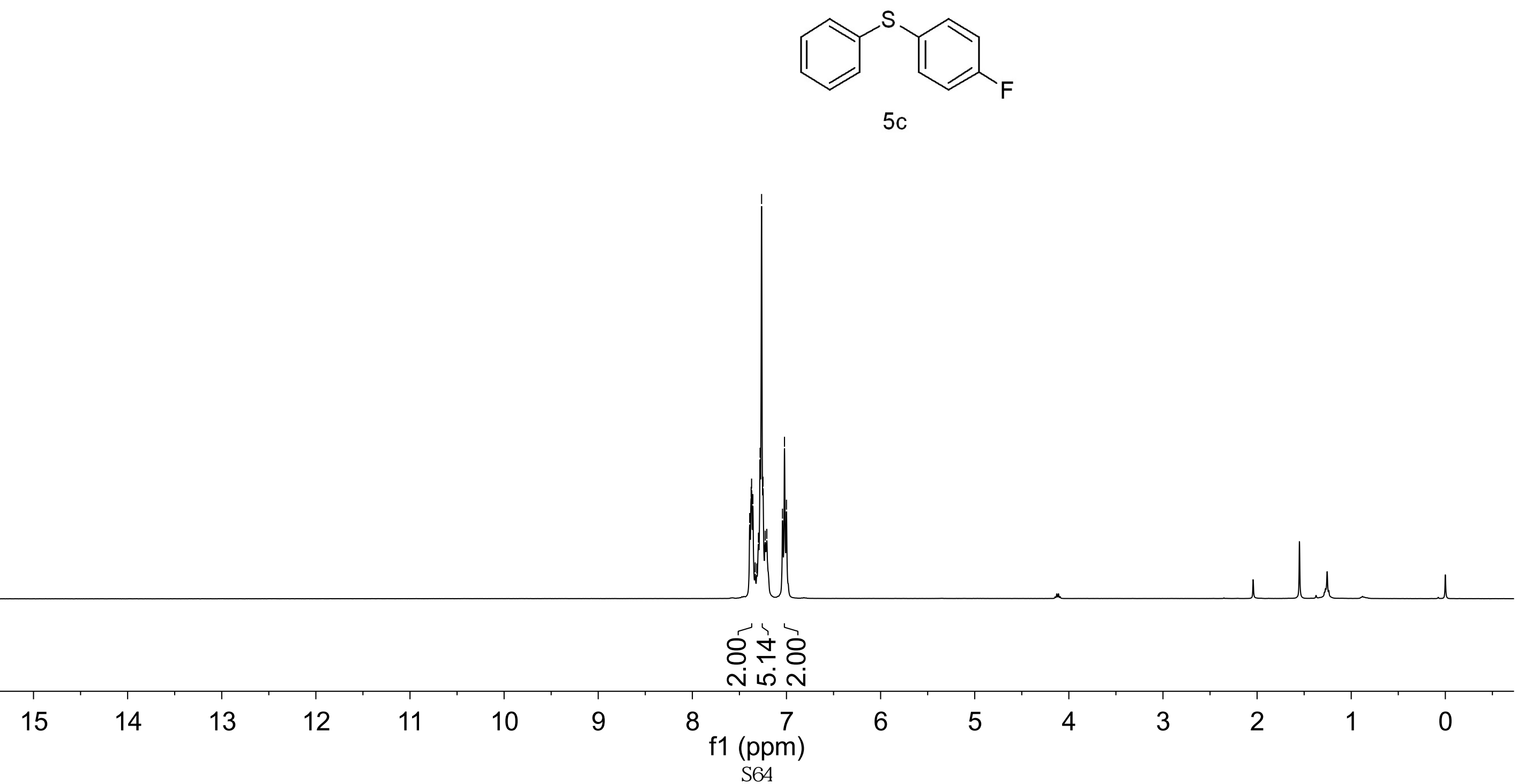


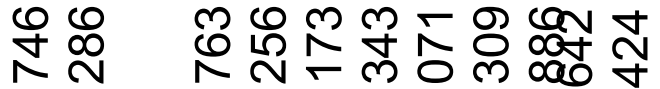

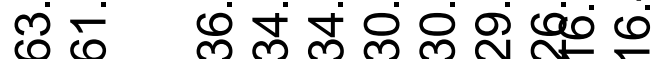 \\ 1}
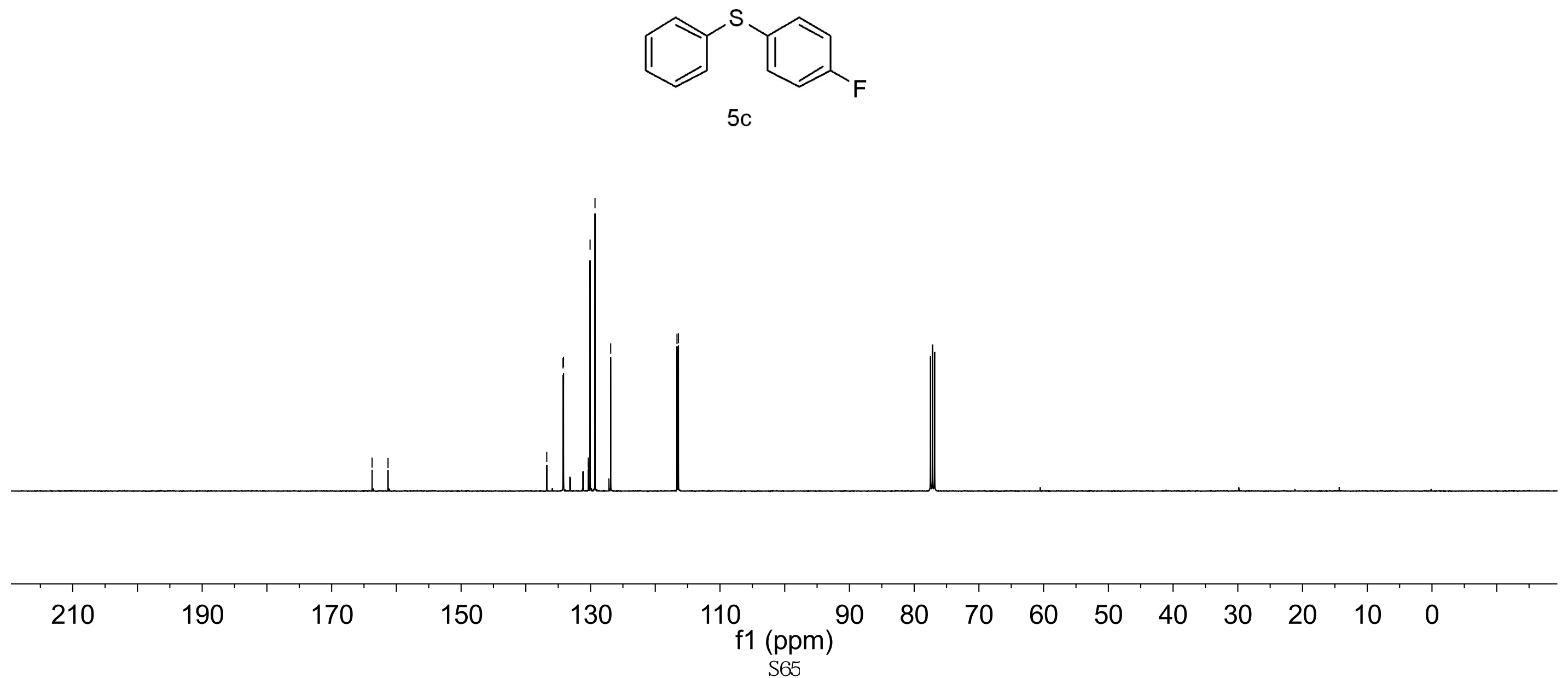


\section{กิ๊}

NNNNN

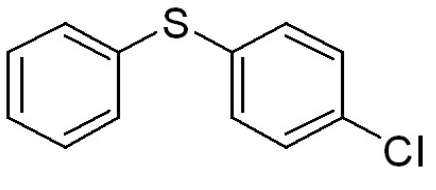

$5 d$

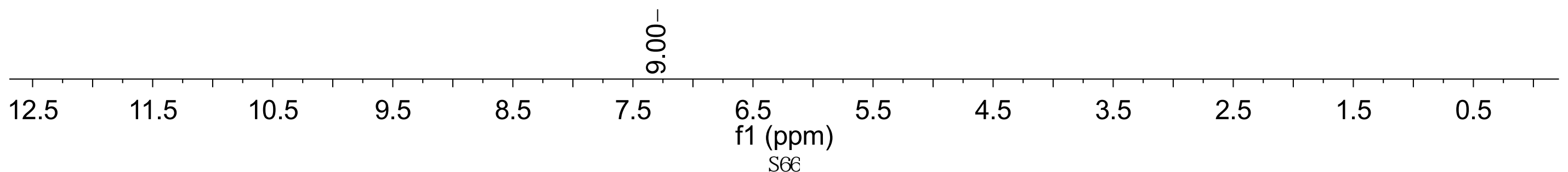




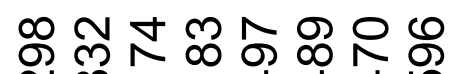

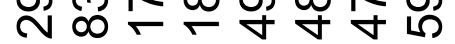

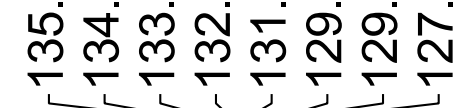

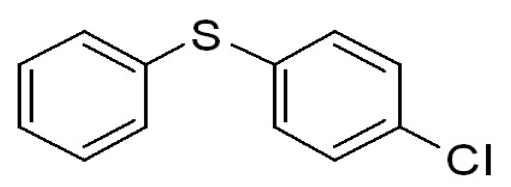

$5 d$

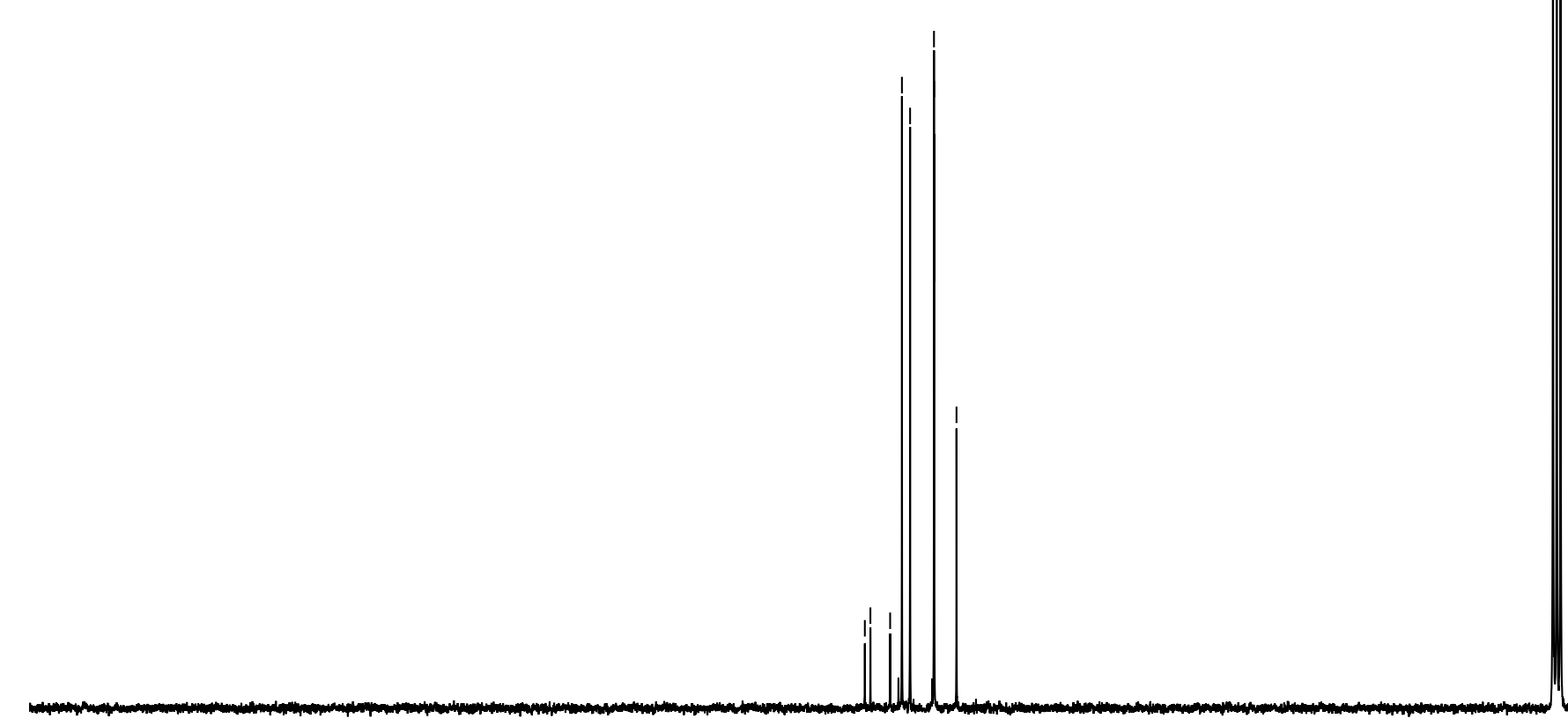

$\begin{array}{llllllllllllllllllll}200 & 190 & 180 & 170 & 160 & 150 & 140 & 130 & 120 & \begin{array}{c}110 \\ \mathrm{f} 1\left(\begin{array}{c}(\mathrm{ppm}) \\ \mathrm{sp7}\end{array}\right.\end{array} & 90 & 80 & 70 & 60 & 50 & 40 & 30 & 20 & 10 & 0\end{array}$




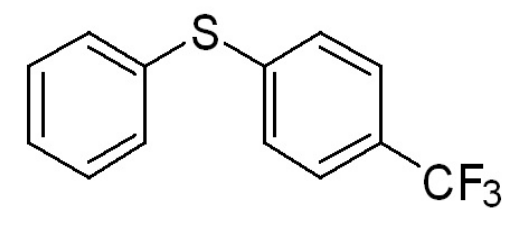

$5 e$

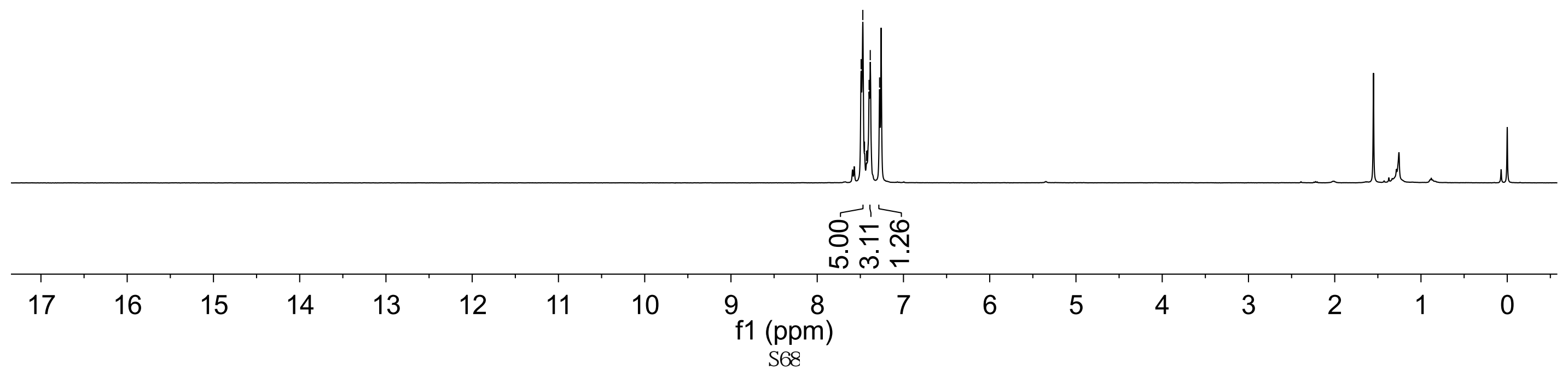




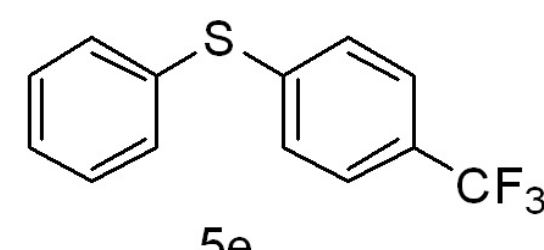

$5 e$

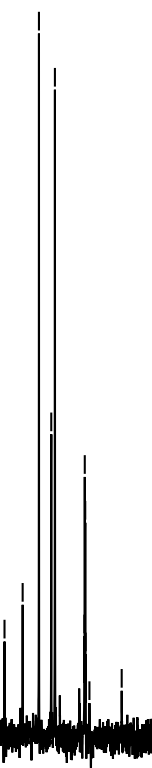

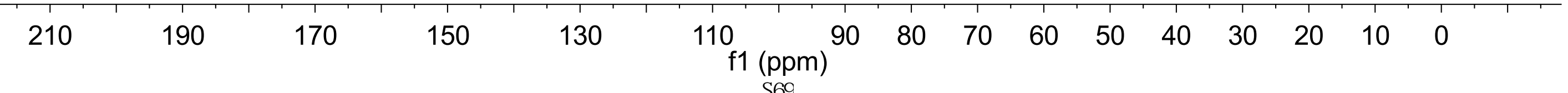




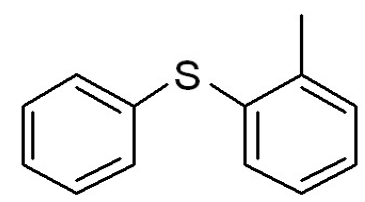

$5 i$

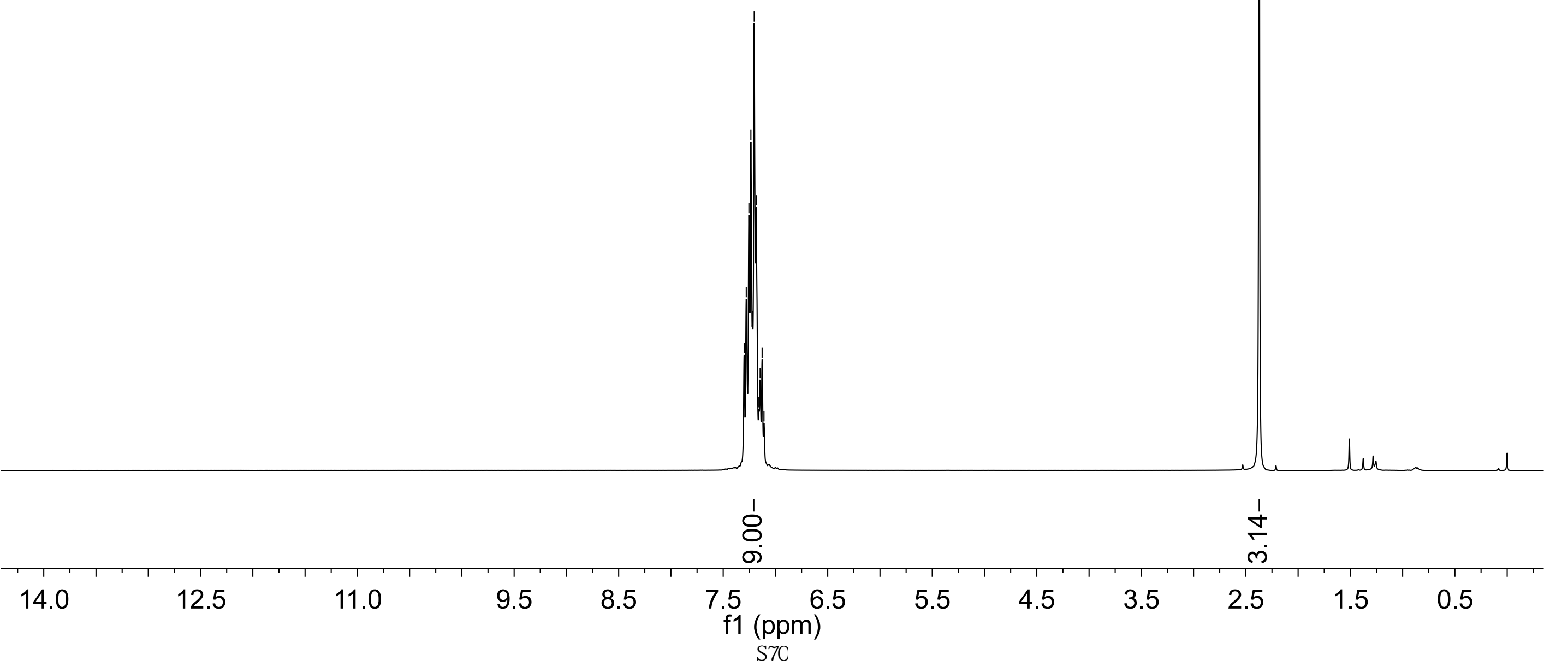




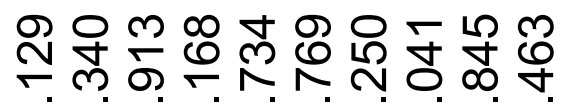

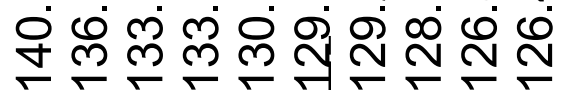

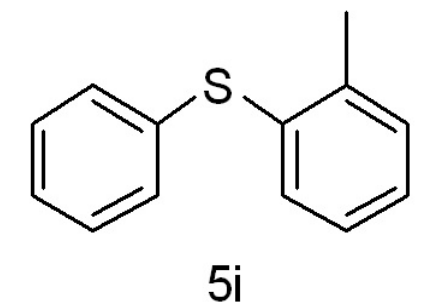

\begin{tabular}{|c|c|c|c|c|c|c|c|c|c|c|c|c|c|c|c|}
\hline 210 & 190 & 170 & 150 & 130 & 110 & & 80 & 70 & 60 & 50 & 40 & 30 & 20 & 10 & 0 \\
\hline
\end{tabular}




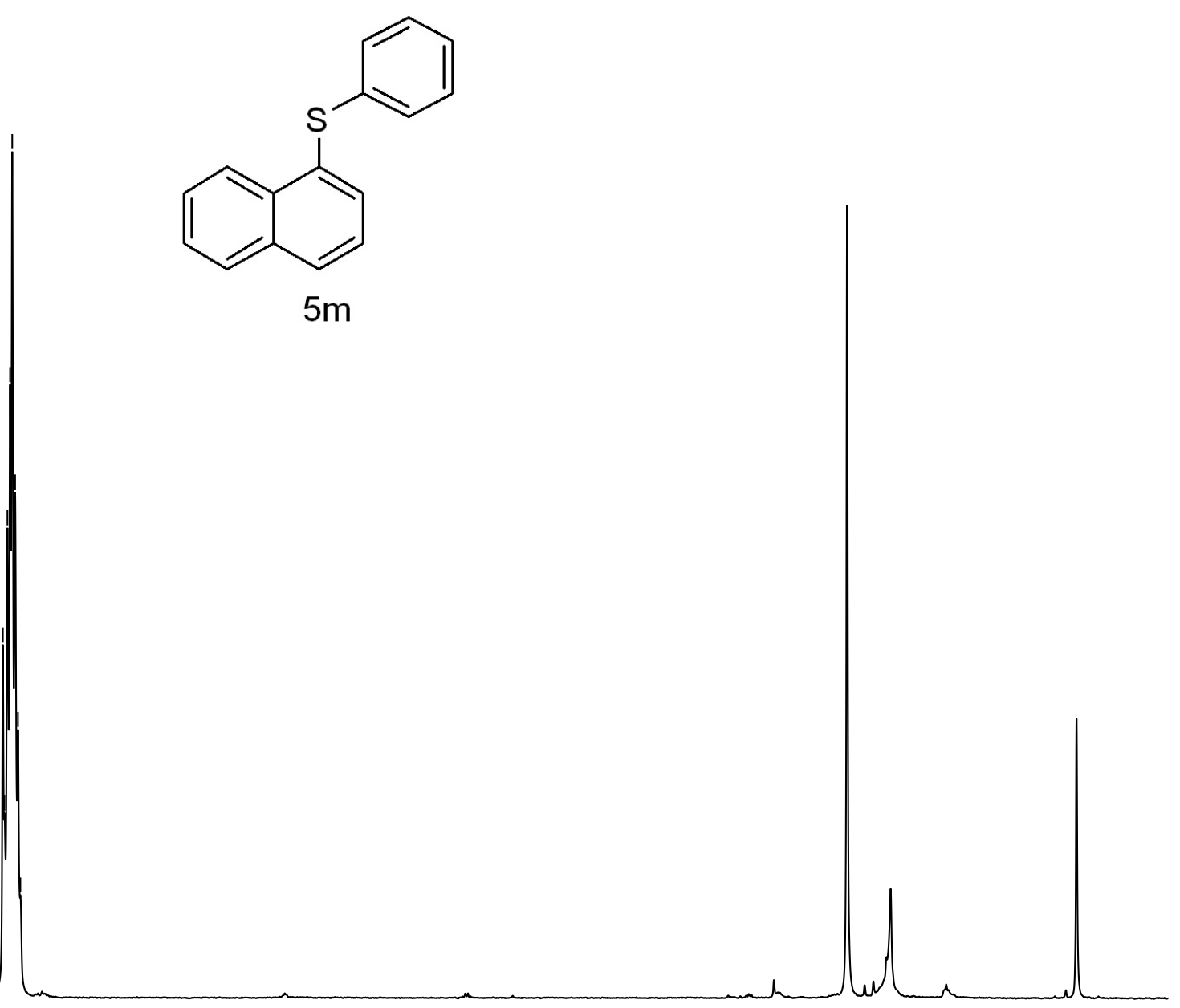

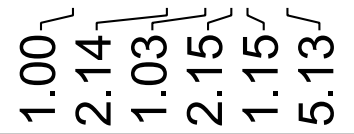




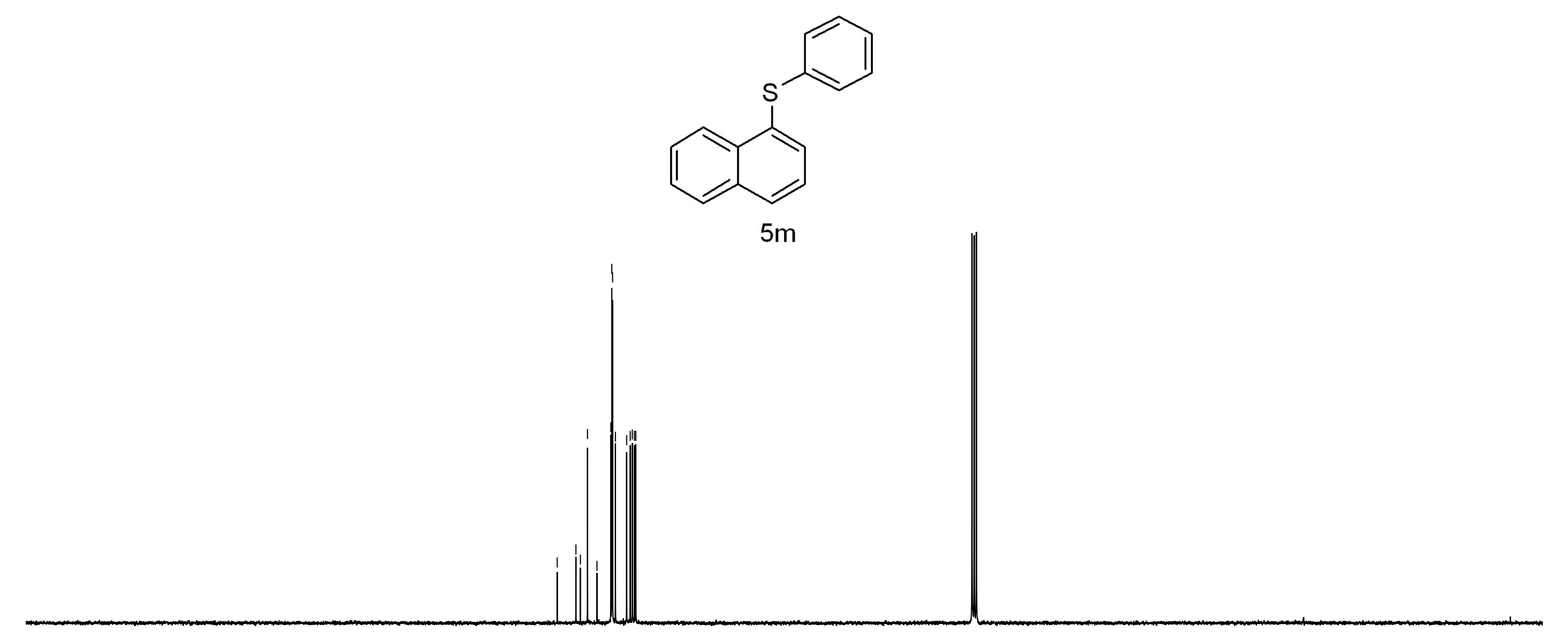

\begin{tabular}{llllllllllllllll}
\hline 210 & 190 & 170 & 150 & 130 & 110 & 90 & 80 & 70 & 60 & 50 & 40 & 30 & 20 & 10 & 0
\end{tabular}




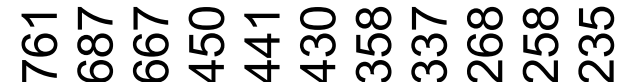

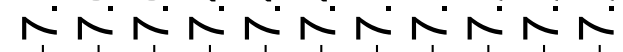

\begin{abstract}
(1)
\end{abstract}

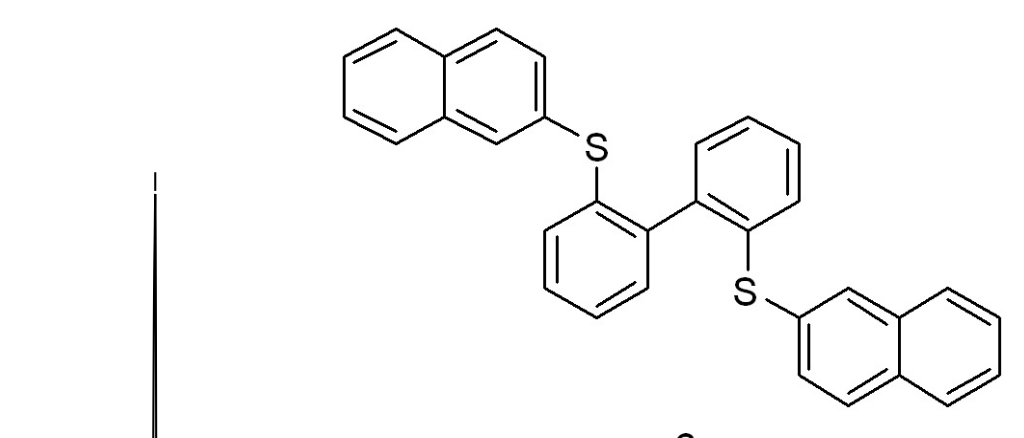

$6 a$

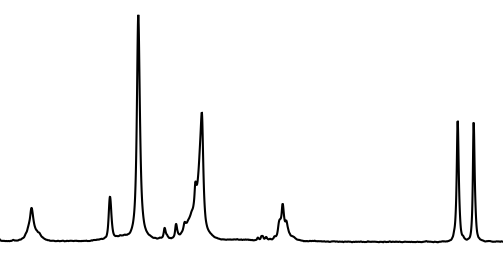

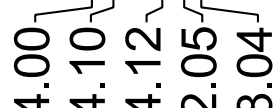

\begin{tabular}{|c|c|c|c|c|c|c|c|c|c|c|c|c|}
\hline 12.0 & 11.0 & 10.0 & 9.0 & 8.0 & 7.0 & $\begin{array}{c}6.0 \\
\mathrm{f} 1 \text { (ppm) } \\
\text { S74 }\end{array}$ & 5.0 & 4.0 & 3.0 & 2.0 & 1.0 & 0.0 \\
\hline
\end{tabular}




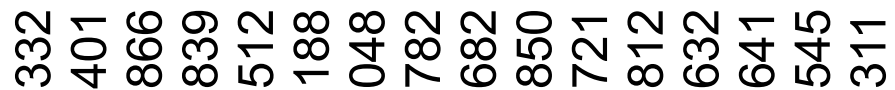

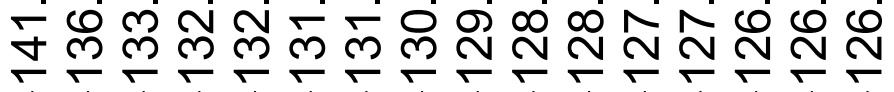

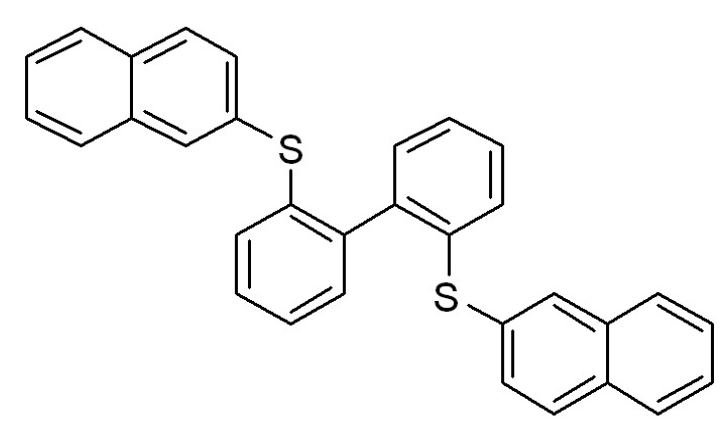

$6 a$

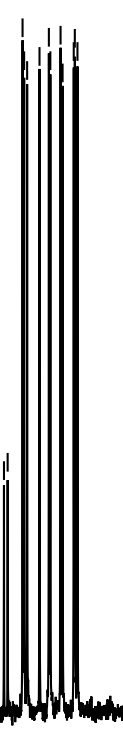

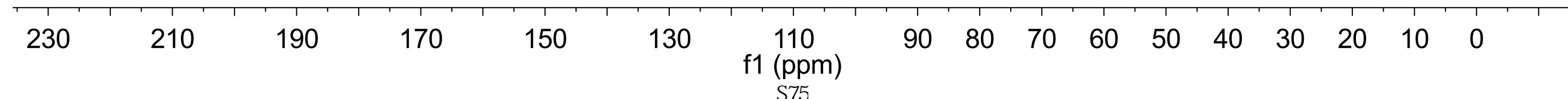




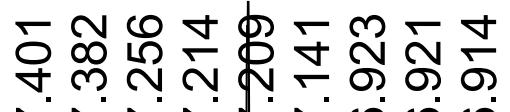

N $N$ N

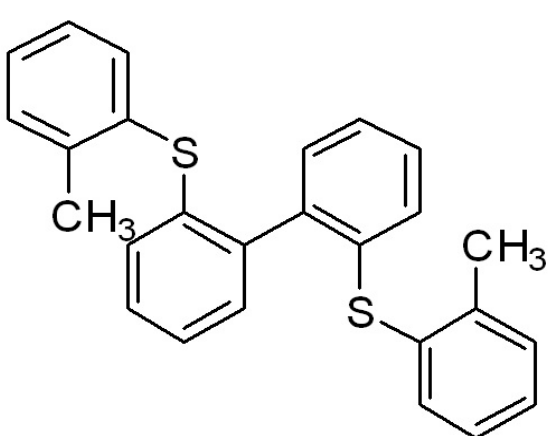

$6 i$

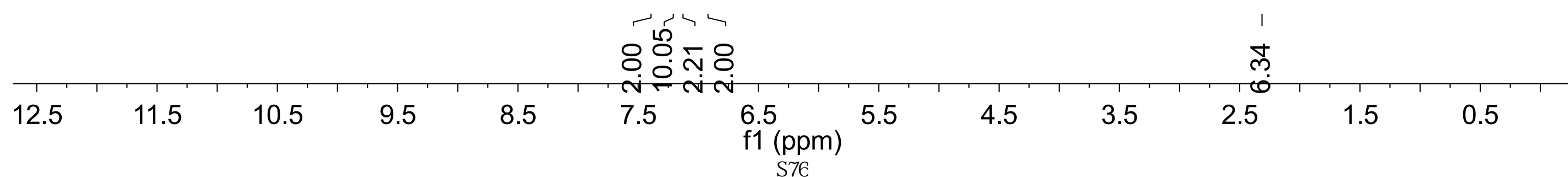



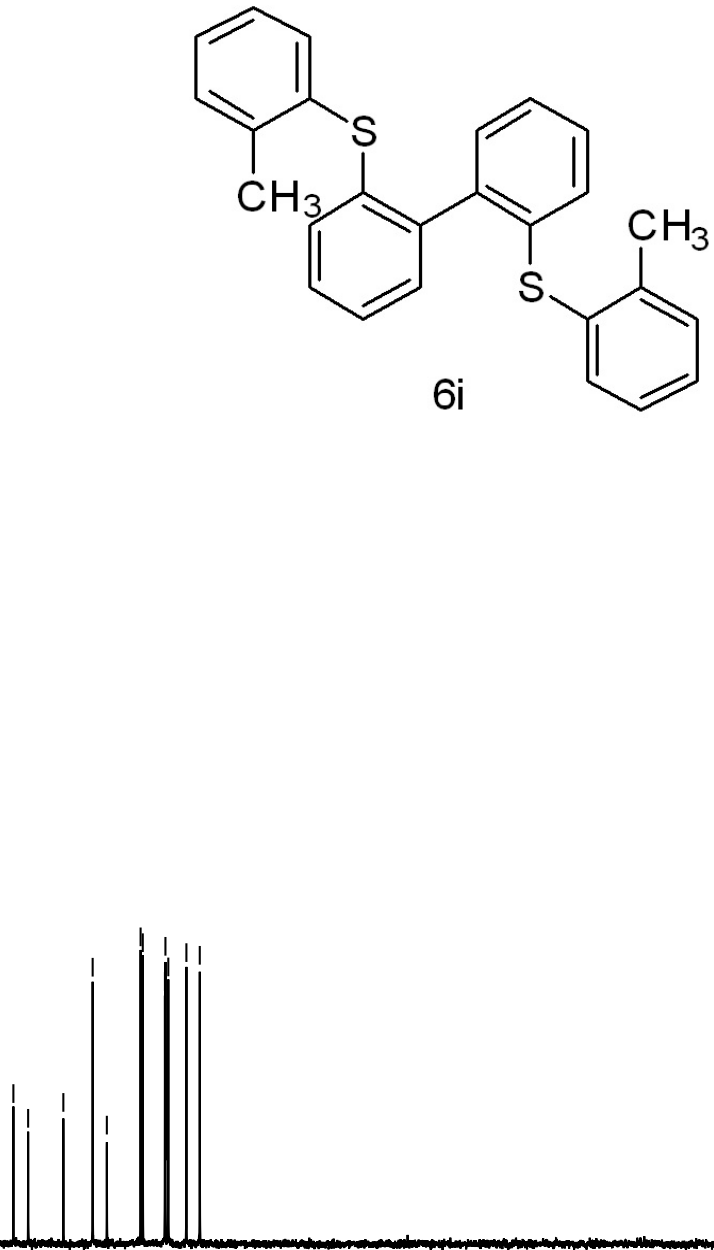

\begin{tabular}{|c|c|c|c|c|c|c|c|c|c|c|c|c|c|c|}
\hline 210 & 190 & 170 & 150 & 130 & $\begin{array}{l}110 \\
\mathrm{f} 1\end{array}$ & & 80 & 70 & 60 & 50 & 40 & 30 & 20 & 10 \\
\hline
\end{tabular}




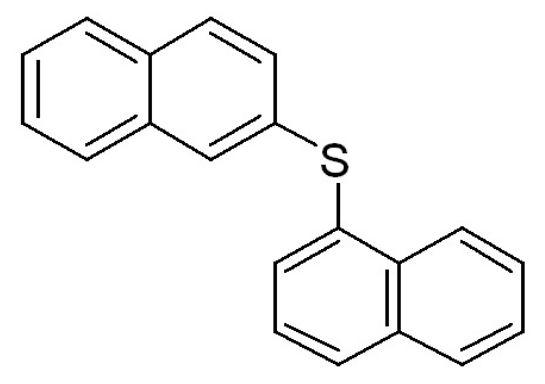

$7 a$

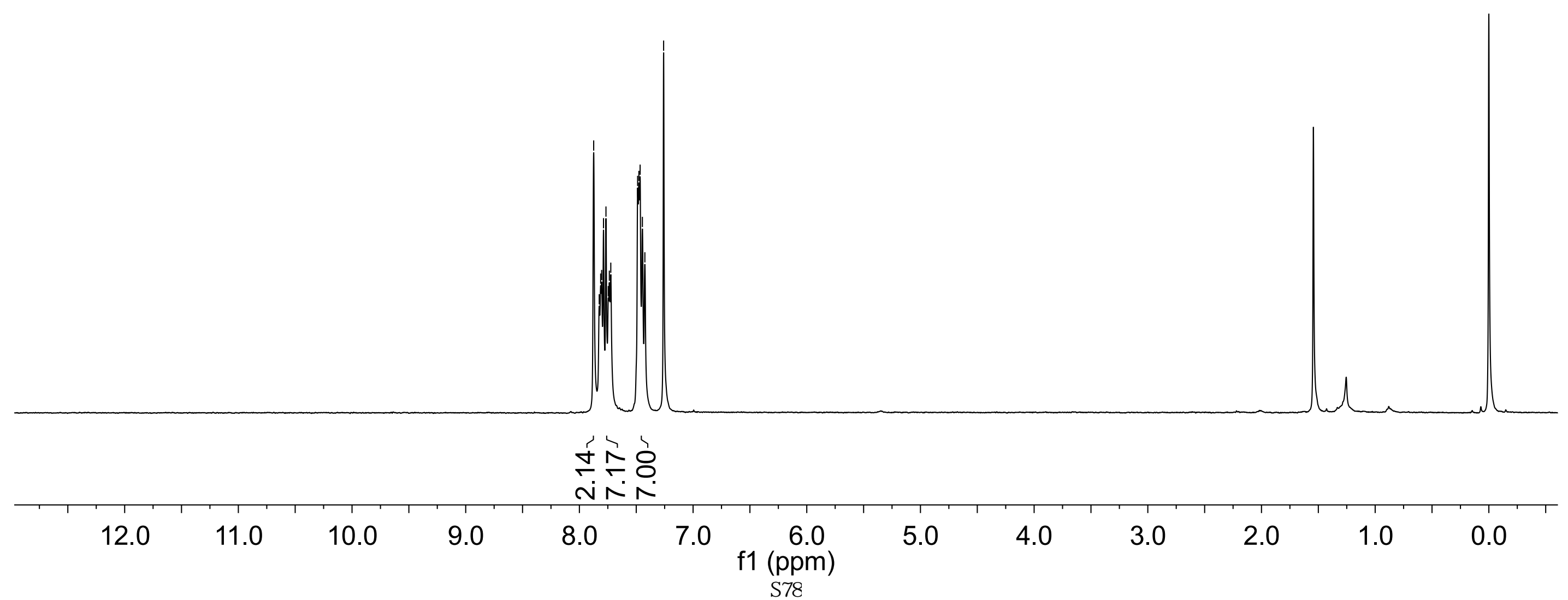


준ํำ ब तै m

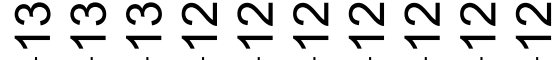

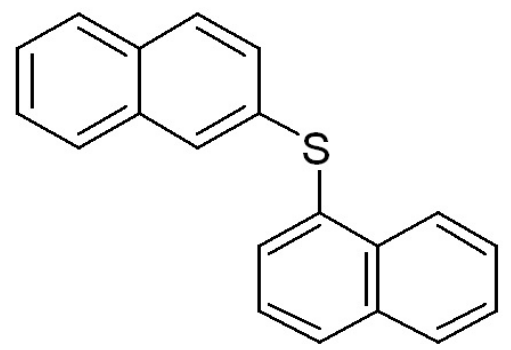

$7 a$

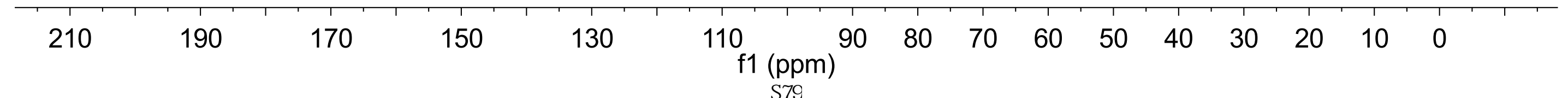




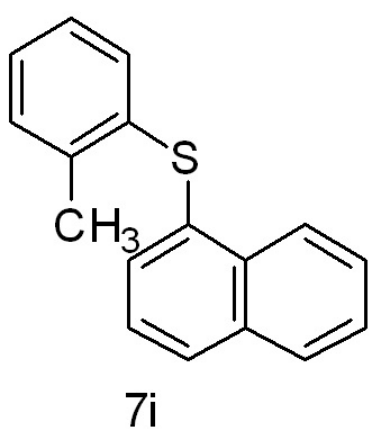

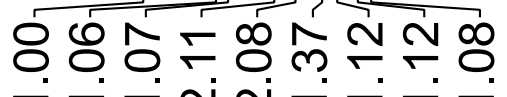

$r+$ r n 


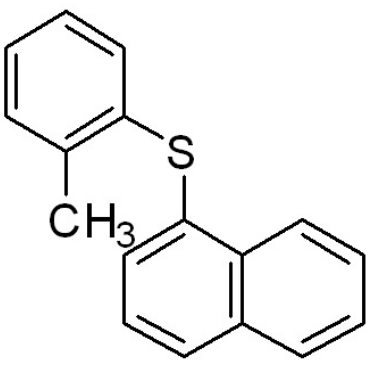

$7 i$

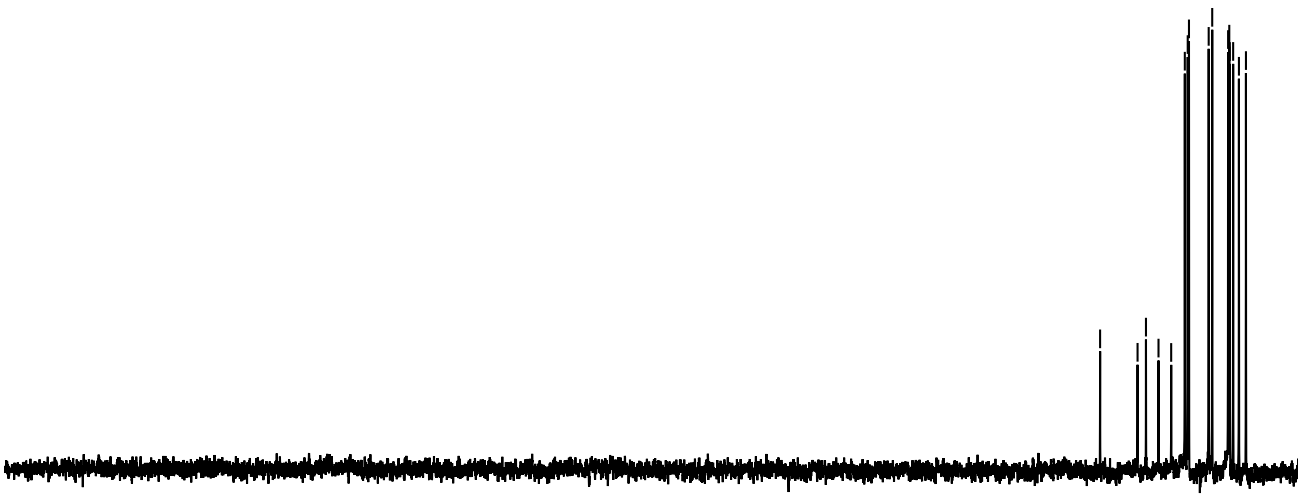

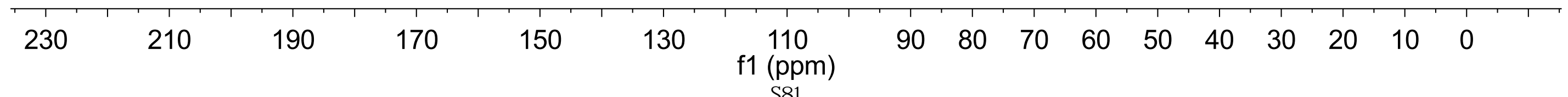

